UNIVERSIDADE DE SÃO PAULO

\title{
ESCOLA DE EDUCAÇÃO FÍSICA E ESPORTE
}

Efeito agudo do exercício aeróbio sobre as vias moleculares de captação de glicose no músculo esquelético em pacientes portadoras da síndrome dos ovários policísticos

WAGNER SILVA DANTAS

São Paulo

2014 
Efeito agudo do exercício aeróbio sobre as vias moleculares de captação de glicose no músculo esquelético em pacientes portadoras da síndrome dos ovários policísticos

Dissertação apresentada à Escola de Educação Física e Esporte da Universidade de São Paulo, como requisito parcial para a obtenção do título de Mestre em Ciências

Área de Concentração: Biodinâmica do Movimento do Corpo Humano

Orientador: Prof. Dr. Bruno Gualano

São Paulo 
Dantas, Wagner Silva

Efeito agudo do exercício aeróbio sobre as vias moleculares de captação de glicose no músculo esquelético em pacientes

portadoras da síndrome dos ovários policísticos / Wagner Silva

Dantas . - São Paulo : [s.n.], 2014.

83p. ; il.

Dissertação (Mestrado) - Escola de Educação Física e

Esporte da Universidade de São Paulo.

Orientador: Prof. Dr. Bruno Gualano.

1. Síndrome do ovário policístico 2. Exercício físico

3. Obesidade 4. Resistência à insulina I. Título. 
Autor: DANTAS, Wagner Silva

Título: Efeito agudo do exercício aeróbio sobre as vias moleculares de captação de glicose no músculo esquelético em pacientes portadoras da síndrome dos ovários policísticos

Dissertação apresentada à Escola de Educação Física e Esporte da Universidade de São Paulo, como requisito parcial para a obtenção do título de Mestre em Ciências

Data:

\section{Banca Examinadora}

Prof. Dr.:

Instituição: Julgamento:

Prof. Dr.:

Instituição: Julgamento:

Prof. Dr.:

Instituição: Julgamento: 
Dedico essa dissertação ao Deus Todo Poderoso por me possibilitar desfrutar dessa importante etapa da minha vida. 


\section{AGRADECIMENTOS}

À minha mãe pelo brilhante exemplo de dignidade, perseverança e luta em condições adversas da vida. Seu amor e desapego me permitiu chegar um pouco mais longe. Sua luta pela minha educação foi marcante na minha constituição.

À minha esposa Karila Dantas pelo incrível amor e compreensão durante meus momentos de ausência. Nessa busca por respostas científicas, descobri o real significado da construção de uma família. Obrigado pela possibilidade de vivenciar o seu amor.

Aos meus filhos Pedro Henrique e Ana Clara pela motivação, inspiração, amor gratuito e paciência de tolerar minha ausência quando os estudos me impediam de enxergar suas necessidades. Seus sorrisos e alegria de viver alimentam os sentimentos mais intensos, puros e verdadeiros em meu coração.

À minha sogra Marta e meu sogro Zaqueu pelo amor, cuidado e apoio incomparável durante essa etapa da minha vida.

Ao meu irmão Diego Dantas e meu cunhado Kauê pela ajuda na "logística" nos momentos difíceis.

Ao Prof. Dr. Bruno Gualano pela orientação segura e competente. Serei eternamente grato à oportunidade e confiança depositada nesse trabalho.

Ao Prof. Dr. José Antônio Miguel Marcondes pelos ensinamentos, dedicação e disponibilidade na realização deste trabalho.

Ao Dr. Cristiano Roberto Grimaldi Barcellos, Dra. Michelle Patrocínio Rocha e Dra. Viviane Yance pelo carinho e companheirismo durante todas as etapas deste trabalho.

À Dra. Vanessa Zambelli (Instituto Butantan) e Prof. Dr. Julio Cesar Batista Ferreira (ICB) pelo ensino e auxílio nos experimentos de expressão proteíca. 
Aos amigos/colegas de convívio do dia a dia no laboratório de nutrição, LACRE e fisiologia: Luana (Lombriga), Bryan (Gringo), Paty Campos, Alan Lins (Delongas), David Santana, Fábio Médici, Thalita Dassouki, Rodrigo Ferraz, Úrsula (pastora), Paulo Jannig, Cristiano Robles, Telma e Luis Bechara. Muito obrigado pela contribuição e colaboração.

Agradeço especialmente aos amigos "jovens" de trabalho árduo e diversão garantida: Vitor Procópio (Mineiro), Willian das Neves (Neguinho), Igor Murai (Samurai), Renato Tavares (Renatovisky), Rafa Pires, Vitão (Dudu), Vinicius (Xaropinho), Carlos Merege (Cabritos Tevez) e Luiz Perandini (LACRE). Agradeço pelas importantes discussões científicas, aprendizado técnico, churrasco e pela cerveja gelada.

À secretária de Pós-Graduação da Escola de Educação Física e Esporte da USP, em especial aos secretários Ilza, Márcio, Mariana e Paulo, pela competência e prontidão no suporte necessário aos alunos de pós-graduação.

Às voluntárias dessa pesquisa. Meus sinceros respeitos.

À Fundação de Amparo à Pesquisa do Estado de São Paulo, pela concessão da bolsa de mestrado e pelo apoio financeiro para realização dessa pesquisa (FAPESP 2012/02827-7 e FAPESP 2012/14650-4). 
"Digo: o real não está na saída nem na chegada: ele se dispõe para a gente é no meio da travessia." João Guimarães Rosa 
"É necessário abrir os olhos e perceber que as coisas boas estão dentro de nós, onde os sentimentos não precisam de motivos nem os desejos de razão. $O$ importante é aproveitar o momento e aprender sua duração, pois a vida está nos olhos de quem saber ver." 


\section{RESUMO}

DANTAS, W.S. Efeito agudo do exercício aeróbio sobre as vias moleculares de captação de glicose no músculo esquelético de pacientes portadoras da síndrome dos ovários policísticos. 2014. 83 f. Dissertação (Mestrado em Ciências) - Escola de Educação Física e Esporte, Universidade de São Paulo, São Paulo. 2014.

A hiperinsulinemia e a resistência à insulina (RI) são descritas em pacientes portadoras da PCOS, independentemente do índice de massa corporal. O exercício físico parece não ser capaz de reverter completamente a RI nessas pacientes, sugerindo uma resposta sub-ótima ao estímulo do treinamento físico nessa população. Assim, o objetivo desse trabalho foi investigar os efeitos agudos do exercício aeróbio sobre a expressão de proteínas envolvidas na sinalização intracelular para captação de glicose em pacientes com PCOS comparadas a mulheres sem comorbidades e sem a PCOS (grupo CTRL). No período basal, as voluntárias realizaram avaliações do perfil lipídico, glicêmico e hormonal, capacidade física e composição corporal. Após a intervenção, as voluntárias realizaram dosagens sanguíneas para a avaliação do perfil inflamatório e glicêmico em resposta ao exercício físico. Além disso, as voluntárias foram submetidas à biopsias musculares, para analises da expressão de proteínas envolvidas na sinalização intracelular para a captação de glicose. A expressão proteica da PI3-k não demonstrou diferenças significantes em resposta à sessão aguda de exercício aeróbio no grupo PCOS. Todavia, o grupo CTRL demonstrou um aumento significante da ativação dessa proteína em resposta à sessão aguda de exercício aeróbio $(p=0.018)$, bem como uma tendência de diferença significante da atividade dessa proteína na condição PÓs $(p=0.073)$ no grupo CTRL em comparação ao grupo PCOS. A fosforilação da AS160 Thr 642 foi significante maior no grupo CTRL em resposta a sessão aguda de exercício aeróbio $(p=0.043)$, enquanto, uma resposta inalterada da fosforilação da AS160 Thr 642 foi observada no grupo PCOS em resposta ao exercício aeróbio agudo. O grupo CTRL apresentou um aumento da fosforilação dessa proteína significante maior que o grupo PCOS na condição PÓs $(\mathrm{p}=0.05)$. Os presentes achados demonstram um prejuízo na sinalização intracelular para captação de glicose no músculo esquelético ao nível da proteína PI3-k p85 e AS160 Thr 642 em resposta ao exercício aeróbio agudo nas mulheres com PCOS comparada as mulheres CTRL. Entretanto, a translocação do GLUT-4 não está prejudicada em resposta ao exercício aeróbio agudo nas mulheres com PCOS comparada as mulheres CTRL. Esses dados sugerem que defeitos de sinalização em proteínas específicas da sinalização insulínica não impedem a efetiva translocação de GLUT-4 no músculo esquelético de pacientes com PCOS, provavelmente pela ativação de mecanismos moleculares compensatórios.

Palavras-chave: síndrome dos ovários policísticos, exercício físico, obesidade, resistência à insulina. 


\begin{abstract}
DANTAS, W.S. Acute effect of aerobic exercise on the molecular pathways of glucose uptake in skeletal muscle in patients with polycystic ovary syndrome. 2014. 83 f. Dissertação (Mestrado em Ciências) - Escola de Educação Física e Esporte, Universidade de São Paulo, São Paulo. 2014.

Hyperinsulinemia and insulin resistance (IR) are described in PCOS patients regardless of body mass index. Exercise does not seem to be able to completely reverse the IR in these patients, suggesting a sub-optimal response to the stimulus of exercise training in this population. The objective of this study was to investigate the acute effect of aerobic exercise on the protein expression involved in intracellular signaling for glucose uptake in patients with PCOS compared with women without PCOS (CTRL group). At baseline, subjects underwent assessments of lipid, glucose and hormone profile, physical fitness and body composition. After the intervention, the volunteers performed blood measurements for the assessment of inflammatory markers and glycemic profile in response to acute aerobic exercise. In addition, the volunteers underwent skeletal muscle biopsies for analysis of the protein expression involved in intracellular signaling for glucose uptake. PI3-k expression showed no significant differences in response to acute exercise bout in the PCOS group. However, the CTRL group showed a significant increase in activation of this protein in response to acute exercise bout $(p=0.018)$ and a trend toward significant difference in activity of this protein after exercise $(p=0.073)$ in the CTRL group compared to the PCOS group. AS160 Thr 642 phosphorylation was significantly higher in the CTRL group in response to acute exercise bout $(p=0.043)$, while an unchanged response of AS160 Thr 642 phosphorylation was observed in the PCOS group in response to acute aerobic exercise. CTRL group showed an increase in phosphorylation of this larger than PCOS group significant protein in the period after the acute exercise bout $(p=0.05)$. The present findings demonstrate a loss in intracellular signaling for glucose uptake in skeletal muscle at the level of the protein $\mathrm{PI} 3$-k p85 and AS160 Thr 642 in response to acute aerobic exercise in women with PCOS compared CTRL women. However, GLUT - 4 translocation is not impaired in response to acute aerobic exercise in women with PCOS compared CTRL women. These data suggest that specific defects of insulin signaling do not impairment the effective GLUT - 4 translocation in skeletal muscle of patients with PCOS, probably by activation of compensatory molecular mechanisms.
\end{abstract}

Keywords: polycystic ovary syndrome, exercise, obesity, insulin resistance. 
SUMÁRIO

RESUMO _ 1

ABSTRACT__ 2

1. INTRODUÇÃO _ 5

2. REVISÃO DE LITERATURA __ 9

2.1. PCOS e Obesidade __ 9

2.2. PCOS e Inflamação __ 12

2.3. Mecanismos moleculares de ação da insulina ___ 17

2.4. PCOS, exercício físico e resistência à insulina ___ 20

3. JUSTIFICATIVA _ 23

4. OBJETIVOS _ 25

4.1. Objetivo Geral __ 25

4.2. Objetivos Específicos__ 25

5. PLANO INICIAL DE TRABALHO E CRONOGRAMA DE EXECUÇÃO PROPOSTO _ 26

6. CASUÍSTICA E MÉTODOS __ 27

6.1. Aprovação do Comitê de Ética em Pesquisa___ 27

6.2. Protocolo Experimental ___ 28

6.3. Seleção e Recrutamento das pacientes ___ 29

6.4. Avaliação Laboratorial ___ 30

6.5. Antropometria e avaliação da composição corporal____ 32

6.6. Acelerômetro _ 33

6.7. Ultrassonografia Pélvica __ 34

6.8. Teste Ergoespirométrico __ 35

6.9. Sessão aguda de exercício aeróbio ___ 37 
6.10. Biópsia Muscular por agulha de sucção 39

6.11. Determinação das concentrações plasmáticas e musculares de citocinas inflamatórias e anti-inflamatórias 41

6.12. Determinação da expressão de proteínas selecionadas e da translocação do GLUT-4 por Western Blotting 43

7. ANÁLISE DOS RESULTADOS 45

8. RESULTADOS 46

8.1. Participantes 46

8.2. Perfil Hormonal 47

8.3. Perfil Lipídico 49

8.4. Controle Glicêmico e Sensibilidade à Insulina 50

8.5. Teste Ergoespirométrico 52

8.6. Nível de atividade física 56

8.7. Determinação da resposta glicêmica e insulinêmica ao exercício aeróbio agudo 57

8.8. Dosagem de citocinas musculares e plasmáticas em resposta a sessão aguda de exercício aeróbio. 59

8.9. Determinação da expressão de proteínas selecionadas e da translocação do GLUT-4 por Western Blotting 62

9. DISCUSSÃO 70

10. CONCLUSÃO 78

11. REFERÊNCIAS BIBLIOGRÁFICAS 79 


\section{INTRODUÇÃO}

Em 1935, Stein e Leventhal, relataram um quadro com sinais e sintomas correlacionados à anovulação. Neste contexto, foram incluídas mulheres que apresentavam histórico de infertilidade, distúrbio menstrual, hirsutismo e obesidade, juntamente com a demonstração de ovários aumentados de volume com cistos e hipertrofia do estroma. Posteriormente denominada de síndrome dos ovários policísticos (PCOS), hoje é considerada como um distúrbio hormonal complexo de base funcional, caracterizada pela anovulação crônica hiperandrogênica, com repercussões na esfera reprodutiva, estética, metabólica e oncológica (Marcondes et al., 2007), afetando de 5 a 10\% das mulheres em idade reprodutiva (Azziz et al., 2004). Com a introdução de novas técnicas de investigação, o que antes era um diagnóstico baseado apenas em manifestações clínicas e anatômicas, passou a incorporar critérios bioquímicos e ultrassonográficos (Marcondes et al., 2011).

Até a presente data, três consensos (consenso do National Institute of Health, Consenso de Rotterdam da Sociedade Européia e Americana de Reprodução Humana e consenso da The Androgen Excess Society) estabeleceram critérios para o diagnóstico da síndrome. Um ponto de concordância desses consensos é que se trata de uma síndrome e não de uma doença específica. Consequentemente, nenhum critério isolado é suficiente para o seu diagnóstico clínico, sendo este de exclusão, ou seja, doenças que mimetizam o seu fenótipo devem ser excluídas, entre as quais disfunções adrenais, tireoidianas, neoplasias virilizantes da adrenal e do ovário, síndromes de resistência grave à insulina e hiperprolactinemia. Esses fenótipos podem corresponder por 5\% a 10\% dos casos da síndrome (Marcondes et al., 2011).

As características fundamentais da síndrome são constituídas por:

i. Disfunção menstrual (oligomenorréia e, menos frequentemente, amenorréia ou até mesmo ciclos regulares, porém, anovulatórios).

ii. Hiperandrogenemia (aumento da concentração plasmática dos andrógenos como a testosterona total, livre e, com menos constância, de sulfato de dehidroepiandrosterona [DHEAS] e androstenediona). 
iii. Hiperandrogenismo (termo utilizado para descrever os sinais clínicos oriundos do aumento da ação biológica dos andrógenos - ex: hirsutismo, acne, e alopecia androgênica).

iv. Morfologia policística do ovário identificada através da ultrassonografia (presença de 12 ou mais folículos medindo entre $2 \mathrm{~mm}$ e $9 \mathrm{~mm}$ de diâmetro ou aumento do volume ovariano $\geq 10 \mathrm{~cm}^{3}$ ).

A PCOS, independentemente do consenso utilizado, permanece como uma síndrome, na qual a presença de um único critério não é suficiente para o diagnóstico. Uma variedade de combinação de sinais e sintomas, bem como de alterações ultrassonográficas e laboratoriais é a regra em pacientes portadoras da PCOS. Essas diferentes manifestações podem ser decorrentes de características genéticas da população, da presença da obesidade e do impacto da resistência à insulina (RI).

A PCOS é hoje tida como um importante fator de risco cardiovascular. Algumas condições podem estar associadas ou serem decorrentes da síndrome, tais como: diminuição da sensibilidade à insulina, obesidade, intolerância aos hidratos de carbono, distúrbios do metabolismo lipídico, hipertensão arterial sistêmica (HAS) ou apnéia obstrutiva do sono (Dahlgren et al., 1992; Pierpoint et al., 1998; Wild et al., 2000; Elting et al., 2001; Rocha et al., 2011).

Hiperinsulinemia e a RI também são descritas em pacientes portadoras da PCOS, independentemente do índice de massa corporal (IMC) (Dantas et al., 2013), embora tais condições sejam indubitavelmente mais prevalentes na presença de obesidade (Rajhowa et al., 2009). A RI pode ser o elo entre a PCOS e a obesidade, já que ambos os quadros são igualmente caracterizados pela diminuição da sensibilidade à insulina, tanto no tecido hepático quanto muscular. De acordo com essa observação, estudos demonstram que a captação de glicose mediada por insulina, mensurada pelo clampeamento euglicêmico/hiperinsulinêmico, está 30-35\% reduzida em pacientes magras e obesas com PCOS, similarmente ao que se observa em pacientes com diabetes mellitus tipo 2 (DM2) (Dunaif, 1997). A associação entre hiperandrogenemia e RI está bem estabelecida em modelos animais e seres humanos (Allemand et al., 2009). Sabe-se que em condições de RI, altos níveis de insulina estimulam a produção de andrógenos ovarianos (Corbould, 
2008a; Cheang et al., 2004). O excesso de andrógeno, sabidamente, é um fator que contribui para a RI de pacientes com PCOS, gerando, assim, um círculo vicioso em que a hiperinsulinemia promove aumento da produção de andrógeno que, por sua vez, contribui para a RI. A figura 1 demonstra os efeitos do excesso de tecido adiposo na hiperandrogenemia. $O$ excesso de tecido adiposo favorece uma maior conversão periférica de androstenediona em testosterona através da ação da enzima 17-beta-hidroxiesteroíde-desidrogenase (17- $\beta$-HSD). Assim, a enzima 5-alfaredutase (5- $\alpha$-redutase) amplifica a conversão da testosterona em dihidrotestosterona (DHT). Ao aumento do volume ovariano também amplifica a formação de testosterona pela gônada citada. O excesso de testosterona, por sua vez, favorece a fosforilação do substrato do receptor de insulina 1 (IRS-1) no resíduo de serina, gerando um quadro de RI nos diversos tecidos sensíveis a ação da insulina (Corbould et al., 2006). Na tentativa de corrigir essa resistência à ação hormonal, o pâncreas secreta maiores quantidades de insulina (hiperinsulinemia compensatória) que, consequentemente, reduz os níveis da globulina transportadora de esteroides sexuais (SHBG), culminando em uma maior biodisponibilidade biológica da testosterona (Corbould, 2008b). Como base em estudos experimentais em ratas submetidas a altas concentrações de testosterona, múltiplos mecanismos têm sido sugeridos para explicar tal fenômeno, a saber: redução na capilarização no músculo esquelético, diminuição na atividade da enzima glicogênio sintase e deficiência na translocação do transportador de glicose 4 (GLUT-4) em direção a membrana sarcoplasmática (Holmang et al., 1990; Holmang et al., 1992; Holmang et al., 2001). 


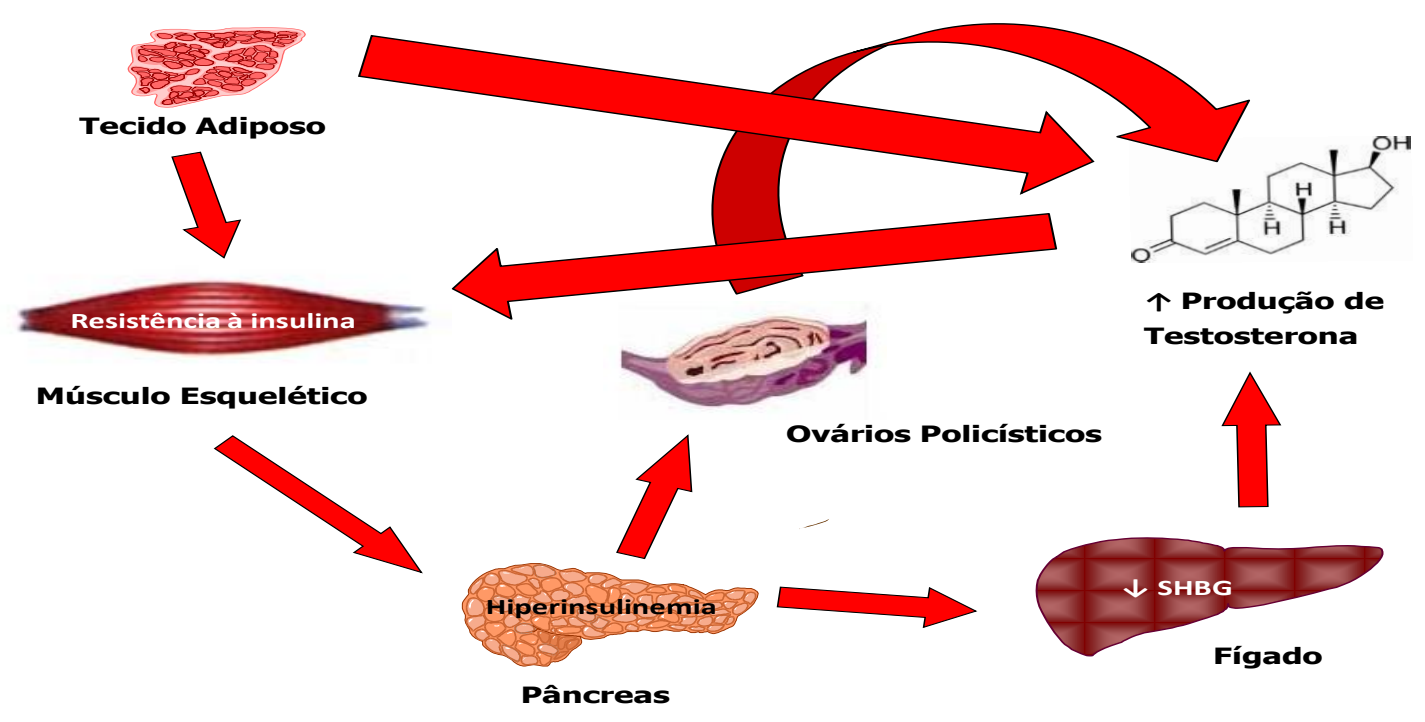

Figura 1. A hiperinsulinemia e a hiperandrogenemia fazem parte de um círculo vicioso. Os andrógenos podem influenciar diretamente a ação da insulina nos diversos tecidos sensíveis a ação desse hormônio. A hiperinsulinemia compensatória à RI aumenta o hiperandrogenismo via ações diretas sobre a produção de andrógenos ovarianos e indiretamente pela inibição da produção hepática da SHBG. Adaptado de Corbould, 2006b.

\section{REVISÃO DE LITERATURA}

\subsection{PCOS e Obesidade}

Os aspectos evolutivos obrigaram os seres humanos a lidar com longos períodos de privação de energia e de alimentos gerando um grande gasto energético voluntário. Não apenas a restrição alimentar modificou ao longo da evolução do homem. A composição alimentar, tamanho das porções, a quantidade e frequência de ingestão de alimentos foram significativamente alterados ao longo milênio (Piper e Bartke, 2008). Consistente com essas informações, WANSINK e WANSINK (2010) demonstraram em um elegante estudo uma relação positiva entre o ano cronológico e a razão entre o tamanho do prato principal e o perímetro cefálico entre diversas imagens de obras de artes, incluindo a Santa Ceia. Portanto, o avanço tecnológico global, menor gasto energético para a provisão de alimentos, produção de alimentos em larga escala, a industrialização e mecanização da agricultura são algumas das 
justificativas para o aumento significativo da obesidade (Wansink e Wansink, 2010) na medida em que repercute com alteração negativa entre o gasto energético comparado a ingestão calórica.

A obesidade cursa clinicamente com o ganho de tecido adiposo capaz de acarretar prejuízos à saúde. A epidemia da obesidade tornou-se a doença endocrinológica mais comum do mundo ocidental e um dos problemas de saúde pública mais importante por atingir diferentes populações em diferentes faixas etárias (Kopelman, 2000).

Com o ganho de peso corporal ocorre diminuição da sensibilidade da insulina e, consequentemente, aumento da RI. Esse quadro de Rl gera um mecanismo compensatório clássico de aumento da secreção de insulina pelas células $\beta$ pancreáticas na tentativa de manter a homeostase glicêmica em valores adequados. Como os tecidos alvos a ação da insulina apresenta diminuição da sensibilidade à ação desse hormônio, ocorre uma produção exagerada desse hormônio caracterizada como resposta hiperinsulinêmica.

A combinação entre o excesso de peso e a $\mathrm{Rl}$ apresenta repercussões reprodutivas. Está bem estabelecido que a obesidade contribua para a $\mathrm{RI}$ e para $\mathrm{O}$ aumento da produção de marcadores androgênicos em mulheres com PCOS (Dunaif, 1997). Foi proposto que o tecido adiposo seria responsável pela conversão periférica de andrógenos em estrona, que por sua vez realizaria feedback negativo no eixo hipotálamo-hipófise, bloqueando a secreção de $\mathrm{FSH}$ e permitindo que o aumento na relação LH/FSH induzisse a hiperandrogenemia ovariana. Portanto, o excesso de andrógenos verificados na PCOS pode ser resultado da hiperinsulinemia compensatória decorrente da RI nos tecidos periféricos (Dunaif, 1997).

Especificamente, o LH parece exercer um crosstalk com vias de sinalização insulínica. CARVALHO et al., (2002) demonstraram que a estimulação simultânea com LH e insulina levou a um aumento da fosforilação em tirosina do IRS-1 e da Akt em serina comparado ao efeito isolado dos dois hormônios. Isso parece ser de suma importância para o conhecimento da fisiopatologia da PCOS, uma vez que a RI parece ser um importante fator de estimulo para a maior produção de andrógenos pelas células da teca do ovário. Sabe-se que o padrão de secreção do LH na PCOS segue um padrão pulsátil de maior amplitude devido à RI (Minanni et al., 1999). Portanto, o maior pulso de LH na PCOS aumentará a conversão do colesterol em 
pregnenolona e a hiperinsulinemia estimulará em excesso o citocromo p450c170, aumentando a conversão de dois fatores: pregnenolona em 17-hidroxipregnenolona e 17-hidroxipregnenolona em dehidroepiandrosterona. O aumento do pulso de LH na PCOS poderia resultar em uma hipersensibilidade das células da teca do ovário à ação da insulina e maior sensibilidade hipofisária ao $\mathrm{GnRH}$, levando a um aumento da produção de andrógenos ovarianos, atresia folicular e anovulação crônica.

Com a descrição de síndromes raras em pacientes apresentando intensa RI, hiperandrogenemia/hiperandrogenismo e acantosis nigricans (marcador cutâneo de RI periférica), foi suposto que a insulina poderia ter ação ovariana e, assim, sugerindo associação entre a Rl e a disfunção ovariana (Carvalho et al., 2003), posteriormente descrita em mulheres obesas com PCOS com discreta intolerância a glicose (Barcellos et al., 2007). Estudo descritivo do Ambulatório de Síndromes Hiperandrogênicas, do Hospital das Clínicas da Faculdade de Medicina da Universidade de São Paulo (HCFMUSP), indicou que $36 \%$ das pacientes com PCOS são obesas e a RI está presente em $60 \%$ das pacientes com PCOS e, muito provavelmente, está fortemente envolvida na etiologia dos distúrbios metabólicos frequentemente encontrados nessa população (Barcellos et al., 2007).

A diminuição plasmática de andrógenos decorrente do uso de agonistas do GnRH não resulta no desaparecimento da RI em pacientes com PCOS (Dunaif et al., 1990). Entretanto, a administração de fármacos com ação bloqueadora da insulina (ex: somatostatina) ou aumentando a sensibilidade periférica ao hormônio (ex: metformina, glitazonas) demonstraram uma diminuição dos níveis androgênicos após o tratamento com as respectivas drogas citadas (Nestler e Jakubowicz, 1996; Dunaif et al., 1996; Kocak et al., 2002). Assim, estes dados reforçam a hipótese de que a hiperinsulinemia presente nas mulheres com PCOS contribui para a manutenção das concentrações androgênicas nessa população.

\subsection{PCOS e Inflamação}

Outros fatores estão relacionados com o acometimento da $\mathrm{Rl}$, incluindo alterações gênicas (Mercado et al., 2002), aumento na produção de espécies reativas de oxigênio (ROS) (Houstin et al., 2006; González et al., 2006b), estresse de 
reticulo endoplasmático (Ropelle et al., 2010) e inflamação em adipócitos associada ao aumento da secreção de citocinas pró-inflamatórias (Ropelle et al., 2010). A alteração da secreção de citocinas pelos adipócitos pode causar prejuízos em tecidos alvo da ação da insulina como o músculo esquelético e o fígado (Hotamisligil, 2000; Schatteberg et al., 2006). Diversos estudos apontam para a tríade formada entre obesidade, RI e estado inflamatório sub-clínico. A presença de marcadores inflamatórios documentados através da quantificação de citocinas plasmáticas são alvos de estudos da relação entre o sistema imunológico e metabólico.

O fator de necrose tumoral a (TNF- $\alpha$ ) foi a primeira molécula a apresentar ligação entre o sistema imunológico e metabólico (Hotamisligil et al.,1993). Estudos realizados em animais e seres humanos com obesidade demonstraram aumento dos níveis séricos de TNF-a (Horng e Hotamisligil, 2011) e também aumento dos níveis desta citocina tanto no tecido adiposo como no tecido muscular (Hotamisligil et al., 1995). HOTAMISLIGIL et al., (1996) demonstraram que a administração de TNF-a em seres humanos leva a um estado de RI decorrente do aumento da fosforilação do IRS-1 em serina na posição 307. Postula-se que duas proteínas quinase possam participar desta ação inibitória: c-Jun $\mathrm{NH}(2)$-terminal serina quinase (JNK) e ikappaB quinase (IKK). A administração de TNF- $\alpha$ em culturas de células levou a um aumento da fosforilação em serina do IRS-1 em paralelo à ativação da JNK e ativação do complexo IKK, sendo esse um dos mecanismos moleculares que o TNF- $\alpha$ leva a um quadro de RI (Wellen e Hotamisligil, 2005).

Outras citocinas pró-inflamatórias mostraram-se capazes de ativar vias

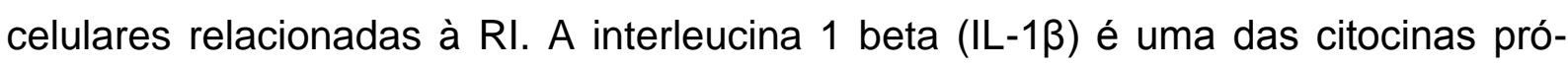
inflamatórias mais importantes, podendo induzir a inflamação aguda em resposta à infecções ou danos teciduais (Masters, 2013). Para que a IL1- $\beta$ exerça atividade biológica é necessário que ela se ligue ao receptor de membrana IL1R1 e este deve acionar a proteína IL1RAcP para que a cascata de sinalização ocorra (Spulber e Schultzberg, 2010). Esta interação irá recrutar a molécula adaptadora conhecida como MyD88 que será responsável por acionar duas proteínas: quinase 1 associada ao receptor de interleucina 1 (IRAK1) e fator 6 associado ao receptor de TNF- $\alpha$ (TRAF6). A ativação dessas três proteínas citadas permite a transdução do sinal até o complexo NFKB (fator nuclear de ativador do $\mathrm{kB}$ )//KB que se deslocarão até o núcleo celular para ativar genes ligados a resposta inflamatória (Spulber e 
Schultzberg, 2010). Desta forma estabeleceu-se a relação causal entre a ativação de vias de sinalização inflamatória na obesidade com a gênese da RI (Hotamisligil et al., 1996).

A interleucina 6 (IL-6) é uma citocina que possui funções relacionadas a inflamação, resposta imune e hematopoiese. Possui papel de molécula de sinalização entre diferentes células na vigência do controle e coordenação da resposta imunológica a lesão ou infecção, sendo a IL-6 secretada por macrófagos e linfócitos (Heinrich et al., 2003). A sinalização intracelular da IL-6 inicia-se com a ligação à subunidade $\alpha$ do receptor de membrana (IL-6r). Após a ligação IL-6/IL-6r ocorre uma ligação com ligação com uma molécula chamada glicoproteína 130 (gp130), então, formando um complexo IL-6/IL-6r/gp130. Após a formação do complexo, a sinalização intracelular é gerada através da via JAK/STAT onde a associação entre IL-6r/gp130 ativa principalmente a proteína conhecida como JAK2 e, após ser fosforilada, ativa o transdutor de sinal e ativador de transcrição conhecido como STAT-3. As proteínas STATs são indutoras de proteínas supressoras da sinalização de citocinas (SOCS). Especificamente, a SOCS tipo 3 (SOCS3) atua como mediador do feedback negativo na sinalização do IL-6, além de afetar a sinalização insulínica por alterar o resíduo de ativação do substrato do IRS-1 (Lebrun e Van Obberghen, 2008).

O tecido muscular esquelético em resposta a contração muscular produz grandes quantidades de IL-6. Desde então, dúvidas foram levantadas sobre o real papel da IL-6 produzida pelo músculo esquelético. Inicialmente, postulou-se que o aumento da produção de IL-6 pelo músculo esquelético seria decorrente do dano muscular ocasionado pelo exercício físico. Entretanto, OSTROWSKI et al., (2000) demonstraram que o pico de concentração de creatina quinase (CK) um dia após uma sessão aguda de exercício físico não mostrou associação com o pico de concentração de IL-6. Parece claro que a resposta cinética da IL-6 induzida por contrações de característica concêntrica (tipo de contração em que há um encurtamento da musculatura solicitada) diferem das contrações de características excêntricas (tipo de contração em que há um alongamento da musculatura solicitada) associadas ao dano muscular (Bruunsgaard et al., 1997). Relacionado à ação muscular concêntrica, o aumento das concentrações de IL-6 está fortemente ligado à duração do exercício e a recuperação de valores de concentração de IL-6 
próximo a valores prévios ao exercício físico parece ocorrer em algumas horas após o estimulo concêntrico (Ostrowski et al., 2000). No entanto, a ação muscular excêntrica demonstrou um modesto aumento nas concentrações plasmáticas de IL6, porém, o pico de concentração de IL-6 permanece elevado após vários dias (Ostrowski et al., 2000).

A contração muscular esquelética é um importante mecanismo para redução da disponibilidade da glicose. Na tentativa de manter uma adequada homeostase glicêmica e evitar um quadro hipoglicêmico durante a contração muscular à medida que ocorre um aumento da captação de glicose pelo músculo esquelético ocorrem também um aumento da produção endógena de glicose derivada do fígado. FEBBRAIO et al., (2004) demonstraram que a IL-6 pode ser uma importante proteína mediadora durante o exercício físico através do aumento da produção endógena de glicose pelo fígado bem como a remoção periférica de glicose em indivíduos saudáveis, sugerindo o importante papel dessa citocina na manutenção da homeostase glicêmica durante o exercício. Entretanto, dados recentes mostraram que a resposta da IL-6 do músculo esquelético de pacientes diabéticos está alterada, sugerindo uma resistência parcial à ação do IL-6 no músculo esquelético notada pelo aumento significativo da produção de IL-6 no músculo esquelético de pacientes com RI por mecanismo compensatório a resistência à ação do IL-6 no tecido muscular. Essa resistência parcial à ação da IL-6 no tecido muscular de sujeitos diabéticos promoveu menor captação de glicose, menor síntese de glicogênio, menor fosforilação da proteína JAK2 e menor fosforilação da proteína STAT3 (Jiang et al., 2013).

Vale ressaltar que de acordo com a literatura, o estado inflamatório associado à $\mathrm{RI}$ está fortemente ligado ao músculo esquelético. Estudos apontam para a infiltração de células inflamatórias no tecido muscular esquelético, geração e secreção de citocinas pró-inflamatórias pelo próprio tecido muscular (Pedersen, 2006) e a presença de diversos componentes da resposta imunológica inata como os receptores para citocinas do tipo Toll (TLRs) (Reyna et al., 2008).

A PCOS é também um estado pró-inflamatório (Escobar-Morreale et al., 2011). GONZÁLEZ et al., (2012a) demonstraram que a sobrecarga de glicose após TOTG é capaz de provocar resposta inflamatória de células mononucleares periféricas (PMNC) em mulheres com PCOS, independente da massa corporal. A 
hiperglicemia gerada pelo TOTG provocaria um estado de glicotoxicidade (YkiJarvinen, 1992) que acentuaria a RI. Já foi demonstrado que em mulheres com PCOS, a hiperglicemia causa um aumento de espécies reativas de oxigênio (ROS) produzidas pelas PMNC (González et al., 2006b). O estresse oxidativo induzido pelo aumento de ROS é um fator para a ativação do fator de transcrição pró-inflamatório NFkB, que culminará na transcrição do gene do TNF-a (González et al., 2012b). Assim, o aumento do TNF- $\alpha$ bem como níveis aumentados de IL-6 em mulheres obesas com PCOS (Escobar-Morreale et al., 2011) pode fazer parte do mecanismo de RI na PCOS.

\subsection{Mecanismos moleculares de ação da insulina}

O músculo esquelético representa aproximadamente $40 \%$ da massa corporal total e exerce papel primordial no metabolismo da glicose, desempenhando um papel ímpar na captação, liberação e armazenamento de glicose (Febbraio et al., 2004). No tecido muscular, bem como no tecido adiposo (embora em menor escala), a insulina aumenta a captação de glicose, diminuindo a produção hepática de glicose. Além disso, esse hormônio promove o armazenamento de substratos, estimula a lipogênese e a síntese de glicogênio e proteínas, e inibe a lipólise, glicogenólise e proteólise.

Para a compreensão dos mecanismos moleculares relacionados à obesidade, faz-se necessário a caracterização da via molecular de sinalização da insulina e seus efeitos biológicos. A sinalização intracelular da insulina inicia-se após a sua ligação ao receptor especifico de membrana, denominado receptor de insulina (IR). Trata-se de uma proteína heterotetramérica com atividade quinase composta por duas subunidades alfa $(\alpha)$ encontrada no meio extracelular e duas subunidades beta ( $\beta$ ) encontrada no meio intracelular. A insulina liga-se a porção $\alpha$ do seu receptor $e$ estimula a fosforilação das porções $\beta$, que apresenta atividade quinase intrínseca. $A$ partir deste evento, a ativação do IR estimula a fosforilação no resíduo de tirosina de diversos substratos, dentre eles, o IRS-1 e 2 IRS-2 (54). Araki et al., (1994) demonstraram as funções fisiológicas do IRS-1 e IRS-2 em modelo animal que não expressavam o genes codificadores das proteínas citadas. Na ausência de 
expressão do gene codificador da IRS-1, havia a presença de RI e retardo do crescimento, mas o animal não se tornava diabético (Saltiel e Kahn, 2001). Posteriormente, um grupo de pesquisadores criou um modelo animal que não expressava o gene codificador do IRS-2. Nesse fenótipo havia um quadro de hiperglicemia exacerbada associado à disfunção da atividade de secreção das células $\beta$ pancreáticas (Araki et al., 1994). A fosforilação em tirosina do IRS-1 e IRS2 cria sítios de reconhecimento para moléculas contendo domínios com homologia à Src 2 (SH2), destacando a PI3-k, considerada de extrema importância para o transporte de glicose (Withers et al., 1998). A PI3-k tem como alvo as proteínas Akt e isoformas da proteína quinase $C(P K C)$ tipo delta $(\zeta)$ e gama $(\lambda)$. A fosforilação do substrato da proteína Akt (AS160) está envolvida na translocação do GLUT-4 para a superfície celular e transporte de glicose (Czech e Corvera, 1999).

Além da ativação da PI3-k, outros sinais podem ser necessários para que a insulina estimule o transporte de glicose (Czech e Corvera, 1999). Uma segunda via envolve a fosforilação do protooncogenese $\mathrm{c}$-Cbl e é aparentemente independente da ativação da PI3-k. Em tecidos sensíveis a ação da insulina (nesse caso, principalmente o tecido adiposo), a proteína Cbl está associada à proteína adaptadora CAP (Cbl associated protein). Uma vez fosforilado, o complexo Cbl-CAP desloca-se para a membrana celular e liga-se a proteína adaptadora Crkll, que também está associada com a proteína C3G. A proteína C3G tem como função a troca de nucleotídeos (nesse caso a troca é de guanosina difosfato para guanosina trifosfato) em uma proteína conhecida como TC10. Essa troca de nucleotídeos ativa a proteína TC10 permitindo que essa proteína sinalize para a translocação do GLUT4 para a membrana celular, em paralelo a ativação da PI3-k (Bouzakri et al., 2005). O conteúdo total de GLUT-4 bem como a eficiência da translocação dessa proteína rumo ao sarcolema são tidos como fatores determinantes da responsividade à insulina na musculatura esquelética. Assim, a redução da expressão ou translocação do GLUT-4 foi indicada como um importante fator na gênese da RI (Ribon et al., 1998).

A contração muscular permite com que o músculo esquelético capte a glicose por via independente da sinalização insulínica. Assim, são distintas as vias que conduzem o sinal intracelular para o transporte de glicose através da insulina e do exercício no músculo esquelético. Entre as proteínas de destaque na captação de 
glicose induzida pelo exercício está a AMPK (proteína quinase ativada por AMP). A AMPK é uma serina/treonina quinase composta como um heterotrímero de 3 subunidades: uma subunidade catalítica a $(63 \mathrm{kDa})$, duas subunidades regulatórias não-catalíticas $\beta(30 \mathrm{kDa})$ e uma subunidade $\mathrm{y}(38-63 \mathrm{kDa})$. Ambas as três subunidades são necessárias para a estabilidade e funcionalidade completa do complexo AMPK (Woods et al., 1996). Há diversas isoformas para cada uma das três subunidades da proteína em questão, embora no músculo esquelético de humanos as isoformas encontradas são $\alpha 2$, $\beta 2$ e ү3 (Hojlund et al., 2004), que surge como o principal sensor de energia intracelular nos mamíferos (Witczak et al., 2008). Essa proteína foi originalmente identificada como o regulador de dois mediadores chaves do metabolismo lipídico: acetil-CoA carboxilase e 3-hidroxi-3-metilglutaril CoA redutase (Witczak et al., 2008). A ativação da AMPK é resultado da redução do estado energético dentro da célula. Com o aumento da relação entre AMP: ATP ocorre uma modificação conformacional da AMPK que a deixa mais suscetível a fosforilação. A AMPK fosforilada ativa vias que geram aumentam do ATP, tais como a oxidação de ácidos graxos e, em contrapartida, desativa vias de consumo de ATP (ex: vias de síntese de ácidos graxos). O aumento da atividade da AMPK em resposta à necessidade de gerara ATP durante o exercício físico promove a translocação do GLUT-4, facilitando o transporte de glicose para o músculo esquelético de forma semelhante à insulina (Treebak et al., 2006).

\subsection{PCOS, exercício físico e resistência à insulina}

Diversos estudos demonstram que a obesidade/excesso de peso tem efeitos deletérios sobre a função reprodutiva. Exercício físico e controle dietético são recomendados como as intervenções clínicas de primeira linha para o tratamento clínico das mulheres com PCOS, especialmente para aquelas com excesso de peso e obesidade (Thyfault, 2008). Mudanças no estilo de vida, incluindo o exercício físico, restauram a função ovulatória, diminuem a produção de andrógenos ovarianos o estado inflamatório e a sensibilidade à insulina em mulheres com PCOS (Thomson et al., 2011). A redução do peso corporal parece ser o principal mecanismo pelo qual os estudos mostram melhoram na sensibilidade à insulina, 
melhora nos parâmetros hormonais e função reprodutiva após programas de mudanças no estilo de vida (Thomson et al., 2011). Todavia, independente da redução da massa corporal, o exercício físico é capaz de melhorar a sensibilidade à insulina no músculo esquelético em populações com RI (Coker et al., 2009).

$\mathrm{O}$ consumo máximo de oxigênio $\left(\mathrm{VO}_{2}\right.$ máx $)$ é um preditor independente de mortalidade por doenças cardiovasculares em homens e mulheres (Blair et al., 1989). Além disso, o $\mathrm{VO}_{2}$ máx é provavelmente o melhor preditor da capacidade funcional e um dos principais determinantes da capacidade de um indivíduo sustentar o exercício físico. Assim, a demanda cardiorrespiratório proveniente do exercício físico influência a capacidade de executar tanto as atividades da vida diária como durante um programa de exercícios físicos (Blair et al., 1989). Estudos prévios demonstraram uma associação inversa entre a $\mathrm{RI}$ e o $\mathrm{VO}_{2}$ máx em diversos grupos de pacientes com anormalidades metabólicas (Giallauria et al., 2009; Orio et al., 2006). Além disso, o $\mathrm{VO}_{2}$ máx é considerado um forte índice determinante de sensibilidade insulínica, tanto em homens como em mulheres. ORIO et al., (2006) realizaram o primeiro trabalho avaliando o $\mathrm{VO}_{2}$ máx de mulheres com PCOS. Neste trabalho, os autores reportaram um prejuízo máximo e submáximo de resposta cardiopulmonar ao exercício comparado a mulheres pareadas pela idade e IMC, justificando que este prejuízo na resposta cardiopulmonar deve-se aos mecanismos envolvidos na RI que propiciariam um prejuízo no metabolismo muscular esquelético e na função mitocondrial. Entretanto, THOMSON et al., (2009) ao comparar mulheres com PCOS pareadas pela idade e IMC e fatores de risco para a doença cardiovascular semelhantes entre os grupos, não observou diferença estatisticamente significante entre os grupos para resposta do $\mathrm{VO}_{2}$ máx. Isto sugere que mulheres com PCOS na ausência de um perfil metabólico adverso podem não apresentar prejuízo do $\mathrm{VO}_{2 \text { máx }}$ avaliado pelo teste ergoespirométrico.

O exercício físico agudo potencializa o efeito da insulina através do aumento da fosforilação do IRS-1 e IRS-2 no resíduo de tirosina, com consequente aumento da atividade da PI3-k no músculo esquelético e maior fosforilação em serina da Akt, proteína fundamental para iniciar a translocação do GLUT-4 para a membrana sarcoplasmática. É estabelecido que a atividade contrátil do músculo esquelético pudesse estimular a translocação do GLUT-4 também na ausência de insulina 
(Ritcher e Hargreaves, 2013). Além disso, alguns estudos sugerem a existência de diferentes "pools" intracelulares de GLUT-4, cada qual sendo primordialmente responsivo à insulina ou ao exercício (Douen et al., 1990). Portanto, os efeitos da insulina e da contração muscular parecem ser aditivos, porém não necessariamente dependentes. Diante do importante papel da contração muscular sobre o aumento do conteúdo total e translocação de GLUT-4 e, consequentemente, sobre a sensibilidade à insulina, diversos estudos têm empregado o modelo do exercício físico para a compreensão da fisiopatologia de condições caracterizadas por RI. Estudos reportam evidências da redução na atividade da IRS-1 associada à PI3-k no músculo esquelético de pacientes com PCOS, sugerindo um defeito na ativação do IR ou na fosforilação do IRS-1 (Corbould et al., 2005).

Um recente estudo demonstrou que um programa de treinamento físico resultou em aumento da sensibilidade à insulina, avaliado através do clampeamento euglicêmico/hiperinsulinêmico, em pacientes obesas com PCOS (IMC = 35.6 \pm 5.8 $\left.\mathrm{kg} / \mathrm{m}^{2}\right)$ e em voluntárias obesas sem a síndrome $\left(\mathrm{IMC}=36.9 \pm 5.9 \mathrm{~kg} / \mathrm{m}^{2}\right)$. Contudo, o exercício físico não foi capaz de reverter completamente a RI nas pacientes com PCOS, sugerindo uma resposta sub-ótima ao estímulo do treinamento físico nessa população (Harrison et al., 2012). De fato, novas investigações podem elucidar os mecanismos pelos quais o exercício físico estimula (ou deixa de estimular) a captação de glicose nas pacientes portadoras da PCOS.

Poucos estudos demonstram o efeito isolado do exercício físico nos parâmetros clínicos e hormonais em mulheres com PCOS. Grande parte dos estudos usaram intervenções de mudanças do estilo de vida (incluindo a restrição calórica/dietética) associado ao exercício físico. Além disso, poucos estudos têm investigado o papel do exercício físico nos mecanismos moleculares responsáveis pela RI na PCOS. As mulheres portadoras da PCOS representam uma parte significativa da população e a incidência de RI nessa população é expressiva, conforme citado no item 2.1. 


\section{JUSTIFICATIVA}

As mulheres portadoras da PCOS representam uma parte significativa da população e a incidência de RI nessa população é expressiva. Sendo assim, a compreensão dos mecanismos moleculares associados à $\mathrm{Rl}$ em pacientes com PCOS pode ser considerada como de vital importância para o desenvolvimento de estratégias terapêuticas (drogas ou exercício) dedicadas ao tratamento da síndrome. Nesse contexto, o exercício físico agudo emerge como excelente modelo de investigação, tendo em vista que as adaptações crônicas ao treinamento físico regular parecem ser o resultado da somatória de estímulos agudos e repetidos de diversas sessões individuais de treinamento. A figura 2 ilustra a hipótese central do estudo.

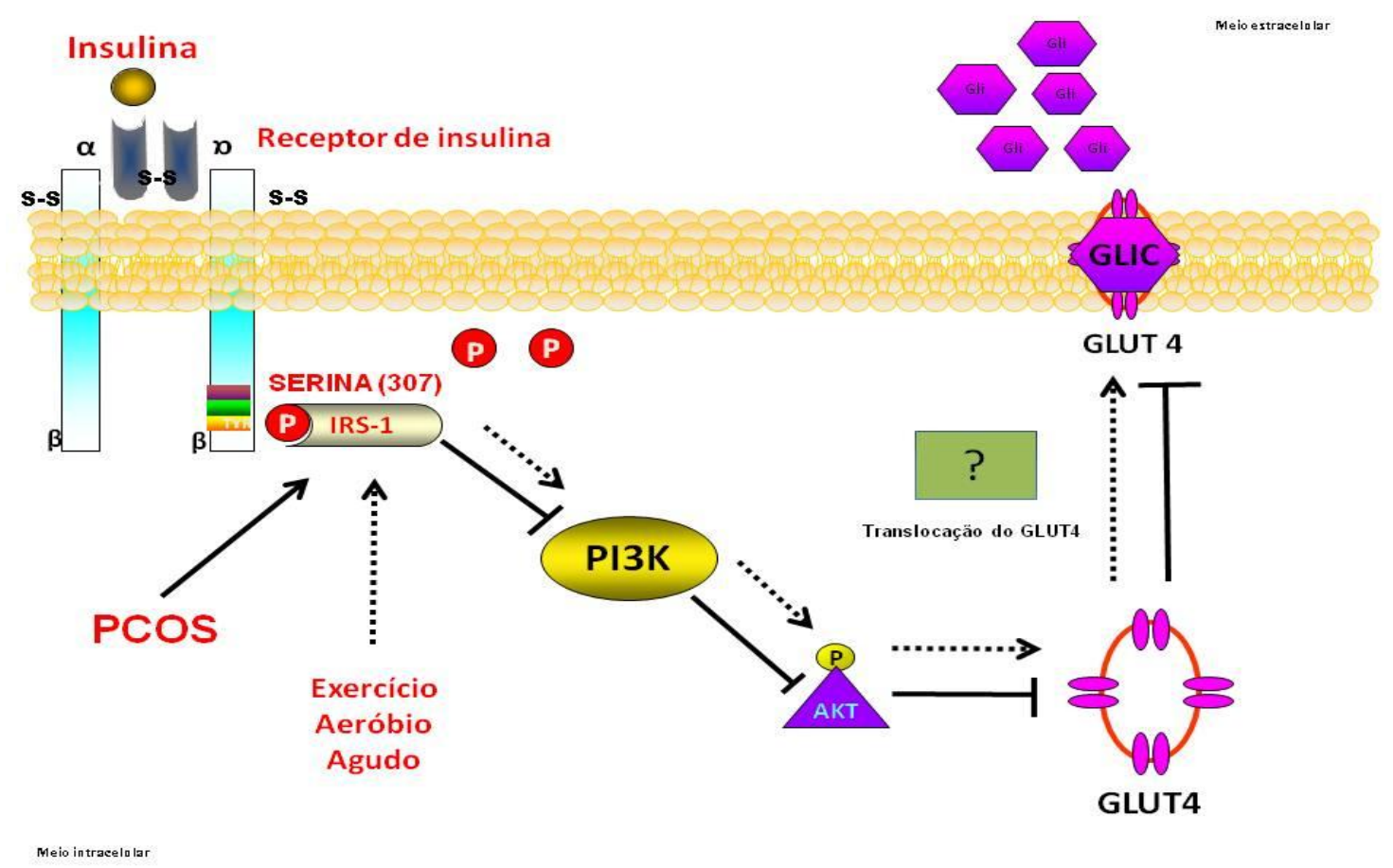

Figura 2. Hipótese central do estudo: A PCOS induz uma redução na atividade do IRS-1 e PI3-k no músculo esquelético, sugerindo um defeito na ativação do receptor de insulina (IR) ou na fosforilação do IRS-1. Tendo em vista que, em resposta a um programa de treinamento físico, pacientes com PCOS apresentam uma resposta subótima no que se refere à melhora da sensibilidade à insulina, aventamos a hipótese de que algum defeito na via "clássica" de sinalização de captação de glicose ("IR/IRS/PI3-k/Akt/GLUT-4") seria observado em resposta a uma sessão aguda de exercício aeróbio. Além disso, postulou- 
se que alterações na expressão proteica ou nas concentrações de citocinas inflamatórias poderiam explicar um possível defeito na sinalização molecular para captação de glicose.

\section{OBJETIVOS}

\subsection{Objetivo Geral}

O objetivo geral do presente estudo foi:

1) investigar o efeito do exercício aeróbio agudo sobre a expressão de proteínas responsáveis pela captação de glicose no músculo esquelético em pacientes com sobrepeso/obesas portadoras da PCOS (grupo PCOS) comparadas a mulheres sobrepeso/obesas sem comorbidades e sem a PCOS (grupo CTRL).

\subsection{Objetivos Específicos}

Os objetivos específicos do presente estudo foram:

1) investigar os efeitos agudos do exercício aeróbio sobre a expressão proteica de IRS-1 total, IRS-1 fosforilada (Ser 307), PI3-k p85, Akt total, Akt fosforilada (Ser 473), Akt fosforilada (Thr 308), AMPK total, AMPK fosforilada (Thr 172), AS160 total, AS160 fosforilada (Thr 642), GLUT-4 total e GLUT-4 membranar em pacientes com sobrepeso/obesas portadoras da PCOS (grupo PCOS) comparadas a mulheres sobrepeso/obesas sem comorbidades e sem a PCOS (grupo CTRL).

2) investigar os efeitos agudos do exercício aeróbio sobre a produção de citocinas pró e anti-inflamatórias em pacientes com sobrepeso/obesas portadoras da PCOS (grupo PCOS) comparadas a mulheres sobrepeso/obesas sem comorbidades e sem a PCOS (grupo CTRL). 


\section{PLANO INICIAL DE TRABALHO E CRONOGRAMA DE EXECUÇÃO PROPOSTO}

O trabalho ocorreu no HCFMUSP. A equipe de pesquisa da Disciplina de Endocrinologia foi composta por quatro médicos, a saber: Dra. Michelle Patrocínio Rocha, Dr. Cristiano Roberto Grimaldi Barcellos, Dra. Viviane dos Reis Vieira Yance e Prof. Dr. José Antônio Miguel Marcondes (Serviço de Endocrinologia da FMUSP Ambulatório de Síndromes Hiperandrogênicas 1MN1000), responsáveis por recrutar, selecionar e acompanhar os voluntários durante o estudo. $O$ teste ergoespirométrico e a sessão aguda de exercício aeróbio foram realizados no Laboratório de Avaliação e Condicionamento em Reumatologia (LACRE) do HCFMUSP e conduzidos pelo aluno de doutorado Luiz Augusto Buoro Perandini e pelo aluno de mestrado Wagner Silva Dantas, respectivamente, sob a supervisão da Dra. Ana Lúcia de Sá Pinto. A biópsia muscular foi realizada na enfermaria da Disciplina de Reumatologia pelo Prof. Dr. Samuel Katsuyuki Shinjo. O aluno Wagner Silva Dantas participou de todas as etapas experimentais sob supervisão do Prof. Dr. Bruno Gualano (EEFE-USP), que coordenou o projeto, conjuntamente ao Prof. Dr. José Antônio Miguel Marcondes.

De acordo com o cronograma de execução inicialmente proposto (Quadro 1), as atividades programadas para os períodos de 2012 a 2014 foram cumpridas com êxito. 
Quadro 1 - Estimativa de tempo sugerida para cumprimento das etapas que serão desenvolvidas no presente projeto.

\begin{tabular}{|c|c|c|c|}
\hline & 2012 & 2013 & 2014 \\
\hline 1. Créditos em disciplinas & $\mathbf{x}$ & $x$ & \\
\hline 2. Experimentos & & $\mathbf{x}$ & \\
\hline 3. Coleta de dados & $\mathbf{x}$ & $\mathbf{x}$ & \\
\hline 4. Análise dos resultados & & $\mathbf{x}$ & $\mathbf{x}$ \\
\hline $\begin{array}{l}\text { 5. Confecção e defesa da dissertação e } \\
\text { preparação de manuscrito }\end{array}$ & & $\mathbf{x}$ & $\mathbf{x}$ \\
\hline
\end{tabular}

\section{CASUÍSTICA E MÉTODOS}

\subsection{Aprovação do Comitê de Ética em Pesquisa}

O presente estudo foi submetido à Plataforma Brasil (CONEP) e aprovado pelo Comitê de Ética e Pesquisa da Escola de Educação Física e Esporte da Universidade de São Paulo sob o protocolo 2012/15 e pelo comitê de Ética e Pesquisa do Hospital das Clínicas da Faculdade de Medicina da Universidade de São Paulo (instituição coparticipante) sob o protocolo CAAE 01431412.3001.0068 (número do parecer: 184.204).

\subsection{Protocolo Experimental}

Antes de participarem da intervenção, as voluntárias passaram por avaliação médica com o intuito de verificar os critérios de elegibilidade e, caso aprovadas, assinaram termo de consentimento livre e esclarecido. As pacientes selecionadas foram submetidas a um teste ergoespirométrico máximo em esteira rolante para 0 
estabelecimento do consumo máximo de oxigênio $\left(\mathrm{VO}_{2}\right.$ máx $)$ e respectivos limiares ventilatórios. Na semana seguinte, as voluntárias foram submetidas à biópsia muscular antes da sessão aguda de exercício aeróbio. Em seguida, as voluntárias realizaram um teste submáximo em esteira de intensidade moderada e, uma hora após o exercício aeróbio, foram submetidas a uma segunda biópsia muscular. Um grupo de mulheres sem comorbidades pareadas por $\mathrm{IMC}$ e $\mathrm{VO}_{2}$ máx realizaram o mesmo protocolo acima descrito, como amostra para o grupo controle. As amostras musculares foram utilizadas para análise de proteínas envolvidas na sinalização intracelular de captação de glicose. O desenho experimental é ilustrado abaixo na Figura 3.

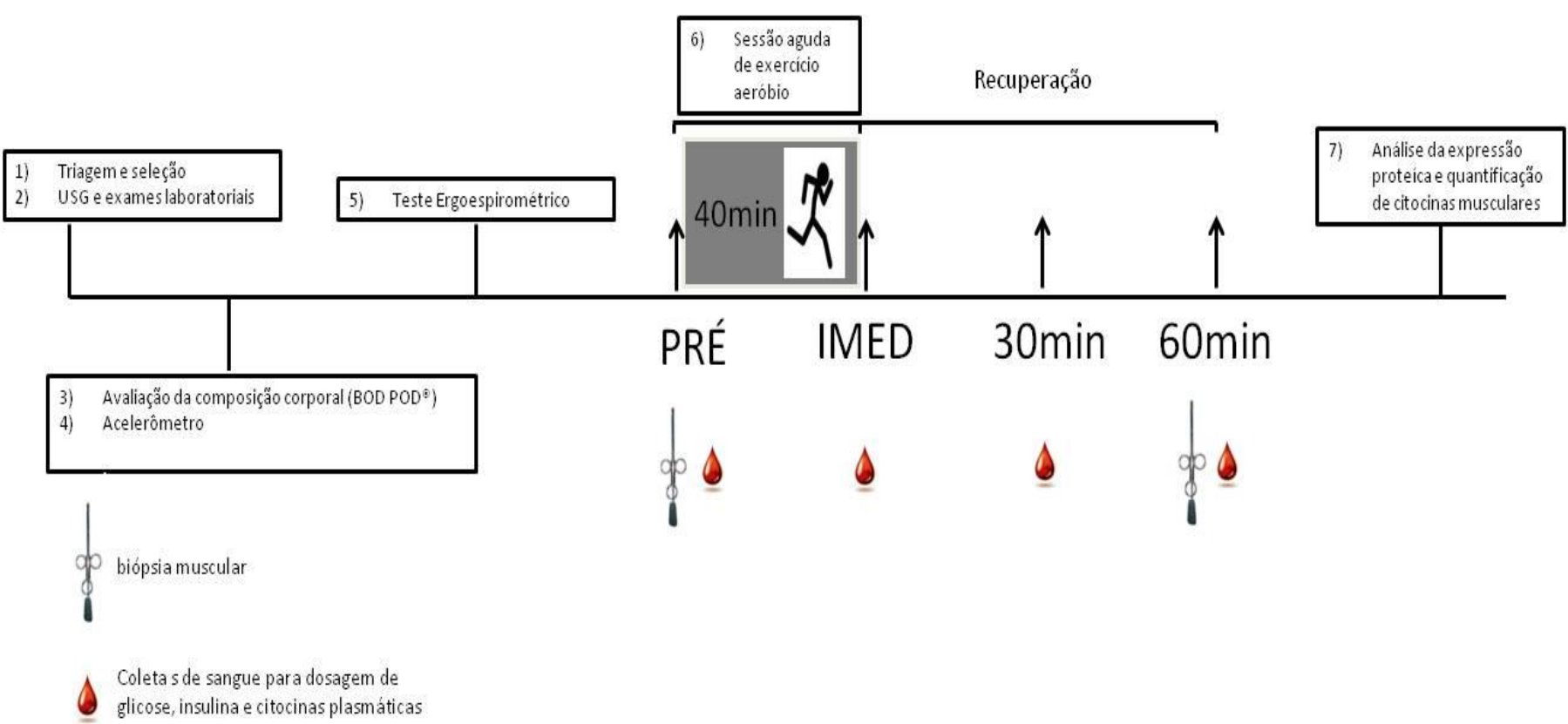

Figura 3. Desenho experimental. USG (ultrassonografia transvaginal). 


\subsection{Seleção e Recrutamento das pacientes}

A seleção das participantes foi feita no Ambulatório de Síndromes Hiperandrogênicas do Serviço de Endocrinologia e Metabologia (1MN1000HCFMUSP). Todas as pacientes foram acompanhadas por médicos endocrinologistas durante o projeto. Foram elegíveis pacientes com a PCOS para inclusão no estudo de acordo com os critérios do consenso da The Androgen Excess Society (AES) (Azziz et al., 2006), adicionado a outros critérios como:

- Idade entre 18 e 35 anos;

- IMC entre $25 \mathrm{~kg} / \mathrm{m}^{2}$ a $40 \mathrm{~kg} / \mathrm{m}^{2}$;

- Sedentárias.

Para as mulheres sem comorbidades (grupo CTRL), foram elegíveis aquelas com as seguintes características:

- ciclos menstruais regulares e ovulatórios (o ciclo menstrual será considerado regular quando o intervalo entre as menstruações não foi menor que 27 dias e maior que 32 dias. Serão confirmados ciclos menstruais ovulatórios quando a progesterona for maior que $7,0 \mathrm{ng} / \mathrm{dL}$ em torno do $20^{\circ}$ ao $25^{\circ}$ dia do ciclo menstrual);

- Ausência de hiperandrogenismo e/ou hiperandrogenemia;

- Idade entre 18 e 35 anos;

- Índice de massa corporal (IMC) entre $25 \mathrm{~kg} / \mathrm{m}^{2}$ a $40 \mathrm{~kg} / \mathrm{m}^{2}$;

- Sedentárias.

Para ambos os grupos (PCOS e CTRL), os critérios de exclusão são:

- Uso de qualquer tipo de medicação nos três meses anteriores e contraceptivos hormonais nos seis meses anteriores à inclusão no estudo;

- Presença de doença renal crônica e insuficiência hepática;

- Evidência clínica de aterosclerose (antecedente de infarto agudo do miocárdio, acidente vascular encefálico ou doença arterial periférica); 
- Diagnóstico de diabetes mellitus pela American Diabetes Association ou Organização Mundial de Saúde;

- Tabagismo;

- Alcoolismo;

\subsection{Avaliação Laboratorial}

As coletas basais e os testes hormonais foram realizados às 8 horas da manhã, após jejum noturno de 12 horas, na sala de testes ( $5^{\circ}$ andar, bloco 4B, sala 13) do Serviço de Endocrinologia do Hospital das Clínicas da Faculdade de Medicina da Universidade de São Paulo. Nas mulheres saudáveis, as coletas de sangue foram realizadas até $05^{\circ}$ dia após 0 inicio da menstruação. Nas pacientes com PCOS, as coletas de sangue foram realizadas aleatoriamente.

As coletas hormonais basais referem- se à dosagem dos seguintes hormônios: estradiol $\left(E_{2}\right)$, 17-hidroxiprogesterona (17-OHP), progesterona (P), hormônio luteinizante (LH), hormônio folículo-estimulante (FSH), testosterona total (TT), androstenediona $(\Delta 4)$, deidroepiandrosterona (DHEA), sulfato de deidroepiandrosterona (DHEAS), globulina ligadora de hormônios sexuais (SHBG), hormônio tireotrófico (TSH), tiroxina livre (T4 livre), prolactina (PRL) e o cortisol basal. A testosterona livre (TL) foi estimada através do cálculo proposto por VERMEULEN et al., (1999). Para a exclusão da forma não clássica da hiperplasia adrenal congênita por deficiência da enzima 21 - hidroxilase, foi realizado o teste de estímulo agudo com ACTH sintético (Cortrosyn TM, Organon - EUA) na dosagem de $250 \mu \mathrm{g}$ a ser administrado por via intravenosa, em bolus, sendo realizadas coletas de sangue para dosagens de cortisol e 17-OHP, imediatamente antes (tempo 0) e 60 minutos após a administração da droga.

Para a análise do perfil lipídico foram dosados: colesterol total (CT), triglicerídeos (TG), VLDL-colesterol, HDL-colesterol e LDL-colesterol. As concentrações séricas de colesterol total, HDL-colesterol e TG foram determinados por métodos enzimáticos colorimétricos. A partir dessas determinações foi possível 
inferir a quantidade de VLDL-colesterol de acordo com a equação de FREDEWALD et al., (1972):

$(\mathrm{VLDL}$-colesterol $=\mathrm{TG} / 5)$ e LDL-colesterol $(\mathrm{LDL}$-colesterol $=$ colesterol total $-(\mathrm{HDL}-$ colesterol + VLDL-colesterol).

Para avaliação da sensibilidade à insulina, foi realizado o teste oral de tolerância à glicose (TOTG). As pacientes compareceram a sala de testes do Serviço de Endocrinologia do Hospital das Clínicas da Faculdade de Medicina da Universidade de São Paulo em jejum noturno de 12 horas, onde foram coletados 3 $\mathrm{ml}$ de sangue da veia antecubital. Foi administrado por via oral $75 \mathrm{~g}$ de solução de dextrose ( $75 \mathrm{~g}$ de dextrose em solução de $300 \mathrm{ml}$ de água) às mulheres saudáveis e pacientes com PCOS, seguidos de coletas de sangue para determinação da glicose e da insulina a ser realizada antes, 30, 60, 90 e 120 minutos após a administração da solução de dextrose.

As amostras foram mantidas em isopor com gelo e imediatamente após o procedimento, centrifugadas $(4000 \mathrm{rpm}, 5$ minutos, 40 C) e analisadas. As concentrações de insulina foram determinadas por técnicas imunofluorométricas. A glicemia foi dosada através de método enzimático colorimétrico. As áreas totais e incrementais abaixo da curva de insulina e glicose foram calculadas por meio do modelo trapezóide. A partir dos valores de glicemia e insulinemia de jejum, foram calculados os índices glicose/insulina (G/l) e Homeostase Model Assessement (HOMA - IR e HOMA - $\beta$ ), que estimam a sensibilidade à insulina e a função das células beta, respectivamente (Matthews et al., 1985). Além disso, foi estimada a sensibilidade à insulina no corpo inteiro (Índice Matsuda), no território hepático (HIR) e muscular (mISI) através da fórmula proposta por ABDUL-GHANI et al., (2007). Para a estimativa da RI em resposta a sessão aguda de exercício aeróbio foi utilizada a equação (Malik et al., 2013): 


\subsection{Antropometria e avaliação da composição corporal}

Com o intuito de caracterizar a amostra, foram realizadas mensurações antropométricas após a consulta médica. O peso das voluntárias foi mensurado em balança digital e a altura determinada na posição em pé com auxílio de estadiômetro. Essas medidas foram utilizadas na realização do IMC por meio da fórmula:

$$
\text { IMC }\left(\mathrm{Kg} / \mathrm{m}^{2}\right)=\text { Peso corporal }(\mathrm{Kg}) / \text { Estatura }(\mathrm{m})^{2}
$$

A composição corporal foi determinada pelo método de pletismografia de corpo inteiro (BOD POD ${ }^{\circledR}$ ) de acordo FIELDS et al., (2000). Os resultados foram expressos em forma absoluta ( $\mathrm{Kg}$ de massa gorda e massa livre de gordura) e em percentual (\%).

\subsection{Acelerômetro}

O acelerômetro é um monitor de atividade física. É um dispositivo pequeno, colocado na altura da crista ilíaca direita do indivíduo por meio de uma fita de encaixe presa a cintura pélvica, capaz de coletar informações em três planos de movimento: médio-lateral $(\mathrm{X})$, ântero-posterior $(\mathrm{Y})$ e vertical $(\mathrm{Z})$, bem como a composição (vetor resultante) desses três planos. O acelerômetro reconhece os movimentos que são executados durante o dia e produz uma medida de atividade física habitual. O nível de atividade física dos pacientes foi medido com o uso do acelerômetro triaxial Actigraph GT3x (Actigraph). Antes da utilização do acelerômetro, os responsáveis legais dos pacientes assinaram um termo de responsabilidade assegurando a devolução do aparelho e receberam as instruções para o uso do mesmo. $O$ acelerômetro foi utilizado por sete dias, sendo necessário o mínimo de quatro dias válidos (tempo válido de registro maior do que 10 horas por dia), durante todo o tempo em que estiveram acordadas, exceto durante o banho e em atividades aquáticas. Adicionalmente, as voluntárias preencheram um diário de uso do aparelho, onde constou o dia, horário de colocação e de possíveis retiradas do mesmo. 
Os dados coletados foram descarregados no computador através do software ActiLife versão 6.6.2. Os sinais coletados pelo aparelho foram convertidos para "counts" de atividade, os quais foram registrados a cada 15 segundos, e posteriormente agrupados a cada 1 minuto para facilitar a descrição e análise. No presente relatório, reportamos os seguintes dados: 1) a atividade diária, obtida através da razão entre o total de counts e o tempo total de uso, 2) o vetor magnitude - valor resultante do conjunto de aceleração nos três eixos - obtido através da razão entre o vetor magnitude total e o tempo total de uso, 3) o tempo gasto em atividades sedentárias, leves, moderadas, vigorosas e moderadas a vigorosas (soma do tempo gasto em atividades moderadas e em atividades vigorosas).

A atividade física habitual das pacientes de ambos os grupos foi mensurada com o intuito de traçar o nível de atividade física atual das pacientes e, portanto, atestar que ambos os grupos são sedentários.

\subsection{Ultrassonografia Pélvica}

As pacientes com PCOS e CTRL foram submetidas à ultrassonografia pélvica via abdominal ou endovaginal, com transdutor setorial de 3,5 e 6,5 MHZ, respectivamente. Foram avaliados o eco endometrial, o volume uterino, a morfologia e o volume ovariano. O exame ultrassonográfico foi considerado como padrão para a documentação de ovários policísticos quando da presença de 12 ou mais folículos ovarianos, com diâmetro variando entre 2 e $9 \mathrm{~mm}$ e/ou volume ovariano superior a $10 \mathrm{~cm}^{3}$ (Azziz et al., 2006).

\subsection{Teste Ergoespirométrico}

Para a determinação dos limiares ventilatórios e potência aeróbia, as pacientes realizaram um teste ergoespirométrico em esteira rolante (Centurion 200, Micromed), seguindo um protocolo em rampa com aumento a cada minuto na carga de trabalho (velocidade e/ou inclinação) até a exaustão. Durante o teste de esforço, 
- comportamento cardiovascular foi continuamente avaliado através de eletrocardiógrafo, com as 12 derivações simultâneas (D1, D2, D3, aVR, aVL, aVF, V1, V2, V3, V4, V5, V6). A frequência cardíaca (FC) foi registrada em repouso com o paciente posicionado na esteira rolante, ao final de cada minuto do teste de esforço e no $1^{\circ}, 2^{\circ}, 4^{\circ}$ e $6^{\circ}$ minuto de recuperação. A pressão arterial foi medida sempre pelo mesmo avaliador, em repouso, a cada dois estágios de exercício e no $1^{\circ}, 2^{\circ}, 4^{\circ}$ e $6^{\circ}$ minuto do período de recuperação.

A avaliação da potência aeróbia máxima foi feita através da medida direta do consumo de oxigênio no pico do exercício $\left(\mathrm{VO}_{2}\right.$ máx ou $\mathrm{VO}_{2}$ pico, designado doravante pela primeira abreviação, à título de padronização). A paciente foi conectada a um ergoespirômetro computadorizado (Metalyzer modelo III b/ breath- by- breath), através de um sistema de sensor que permitiu a mensuração da ventilação pulmonar (VE) a cada expiração. Através de sensores de oxigênio $\left(\mathrm{O}_{2}\right)$ e de dióxido de carbono $\left(\mathrm{CO}_{2}\right)$, foram analisadas as frações expiradas de $\mathrm{O}_{2}$ e $\mathrm{CO}_{2}$ a cada ciclo respiratório.

A partir das análises da VE e das concentrações dos gases expirados, foram calculados o consumo de oxigênio $\left(\mathrm{VO}_{2}\right)$ e a produção de dióxido de carbono $\left(\mathrm{VCO}_{2}\right)$. Os testes foram considerados máximos quando um ou mais critérios a seguir foram atingidos: $i$. evidência subjetiva de exaustão (ex. hiperventilação acentuada seguida por desistência do paciente); ii. frequência cardíaca de pico > 95\% da FC máxima predita; iii. razão da troca respiratória (RER) > 1,10; plateau no consumo de oxigênio por dois estágios consecutivos. Em todos os casos acima, 0 valor de consumo de oxigênio imediatamente antes da interrupção do teste foi considerado como o $\mathrm{VO}_{2}$ máx.

Para a determinação do limiar anaeróbio (LAn), utilizaram-se os seguintes critérios: $i$. incremento nos valores de equivalente ventilatório de oxigênio $\left(\mathrm{VE} / \mathrm{VO}_{2}\right)$ e pressão parcial de oxigênio ao final da expiração $\left(\mathrm{PETO}_{2}\right)$, sem concomitante elevação do equivalente ventilatório de dióxido de carbono $\left(\mathrm{VE} / \mathrm{VCO}_{2}\right)$; ii. perda de linearidade da relação entre consumo de oxigênio $\left(\mathrm{VO}_{2}\right)$ e a produção de dióxido de carbono $\left(\mathrm{VCO}_{2}\right)$; iii. incremento não-linear do valor da razão da troca respiratória (RER). 
O ponto de compensação respiratória (PCR) foi determinado de acordo com os seguintes critérios: $i$. menor valor de $\mathrm{VE} / \mathrm{VCO}_{2}$, antes do incremento progressivo dessa variável; ii. maior pressão parcial de dióxido de carbono ao final da expiração $\left(\mathrm{PETCO}_{2}\right)$, antes do decréscimo progressivo dessa variável.

Os limiares foram determinados por um único avaliador experiente. Todos os testes foram conduzidos sob a supervisão de um médico.

\subsection{Sessão aguda de exercício aeróbio}

As mulheres foram orientadas a manterem a ingestão alimentar habitual e os níveis de atividade física durante todo o protocolo experimental. As pacientes compareceram ao Laboratório de Avaliação e Condicionamento em Reumatologia (LACRE) por volta das 8 horas da manhã, após seguirem dieta padronizada do Serviço de Nutrição do Hospital das Clínicas da Faculdade de Medicina para a alimentação durante o café da manhã, composta por um pão francês com dois queijos tipo "polenguinho", uma geleia (unidade individual) e um suco de soja de caixinha de $200 \mathrm{~mL}$ de volume. As pacientes foram orientadas a ingerem os alimentos citados as 6 horas e trinta minutos da manhã e em no máximo 15 minutos. A sessão aguda de exercício aeróbio foi composta de 40 minutos de duração total da atividade a uma intensidade correspondente a $50 \%$ da carga $(\Delta 50)$ entre o limiar aeróbio (LAn) e o ponto de compensação respiratória (PCR). Nos 5 minutos iniciais, as pacientes realizavam aquecimento a 2,5 milhas por hora $(\sim 4,7$ quilômetros por hora) e iniciaram por 30 minutos o exercício na intensidade estipulada com base no teste ergoespirométrico. Após o término, as pacientes realizavam um desaquecimento (volta à calma) por 5 minutos a uma intensidade de 2,5 milhas por hora. As pacientes foram monitoradas através do frequencímetro POLAR RS800CX $\circledast$ para certificar a intensidade estabelecida para cada voluntária. Após a sessão, a aquisição dos resultados provenientes do frequencímetro foi passada para um computador para posterior análise dos resultados (figura 4).

$\mathrm{Na}$ sessão aguda de exercício aeróbio, as mulheres foram submetidas a coletas de sangue $(\sim 4 \mathrm{ml})$ nos seguintes períodos propostos: repouso (PRÉ), 
imediatamente após o término do exercício aeróbio agudo (IMED), trinta minutos após o término do exercício aeróbio agudo (30'PÓS) e 60 minutos após o término do exercício aeróbio agudo (60'PÓS) para análise de glicemia, insulinemia e citocinas plasmáticas.

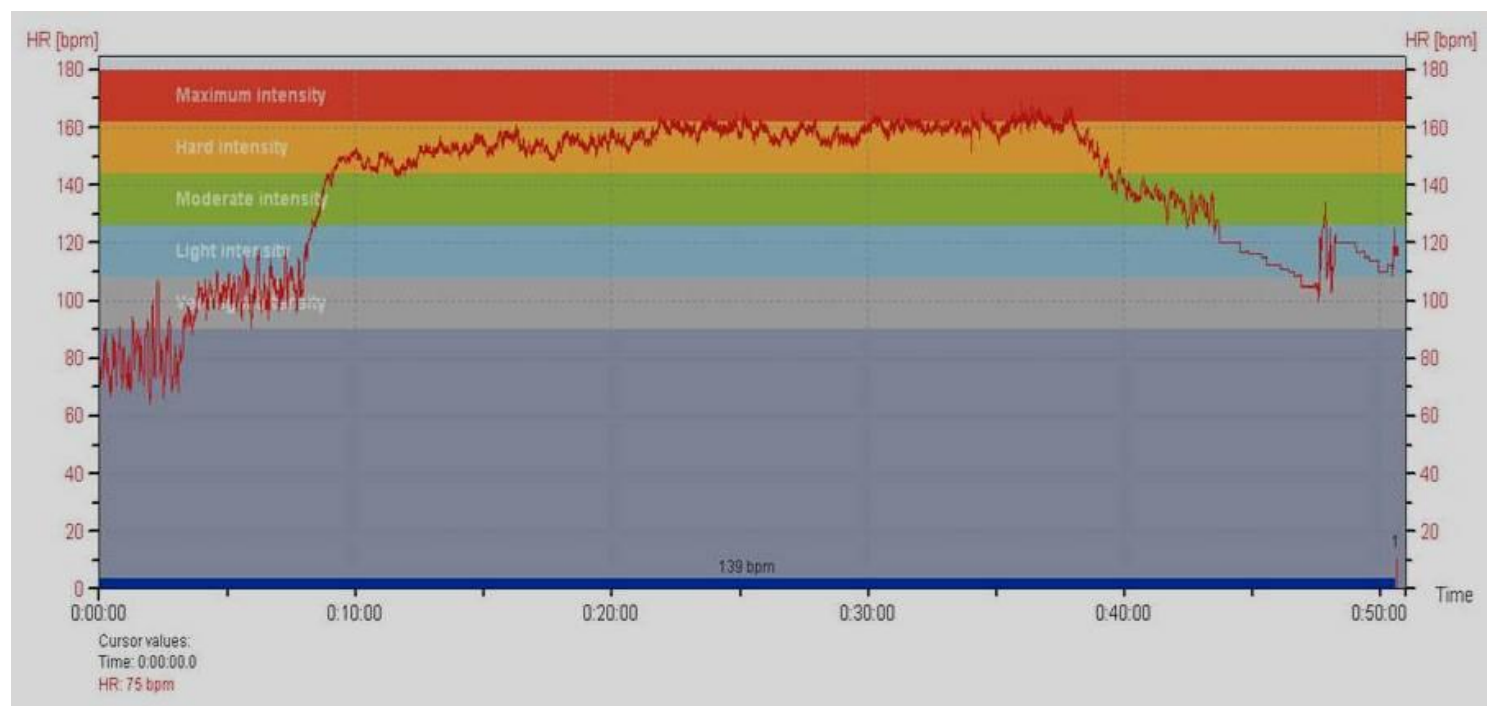

Figura 4. Imagem representativa da aquisição de dados pelo frequencímetro POLAR RS800CX® para monitoramento da intensidade da sessão aguda de exercício aeróbio.

As amostras para análise de citocinas plasmáticas foram coletadas em tubo contendo ácido etilenodiamino tetra-acético (EDTA) e mantidas em isopor com gelo. Para análise da insulina, as amostras foram coletas em tubo seco da marca BD Vacutainer ${ }^{\circledR}$ SST II Advance. As amostras para análise glicêmica foram coletadas em tubo contendo fluoreto de sódio (NaF) e EDTA. As amostras de glicemia e insulina foram analisadas pelo Laboratório Central do HCFMUSP através de ensaio enzimático colorimétrico e radioimunoensaio, respectivamente. Imediatamente após a coleta, as amostras para a análise das citocinas plasmáticas foram homogeneizadas por inversão de 5 a 8 vezes para evitar hemólise e centrifugadas a $1800 \mathrm{~g}$ durante 10 minutos a $4^{\circ} \mathrm{C}$. O plasma foi pipetado e dispensado em microtubos (alíquotas), que foram congelados a $-80^{\circ} \mathrm{C}$ para as subsequentes análises. 


\subsection{Biópsia Muscular por agulha de sucção}

As biópsias foram realizadas na enfermaria da Disciplina de Reumatologia pelo Prof. Dr. Samuel Katsuyuki Shinjo, professor responsável pelo Laboratório de Miopatias Inflamatórias do Serviço de Reumatologia (HCFMUSP). Antes (PRÉ) e sessenta minutos após a sessão aguda de exercício aeróbio (PÓS), as voluntárias foram submetidas a biópsias musculares por agulha de sucção, que permitiu obter uma pequena amostra de aproximadamente 60 - $100 \mathrm{mg}$ da porção média do músculo vasto lateral da coxa.

As voluntárias foram orientadas a deitar-se em uma maca, mantendo os joelhos estendidos e a musculatura relaxada. O médico responsável fez a assepsia e antissepsia da perna direita e, em seguida, administrou $3 \mathrm{~mL}$ de xilocaína a $2 \%$ sem vasoconstrictor para anestesia local. A aplicação do anestésico foi feita com agulhas hipodérmicas descartáveis, de forma subcutânea. Após anestesia local, foi realizada a incisão para a entrada da agulha de biópsia no tecido muscular. Para tanto, foi utilizada lâmina de bisturi $n^{\circ} 11$, esterilizada, individual e descartável para realizar a incisão de aproximadamente $0,5 \mathrm{~cm}$ de extensão. A incisão cortou a pele $e$ a fáscia muscular. A agulha de biópsia, esterilizada e de uso individual, foi então inserida através do orifício gerado pela incisão. Após uma sucção, aplicada na extremidade superior externa da agulha por uma seringa de $120 \mathrm{~mL}$, uma pequena amostra de músculo foi succionada para o interior da agulha e cortada pela sua lâmina interna da agulha.

Após uma hora da execução da sessão aguda de exercício aeróbio, o médico responsável realizou assepsia e antissepsia do orifício gerado pela incisão e repetiu o procedimento descrito no parágrafo anterior, com o intuito de obter nova amostra muscular.

Após a retirada da agulha, foi aplicada pressão sobre o ponto de incisão para prevenir sangramento. A incisão foi fechada com bandagem esterilizada e coberta com uma pequena atadura para prevenir o seu desprendimento. Uma faixa envolveu a coxa sobre a região da biópsia, aplicando pressão contínua, a fim de evitar qualquer edema local. As voluntárias foram instruídas a manter a bandagem por 24 
horas e a incisão limpa e seca pelo período de 72 horas. A figura 5 ilustra o procedimento.

Cabe salientar que, embora as biópsias tenham sido realizadas através da mesma incisão, as amostras musculares extraídas são oriundas diferentes pontos do ventre muscular já que a inserção da agulha foi realizada em ângulos levemente diferentes. De fato, há evidências de que o procedimento de biópsia seriada, tal qual realizada no presente estudo, não promove significativa alteração na expressão de proteínas relacionadas à resposta inflamatória (Caron et al., 2011).

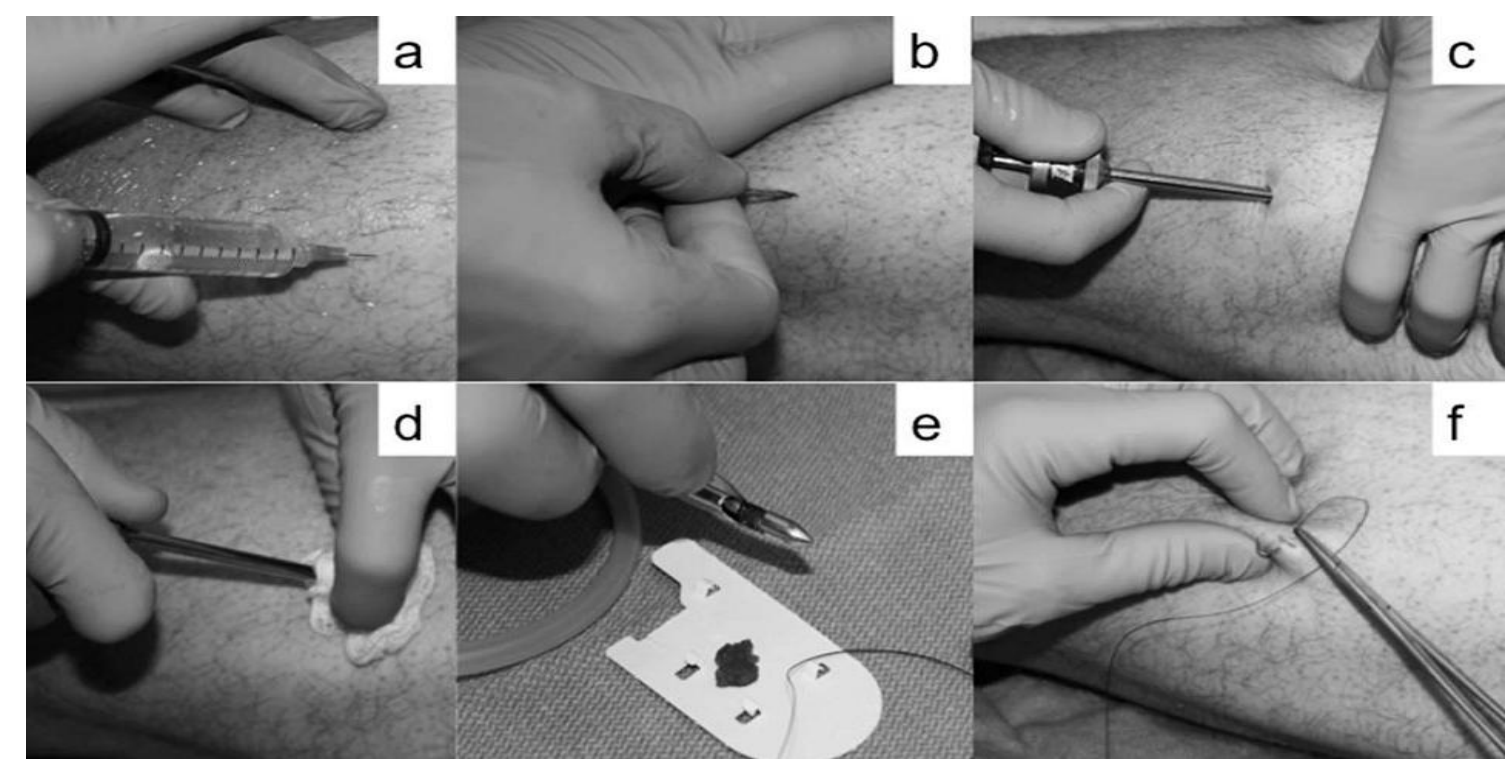

Figura 5. llustração do procedimento de biópsia muscular por agulha de sucção (A) a pele e o tecido subcutâneo são anestesiados com xilocaína; (B) é feita uma incisão de 4$5 \mathrm{~mm}$ para rompimento da fáscia muscular; (C) a agulha é inserida no orifício até o músculo, a sucção é realizada e a agulha é então fechada; (D) a agulha é removida; (E) o tecido muscular é removido da agulha e congelado a $-80^{\circ} \mathrm{C}$ para posterior análise; $(F)$ a sutura é realizada (em nosso método, tal procedimento não é realizado). Extraído de TARNOPOLSKY et al., (2011). 


\subsection{Determinação das concentrações plasmáticas e musculares de citocinas inflamatórias e anti-inflamatórias}

As dosagens de citocinas foram feitas nas amostras de plasma e tecido muscular nos períodos do repouso (PRÉ) e sessenta minutos após a sessão aguda de exercício aeróbio (PÓS). Os tecidos musculares coletados nas biópsias musculares foram homogeneizados em tampão de extração gelado com $150 \mathrm{mM}$ $\mathrm{NaCl}, 5 \mathrm{mM}$ EDTA, $10 \mathrm{mM}$ Tris- $\mathrm{HCl}, 0.1 \%$ Triton X100, pH 7.4. Os homogeneizados foram centrifugados por 20 minutos, a $12000 \mathrm{rpm}$ em temperatura de $4^{\circ} \mathrm{C}$. Para análise das concentrações de citocinas plasmáticas em resposta ao exercício aeróbio agudo foram coletados $4 \mathrm{ml}$ de sangue da veia antecubital nos períodos PRÉ e PÓS. A coleta de sangue utilizou o EDTA como o anticoagulante recomendado pelo fabricante e, após a coleta, centrifugado por 10 minutos a 1000 $\mathrm{xg}$. Imediatamente após a centrifugação, diversas alíquotas foram armazenadas a uma temperatura de $-80^{\circ} \mathrm{C}$. Foram avaliadas as concentrações do fator de necrose tumoral alfa (TNF- $\alpha$ ), interleucina 1 beta (IL-1 $\beta$ ), interleucina 4 (IL-4), interleucina 6 (IL-6) e interleucina 10 (IL-10) utilizando a Tecnologia Luminex ${ }^{\mathrm{TM}}$ XMAP (Millipore ${ }^{\circledR}$, Billerica, MA - EUA). Neste sistema, microesferas de látex são coradas com dois fluoróforos. Os kits LINCOplex ${ }^{\mathrm{TM}}$ foram desenvolvidos com estas microesferas e se fundamentam no imunoensaio. Anticorpos de captura específicos para cada analito estão imobilizados as microesferas através de ligações covalentes não reversíveis. Depois que o analito (amostra) se liga aos anticorpos de captura localizados na superfície das microesferas, a detecção final é feita através de um terceiro marcador fluorescente, ficoeritrina ligada ao anticorpo de detecção. O resultado final é um ensaio "sanduíche" realizado através de microesferas. O equipamento Luminex 100 movimenta estas esferas em fila única através de feixes de dois lasers diferentes em um citômetro de fluxo. O primeiro feixe de laser detecta (classifica) a microesfera (código de cor para o ensaio) e o segundo quantifica o sinal de reporte em cada microesfera. As concentrações plasmáticas de cada citocina foram expressas em $\mathrm{pg} / \mathrm{ml}$ e as concentrações de citocina dosadas no tecido muscular esquelética foram expressas em pg/ $80 \mu \mathrm{g}$ de proteína. 


\subsection{Determinação da expressão de proteínas selecionadas e da translocação do GLUT-4 por Western Blotting}

A expressão proteica do IRS-1 total (Millipore, EUA, titulação 1:1000), IRS-1 fosforilada (Ser 307) (Millipore, EUA, titulação 1:1000), PI3-k p85 (Millipore, EUA, titulação 1:1000), Akt total (Cell Signaling, EUA, titulação 1:750), Akt fosforilada (Ser 473) (Cell Signaling, EUA, titulação 1:750), Akt fosforilada (Thr 308) (Cell Signaling, EUA, titulação 1:750), AMPK total (Cell Signaling, EUA, titulação 1:1000), AMPK fosforilada (Thr 172) (Cell Signaling, EUA, titulação 1:1000), AS160 total (Cell Signaling, EUA, titulação 1:1000), AS160 fosforilada (Thr 642) (Cell Signaling, EUA, titulação 1:1000), GLUT-4 total (Millipore, EUA, titulação 1:750), GAPDH ( Santa Cruz, EUA, titulação 1:1000), $\beta$ - tubulina (Cell Signaling, EUA, titulação 1:1000), ERK1/2 total (Santa Cruz, EUA, titulação 1:1000) e Caveolina total (Santa Cruz, EUA, titulação 1:1000) foram determinadas pela técnica de Western Blotting, de acordo com os procedimentos a seguir. As amostras musculares foram imediatamente homogeneizadas em tampão de extração $(150 \mathrm{mM} \mathrm{NaCl}, 5 \mathrm{mM}$ EDTA, $10 \mathrm{mM}$ Tris- $\mathrm{HCl}, 0.1 \%$ Triton X100, $\mathrm{pH}$ 7.4). Os homogeneizados foram centrifugados por 20 minutos, a $12000 \mathrm{rpm}$ em temperatura de $4^{\circ} \mathrm{C}$. O sobrenadante foi utilizado para quantificar a concentração total de proteínas. Em seguida, cada amostra foi diluída em tampão Laemmli na proporção de 1:5. Trinta microgramas de proteína do sobrenadante foram submetidos à eletroforese em gel de poliacrilamida (SDS-PAGE 10\%), no aparelho para minigel (Mini-Protean).

A transferência das proteínas separadas no gel foi feita eletricamente sob 110 volts para uma membrana de nitrocelulose com duração de 1 hora e 30 minutos. A ligação inespecífica de proteínas na membrana de nitrocelulose foi minimizada pela incubação destas com $10 \mathrm{ml}$ de solução bloqueadora (5\% de leite desnatado MOLICO®) por 1 hora na temperatura ambiente. Em seguida, as mesmas foram lavadas três vezes por dez minutos com solução TBS-T (solução tampão com tris e tween) seguido de mais uma lavagem de dez minutos com solução PBS (solução com tampão fosfato) para retirada do excesso de tween. As bandas existentes nas membranas incubadas foram visualizadas por fotodocumentador ImageQuant LAS 4000 (GE Healthcare®) pós-reação de quimiluminescência. O método da quimiluminescência consiste nos seguintes passos: após incubação da membrana 
com o anticorpo primário, a membrana é novamente incubada por uma hora e meia com o anticorpo anti-lgG marcado com peroxidase em solução bloqueadora (1:10000). Em seguida, as membranas são lavadas novamente três vezes com solução TBS-T para remover o excesso de anticorpo. Por fim, a imunodetecção foi realizada por meio do método de quimioluminescência de acordo com as instruções do fabricante (ECL, SuperSignal West Femto Chemilumininescent Substrate, Thermo Scientific () ). As análises quantitativas dos blots foram realizadas por meio do programa Scion (Scion Corporation, EUA). Como normalizador utilizamos a quantificação do rastro de proteínas por meio da coloração das membranas com s Ponceau, conforme ROMERO-CALVO et al. (2010) (86).

A análise da translocação de GLUT-4 das vesículas para a membrana sarcoplasmática foi realizada por meio do fracionamento específico dos compartimentos celulares e posterior determinação da proteína na membrana celular. Amostras de tecido muscular foram homogeneizadas em tampão tris-HCL $(20 \mathrm{mM})$, EDTA $(20 \mathrm{mM})$, EGTA $(10 \mathrm{mM})$, sacarose $(0,25 \mathrm{mM})$, coquetel inibidor de protease e fosfatase (1:300) e, em seguida, submetidas a centrifugações diferenciais para separação dos compartimentos celulares. O homogenato do tecido foi centrifugado em centrífuga de bancada (Hettich- Universal 32L) a $760 \mathrm{~g}$ por 5 minutos para separação da fração total. Em seguida, o sobrenadante foi submetido à nova centrifugação a $100.000 \mathrm{~g}$ por 1 hora em ultracentrífuga (Beckman - Optima L 90K). O sobrenadante (fração citossólica) foi coletado. O pellet resultante dessa centrifugação foi ressuspendido em tampão contendo $1 \%$ de triton, homogeneizado mecanicamente por sonicação (MA - 103 ultrassom) e submetido à outra ultracentrifugação a $100.000 \mathrm{~g}$ por uma hora. A fração solúvel (sobrenadante) contendo a membrana celular foi coletada e o pellet contendo a fração nuclear e citoesqueleto descartada. As amostras contendo membrana celular foram submetidas à análise por Western Blot (MiniPlotter Tetra - BioRad) em gel de SDS (dodecil-sulfato de sódio), conforme descrito anteriormente. A razão GLUT-4 sarcoplasmático/GLUT-4 total permitiu inferir a taxa de translocação dessa proteína à membrana (Gualano et al., 2011). 


\section{ANÁLISE DOS RESULTADOS}

Os dados são apresentados como média \pm erro padrão. A normalidade dos dados foi verificada pelo teste de Shapiro-Wilk e apenas os dados de citocinas e expressão proteica não apresentaram distribuição normal. Para as comparações dos resultados entre os dois grupos na condição basal e em resposta a sessão aguda de exercício aeróbio foi aplicado o teste $t$ de Student. Para a análise da resposta glicêmica e insulinêmica ao TOTG, resposta glicêmica e insulinêmica à sessão aguda de exercício aeróbio e resposta ventilatória ao teste ergoespirométrico, foi aplicado o teste de ANOVA two-way como post hoc de Bonferroni para comparações múltiplas dos dados paramétricos. Os dados intragrupos dos níveis plasmáticos e musculares de citocinas e a expressão proteica das amostras de músculo esquelético foram analisados por meio da ANOVA de Friedman (medidas repetidas) seguido pelo teste de Wilcoxon. Para a análise dos dados intergrupo das variáveis supracitadas foi aplicado o teste de Kruskall-Wallis seguido pelo teste de Mann-Whitney U. Valores de $p \leq 0,05$ foram considerados estatisticamente significantes, enquanto valores de $p \leq 0,1$ foram aceitos como tendência à significância.

\section{RESULTADOS}

\subsection{Participantes}

As pacientes foram recrutadas e selecionadas no período de setembro de 2012 a maio de 2013. Vinte e uma mulheres portadoras da PCOS e dezoito mulheres do grupo CTRL responderam ao convite de participação na pesquisa por email e telefone. Das 39 voluntárias avaliadas, quinze voluntárias portadoras da PCOS e doze voluntárias sem comorbidades preenchiam os critérios de inclusão no estudo. A tabela 1 ilustra as características das pacientes de acordo com o grupo experimental. Foram observadas diferenças significantes entre os grupos para a pressão arterial sistólica (PAS), sendo os maiores valores observados no grupo PCOS. A idade foi significantemente maior no grupo CTRL comparado ao grupo 
PCOS. A circunferência abdominal (CA) demonstrou uma tendência de aumento no grupo PCOS comparado ao grupo CTRL $(p=0,0970)$.

Tabela 1. Características dos grupos.

\begin{tabular}{cccc}
\hline Variável & PCOS $(\mathbf{n = 1 5})$ & CTRL $(\mathbf{n}=12)$ & $\begin{array}{c}\boldsymbol{p}(\boldsymbol{P C O S} \text { v } \\
\text { CTRL })\end{array}$ \\
\hline Idade (anos) & $24,87 \pm 1,133$ & $29,67 \pm 1,361$ & 0,0114 \\
IMC (Kg/m $\left.{ }^{2}\right)$ & $32,98 \pm 1,313$ & $30,38 \pm 1,182$ & 0,1638 \\
CA (cm) & $101,9 \pm 3,221$ & $94,38 \pm 2,691$ & 0,0970 \\
CQ (cm) & $109,7 \pm 2,249$ & $106,1 \pm 3,108$ & 0,4118 \\
PAS (mmHg) & $131,8 \pm 1,813$ & $122,3 \pm 3,679$ & 0,0214 \\
PAD (mmHg) & $83,60 \pm 2,049$ & $78,75 \pm 2,068$ & 0,1121 \\
MG (\%) & $40,34 \pm 1,787$ & $37,26 \pm 2,564$ & 0,3285 \\
MLG (\%) & $59,66 \pm 1,787$ & $62,75 \pm 2,562$ & 0,3274 \\
TMB (kcal/dia) & $1501 \pm 70,18$ & $1405 \pm 60,25$ & 0,3091 \\
\hline
\end{tabular}

Dados em média (erro padrão) e nível de significância para a interação de PCOS vs CTRL. IMC (Índice de massa corporal); CA (Circunferência abdominal); CQ (Circunferência de quadril); (Pressão Arterial Sistólica); PAD (Pressão Arterial Diastólica); MG (massa de gordura); MLG (massa livre de gordura); TMB (Taxa metabólica basal).

\subsection{Perfil Hormonal}

As características hormonais dos grupos são expressas na Tabela 2. Foi observado aumento significante da TT e TL no grupo PCOS e uma redução significante da SHBG no grupo PCOS. Na casuística estudada, o FSH e o TSH apresentaram uma tendência de redução e aumento, respectivamente, no grupo PCOS. Embora o TSH tenha apresentado uma tendência de aumento no grupo PCOS comparado ao grupo CTRL e tal hormônio sirva como variável de confusão no diagnóstico da PCOS, o nível deste hormônio encontra-se dentro dos níveis de normalidade, segundo o Laboratório Central do Hospital das Clínicas da Faculdade 
de Medicina da Universidade de São Paulo, conferindo a exclusão do diagnóstico de hipotireoidismo.

Tabela 2. Características hormonais das pacientes do estudo.

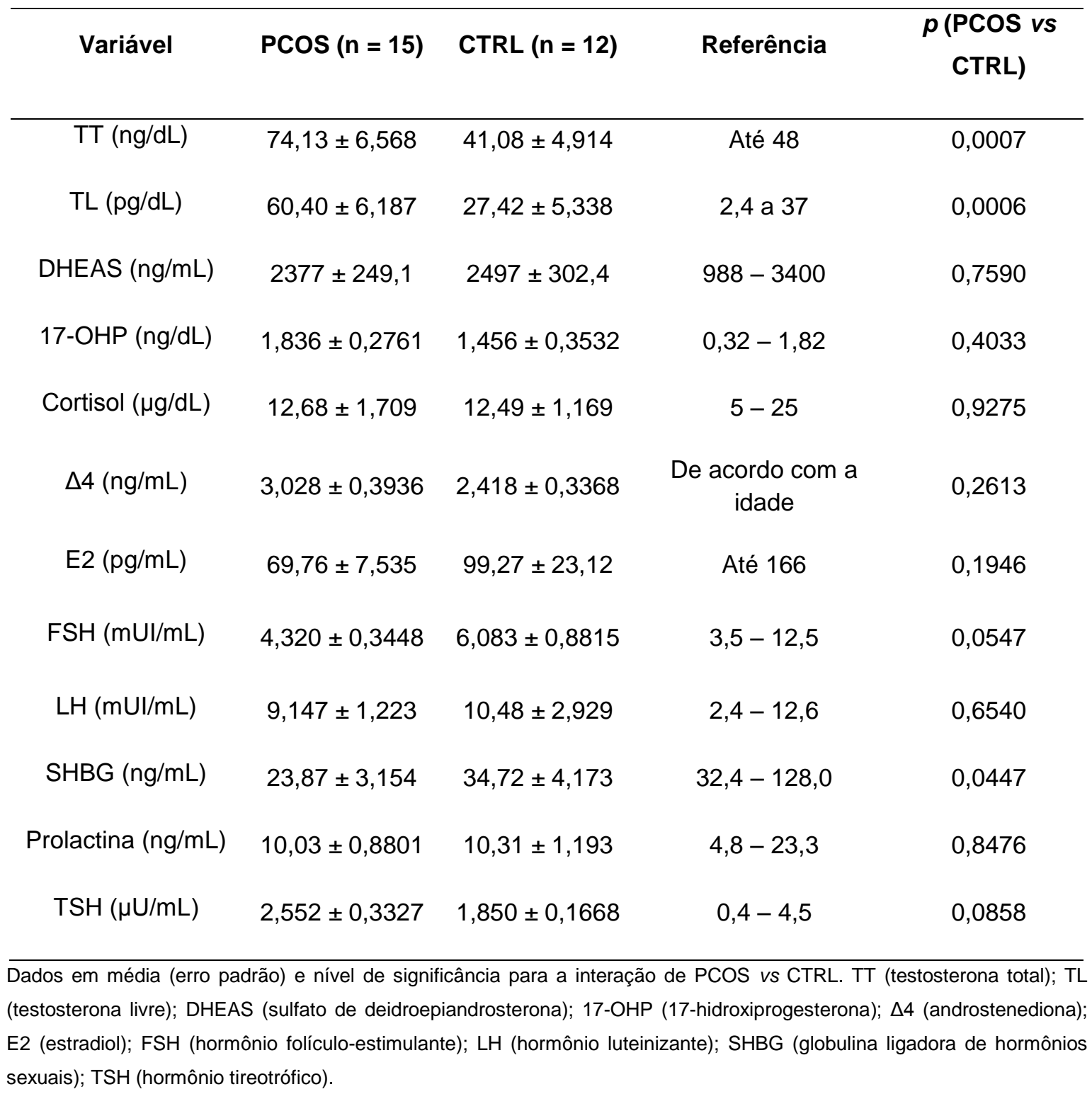

\subsection{Perfil Lipídico}

Os dados referentes ao perfil lipídico dos grupos são expressos na tabela 3. Foi observado uma redução significante do HDL - colesterol e um aumento significante do VLDL - colesterol para o grupo PCOS. Para o TG, o grupo PCOS 
demonstrou uma tendência de aumento da variável em comparação ao grupo CTRL. Embora haja diferença estatisticamente significante entre os grupos para as variáveis mencionadas anteriormente, o VLDL - colesterol encontrou-se abaixo do nível de risco para esteatohepatite e risco cardiovascular; o HDL - colesterol do grupo PCOS encontrou-se abaixo dos valores de referência do Laboratório Central do HCFMUSP referente ao risco cardiovascular.

Tabela 3. Características do perfil lipídico das pacientes do estudo.

\begin{tabular}{ccccc}
\hline Variável & PCOS $(\mathbf{n}=15)$ & CTRL $(\mathbf{n}=12)$ & Referência & $\begin{array}{c}\boldsymbol{p} \text { (PCOS } \\
\text { vs } \mathbf{C T R L})\end{array}$ \\
\hline $\mathrm{CT}(\mathrm{mg} / \mathrm{dL})$ & $187,6 \pm 7,026$ & $179,8 \pm 9,306$ & Inferior a 200 & 0,4982 \\
$\mathrm{TG}(\mathrm{mg} / \mathrm{dL})$ & $132,9 \pm 13,78$ & $98,75 \pm 8,576$ & Inferior a 150 & 0,0590 \\
$\mathrm{HDL}(\mathrm{mg} / \mathrm{dL})$ & $40,67 \pm 1,687$ & $52,92 \pm 2,636$ & 45 a 65 & 0,0004 \\
$\mathrm{LDL}(\mathrm{mg} / \mathrm{dL})$ & $120,6 \pm 6,296$ & $107,1 \pm 7,743$ & Inferior a 130 & 0,1830 \\
VLDL $(\mathrm{mg} / \mathrm{dL})$ & $27,33 \pm 2,912$ & $19,75 \pm 1,697$ & Inferior a 40 & 0,0454 \\
\hline
\end{tabular}

Dados em média (erro padrão) e nível de significância para a interação de PCOS vs CTRL. CT (Colesterol Total); TG (Triglicérides); HDL (lipoproteína de alta densidade); LDL (lipoproteína de baixa densidade); VLDL (lipoproteína de muito baixa densidade).

\subsection{Controle Glicêmico e Sensibilidade à Insulina}

A figura 6 representa os níveis séricos de glicose e insulina obtidos durante 0 teste oral de tolerância à glicose (TOTG). Não houve diferença estatisticamente significante entre os grupos para a resposta glicêmica em relação aos pontos da curva do TOTG, assim como para a área total (figura 6A) e incremental (dados não demonstrados) abaixo da curva de glicose (AUC glicose). Para a análise da insulina em resposta ao TOTG, o grupo PCOS demonstrou um aumento significantemente maior nos pontos 60, 90 e 120 minutos comparado ao grupo CTRL (figura 6C). A área total (figura 6D) e incremental (dados não demonstrados) abaixo da curva de 
insulina (AUC insulina) foi significantemente maior no grupo PCOS comparado ao grupo CTRL.

A

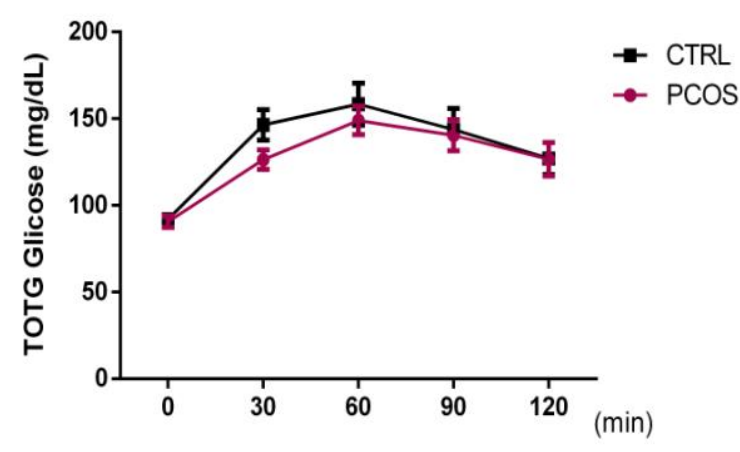

C

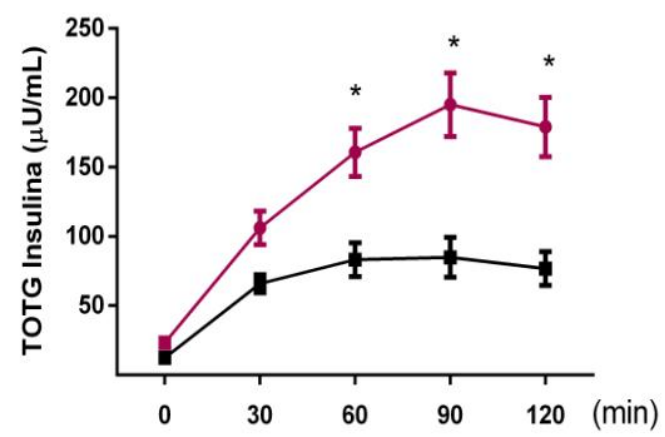

B

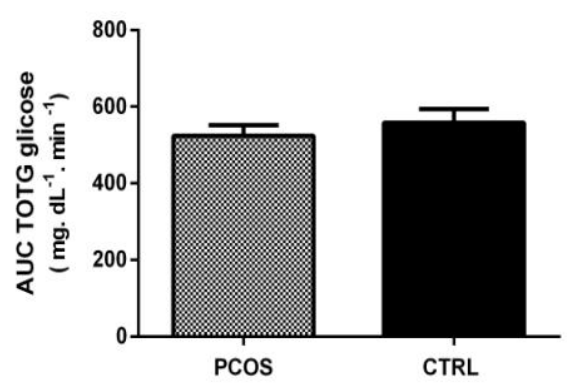

D

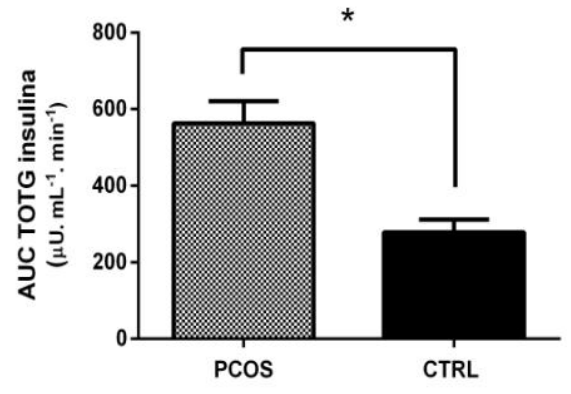

Figura 6. Curva de glicemia (figura A), área total abaixo da curva (AUC) de glicose (figura B), curva de insulina (figura $C$ ) e área total abaixo da curva (AUC) de insulina (figura D) obtida a partir do teste oral de tolerância à glicose (TOTG), no período basal (média e erro padrão). * PCOS vs CTRL ( $p \leq 0,05)$.

A Tabela 4 apresenta as estimativas de resistência e sensibilidade insulínica à partir do TOTG. De acordo com todos os índices avaliados, o grupo PCOS apresentou uma significante redução da sensibilidade à insulina nos diversos territórios em comparado ao grupo CTRL. 
Tabela 4. Estimativa da sensibilidade e resistência insulínica das pacientes do estudo.

\begin{tabular}{cccc}
\hline Variável & PCOS $(\mathbf{n}=\mathbf{1 5})$ & CTRL $(\mathbf{n}=12)$ & $\boldsymbol{p}$ (PCOS vs CTRL) \\
\hline G/I & $0,25 \pm 0,03452$ & $0,1350 \pm 0,0122$ & 0,0085 \\
HOMA - IR & $5,429 \pm 0,9119$ & $2,843 \pm 0,2965$ & 0,0218 \\
HOMA- $\beta$ & $310,5 \pm 35,12$ & $155,4 \pm 13,42$ & 0,0009 \\
Índice MATSUDA & $1,882 \pm 0,2708$ & $3,510 \pm 0,4208$ & 0,0027 \\
HIR & $7098 \pm 789,8$ & $4760 \pm 531,4$ & 0,0284 \\
mISI & $0,3958 \pm 0,04259$ & $0,8319 \pm 0,1975$ & 0,0227
\end{tabular}

Dados em média (erro padrão) e nível de significância para a interação de PCOS vs CTRL. G/l (índice glicose/insulina); HOMA-IR (Homeostase Model Assessement - resistência à insulina); HOMA- $\beta$ (Homeostase Model Assessement - célula beta); HIR (estimativa da resistência à insulina no fígado); mISI (estimativa da sensibilidade à insulina no músculo esquelético).

\subsection{Teste Ergoespirométrico}

A Tabela 5 representa as características cardiopulmonares das pacientes do estudo. $\mathrm{O} \mathrm{VO} 2$ máx. relativo demonstrou uma tendência de redução no grupo PCOS comparado ao grupo CTRL. Embora essa variável tenha demonstrado tendência de diferença entre os grupos, não há diferença significante para a massa muscular (em $\mathrm{kg}$ ) entre os grupos, assim como para a massa de gordura (em kg). $\mathrm{O} \mathrm{VO}_{2}$ relativo no PCR foi significantemente menor no grupo CTRL comparado ao grupo PCOS. Para as demais variáveis cardiopulmonares avaliadas, não foram constatadas diferenças significantes entre os grupos. Houve uma tendência de redução no tempo de teste no grupo PCOS em comparação ao grupo CTRL. A figura 7 representa as respostas ventilatórias durante o teste ergoespirométrico em pacientes com PCOS e mulheres CTRL. Para nenhuma das variáveis ventilatórias analisadas durante 0 teste ergoespirométrico foram encontradas diferenças significantes entre os grupos. 
Tabela 5 - Características cardiopulmonares das pacientes do estudo.

\begin{tabular}{|c|c|c|c|}
\hline Variável & $\operatorname{Pcos}(n=15)$ & CTRL $(n=12)$ & $\begin{array}{c}p(P C O S \text { vs } \\
\text { CTRL })\end{array}$ \\
\hline $\mathrm{VO}_{2 \text { máx }}(\mathrm{L} / \mathrm{min})$ & $2,204 \pm 0,0824$ & $2,208 \pm 0,117$ & 0,9728 \\
\hline $\mathrm{VO}_{2 \text { máx }}(\mathrm{ml} / \mathrm{kg} / \mathrm{min})$ & $24,45 \pm 0,9085$ & $28,25 \pm 1,734$ & 0,0506 \\
\hline $\mathrm{VO}_{2} \mathrm{LAn}(\mathrm{L} / \mathrm{min})$ & $1,108 \pm 0,05811$ & $1,079 \pm 0,09010$ & 0,7816 \\
\hline $\mathrm{VO}_{2} \mathrm{LAn}(\mathrm{ml} / \mathrm{kg} / \mathrm{min})$ & $12,36 \pm 0,7401$ & $13,63 \pm 1,032$ & 0,3129 \\
\hline $\mathrm{VO}_{2} \mathrm{PCR}(\mathrm{L} / \mathrm{min})$ & $1,747 \pm 0,07117$ & $1,839 \pm 0,1105$ & 0,4731 \\
\hline $\mathrm{VO}_{2} \mathrm{PCR}(\mathrm{ml} / \mathrm{kg} / \mathrm{min})$ & $19,34 \pm 0,71$ & $23,56 \pm 1,506$ & 0,0121 \\
\hline Tempo do teste (min) & $11,90 \pm 0,3559$ & $13,08 \pm 0,6479$ & 0,1041 \\
\hline Tempo do LAn (min) & $5,533 \pm 0,3948$ & $5,917 \pm 0,3417$ & 0,4823 \\
\hline Tempo do PCR (min) & $9,833 \pm 0,3673$ & $10,21 \pm 0,5417$ & 0,5597 \\
\hline RER pico & $1,107 \pm 0,01835$ & $1,080 \pm 0,02579$ & 0,3839 \\
\hline RER LAn & $0,7173 \pm 0,01119$ & $0,7258 \pm 0,01752$ & 0,6319 \\
\hline RER PCR & $0,9187 \pm 0,01245$ & $0,9117 \pm 0,01641$ & 0,7321 \\
\hline FC máxima (bpm) & $179,3 \pm 3,151$ & $178,4 \pm 2,463$ & 0,8398 \\
\hline FC atingida (\%) & $92,35 \pm 1,333$ & $93,78 \pm 1,432$ & 0,4692 \\
\hline FC recuperação 1' (bpm) & $164,1 \pm 3,7$ & $164,6 \pm 4,284$ & 0,9277 \\
\hline$\Delta \downarrow \mathrm{FC} 1^{\prime}(\mathrm{bpm})$ & $16,13 \pm 1,877$ & $13,67 \pm 3,003$ & 0,4753 \\
\hline
\end{tabular}

Dados em média (erro padrão) e nível de significância para interação de PCOS vs CTRL. $\mathrm{VO}_{2}$ máx. (consumo máximo de oxigênio); $\mathrm{VO}_{2} \mathrm{LAN}$ (consumo máximo de oxigênio no limiar aeróbio ); $\mathrm{VO}_{2} \mathrm{PCR}$ (consumo máximo de oxigênio no ponto de compensação respiratória); RER (relação de troca respiratória); FC (frequência cardíaca); FC recuperação 1' (redução da frequência cardíaca no primeiro minuto de recuperação após a sessão aguda de exercício aeróbio ); $\Delta \downarrow$ FC 1' (delta da redução da frequência cardíaca no primeiro minuto de recuperação após a sessão aguda de exercício aeróbio). 
A

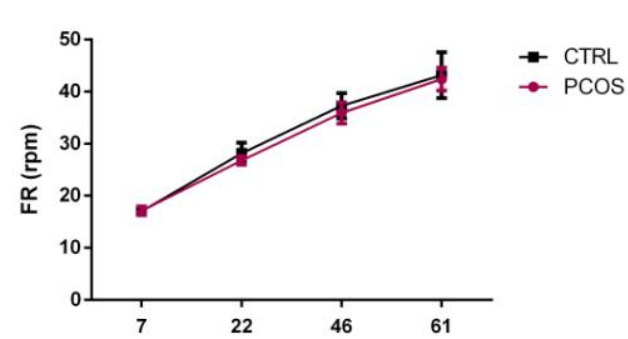

C

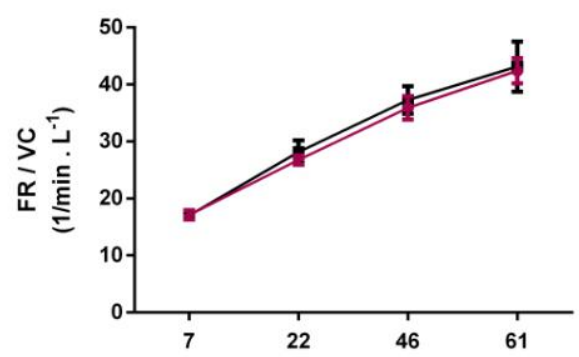

E

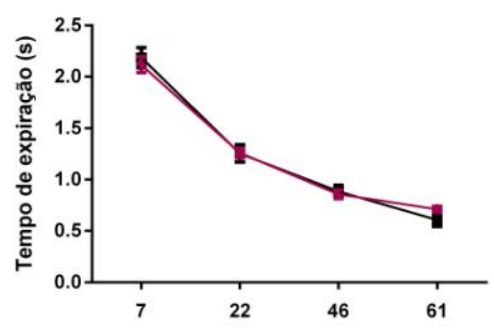

G

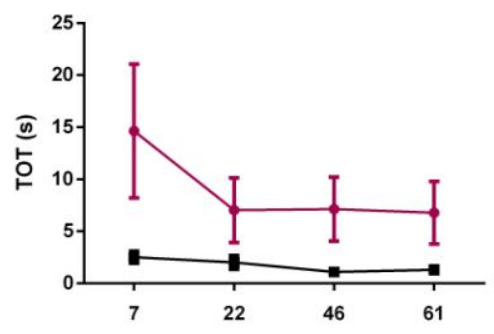

B

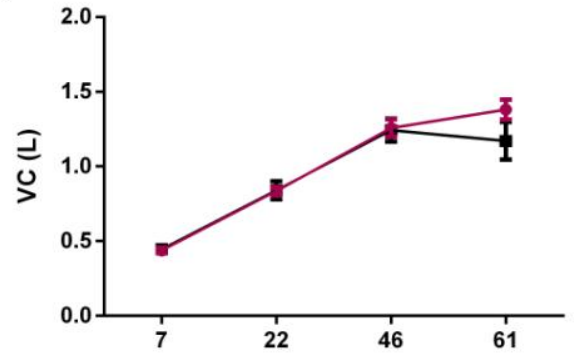

D

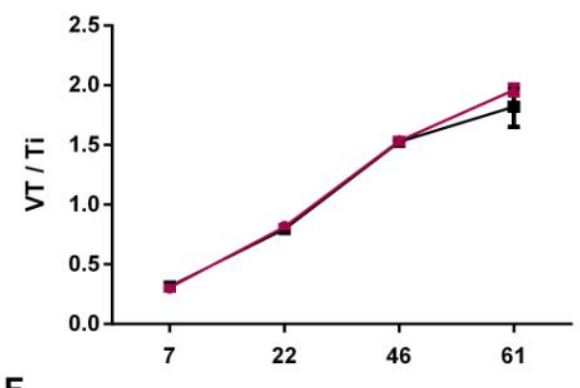

F

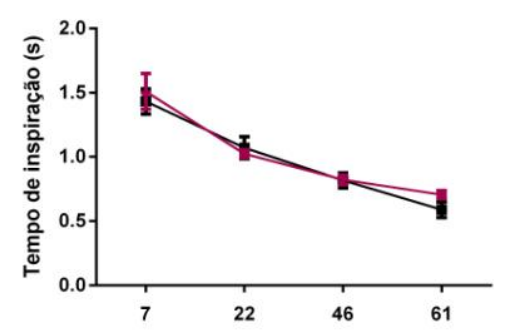

H

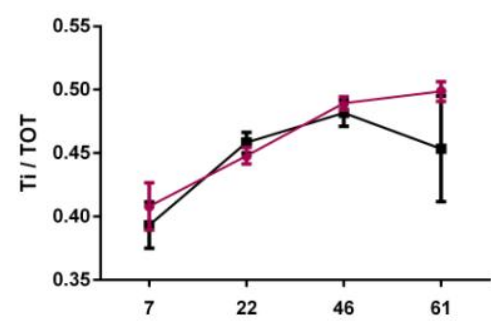

Figura 7. Padrão e os componentes relacionados com a resposta ventilatória durante 0 exercício incremental (teste ergoespirométrico). (A) Frequência Respiratória: (B) Volume Corrente; (C) Razão entre frequência respiratória e volume corrente; (D) Razão entre volume corrente e tempo de inspiração; (E) Tempo de expiração; (F) Tempo de inspiração; (G) Somatório do tempo de expiração + tempo de inspiração; (H) Razão entre o tempo de inspiração e tempo total respiratório.

A figura 8 representa as variáveis ventilatórias relacionadas ao equivalente 
ventilatório de gás carbônico $\left(\mathrm{VEVCO}_{2}\right)$ (parte $\left.\mathrm{A}\right)$ e pressão expirada de dióxido de carbono $\left(\mathrm{PetCO}_{2}\right)$ (parte $\left.\mathrm{B}\right)$. Nenhuma das variáveis analisadas apresentou diferença significante entre os grupos.
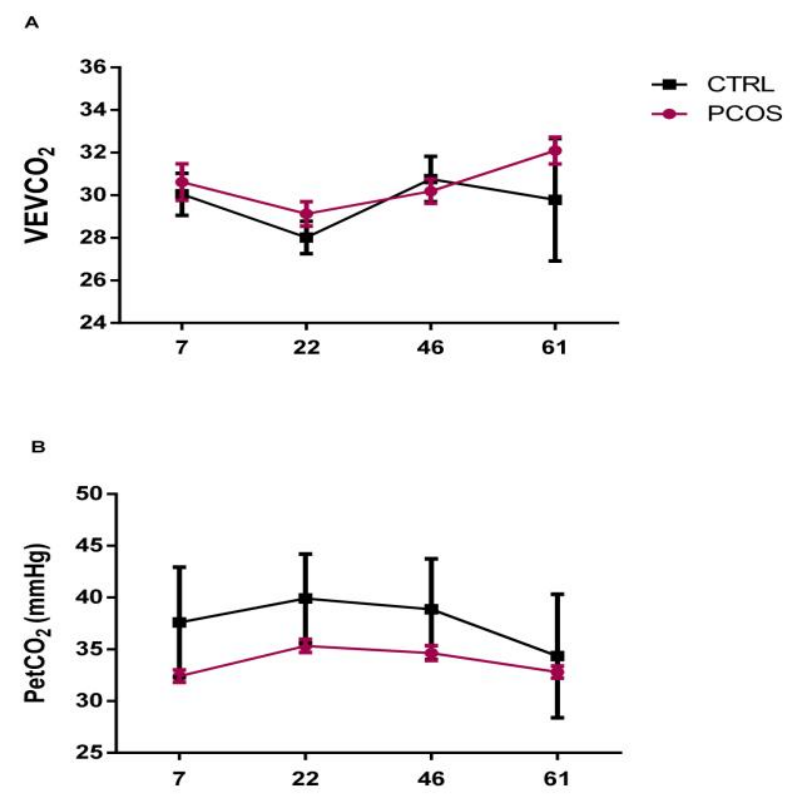

Figura 8. Componentes das trocas gasosas respiratórias durante o exercício incremental (teste ergoespirométrico) em pacientes com PCOS e mulheres sem comorbidades (CTRL).

\subsection{Nível de atividade física}

A Tabela 6 apresenta as características relacionadas ao nível de atividade física das pacientes do estudo. O grupo PCOS demonstrou uma tendência de aumento do percentual de tempo total em nível sedentário comparado ao grupo CTRL, durante o período de uso do acelerômetro. O grupo CTRL apresentou uma tendência de aumento do percentual de tempo total em intensidade leve comparado ao grupo PCOS, durante o período de uso do acelerômetro. Após a relativização do tempo total pelo número de dias usados, o grupo CTRL demonstrou uma tendência de aumento da quantidade de tempo mantida em um nível de atividade física de intensidade leve. As demais variáveis relacionadas ao nível de atividade física não 
demonstraram diferenças significantes.

Tabela 6. Características do nível de atividade física das pacientes do estudo.

\begin{tabular}{|c|c|c|c|}
\hline Variável & $P \cos (n=15)$ & CTRL (n = 12) & $\begin{array}{c}p(P C O S v S \\
\text { CTRL })\end{array}$ \\
\hline Tempo de uso (min) & $5572 \pm 268,9$ & $5650 \pm 409,7$ & 0,8931 \\
\hline Sedentário (\%) & $63,73 \pm 2,047$ & $56,76 \pm 3,133$ & 0,0903 \\
\hline Leve (\%) & $32,75 \pm 2,058$ & $39,56 \pm 2,848$ & 0,0778 \\
\hline Moderado (\%) & $3,5 \pm 0,7658$ & $3,556 \pm 0,6746$ & 0,9571 \\
\hline Vigoroso (\%) & $0,0 \pm 0,0$ & $0,11 \pm 0,08889$ & 0,2586 \\
\hline AFMV (\%) & $3,5 \pm 0,7658$ & $3,667 \pm 0,6936$ & 0,8737 \\
\hline Total de passos & $80715 \pm 12866$ & $86053 \pm 11985$ & 0,7654 \\
\hline Tempo de uso (min/dia) & $832,7 \pm 30,60$ & $864,7 \pm 35,92$ & 0,5138 \\
\hline Sedentário (min/dia) & $531,2 \pm 26,54$ & $488,6 \pm 30,42$ & 0,3136 \\
\hline Leve (min/dia) & $271,5 \pm 16,52$ & $343,5 \pm 29,54$ & 0,0577 \\
\hline Moderado (min/dia) & $30,00 \pm 7,248$ & $31,29 \pm 6,226$ & 0,8935 \\
\hline Vigoroso (min/dia) & $0,0 \pm 0,0$ & $1,080 \pm 0,9297$ & 0,2924 \\
\hline AFMV (min/dia) & $25,59 \pm 7,793$ & $31,08 \pm 7,288$ & 0,6138 \\
\hline $\begin{array}{c}\text { AFMV em períodos } \geq 10 \\
\text { minutos }\end{array}$ & $16,79 \pm 6,811$ & $10,06 \pm 3,530$ & 0,3784 \\
\hline Total de passos / dia & $12224 \pm 1991$ & $13721 \pm 1515$ & 0,5532 \\
\hline
\end{tabular}

Dados em média (erro padrão) e nível de significância para interação de PCOS vs CTRL. AFMV (atividade física de intensidade moderada à vigorosa). 


\subsection{Determinação da resposta glicêmica e insulinêmica ao exercício aeróbio agudo}

A figura 9 representa as concentrações de glicose e insulina obtidas durante a sessão aguda de exercício aeróbio. Houve uma redução significante da glicose no grupo PCOS trinta minutos após a sessão aguda de exercício aeróbio (30' PÓs) em relação ao período pré-exercício (figura 9A). Não houve diferença significante entre os grupos para a área total (figura 9C) e incremental (dados não demonstrados) abaixo da curva de glicose (AUC glicose) durante a sessão aguda de exercício aeróbio. Para a análise da insulina em resposta a sessão aguda de exercício aeróbio, o grupo PCOS apresentou uma concentração de insulina significantemente maior que o grupo CTRL no período PRÉ (figura 9D). Houve uma redução significante da insulina no grupo PCOS no ponto sessenta minutos após a sessão aguda de exercício aeróbio (60' PÓS) comparado ao período pré-exercício (figura 9D). A área total (figura 9F) e incremental (dados não demonstrados) abaixo da curva de insulina (AUC insulina) foi significantemente maior no grupo PCOS comparado ao grupo CTRL em resposta a sessão aguda de exercício aeróbio. escore delta (PÓS - PRÉ) de redução da glicemia (figura 9B) em resposta a sessão aguda de exercício aeróbio não se mostrou diferente entre os grupos. Entretanto, o escore delta de redução da insulina (figura 9E) em resposta a sessão aguda de exercício aeróbio foi significantemente menor no grupo PCOS comparado ao grupo CTRL. 
A

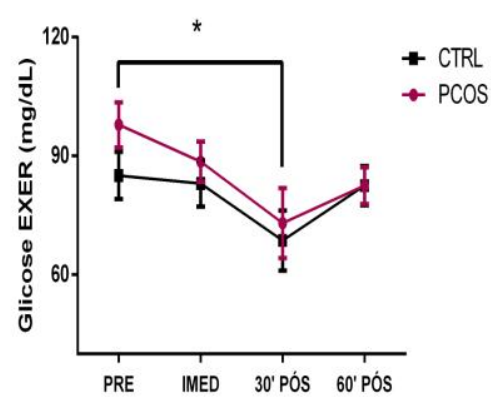

D

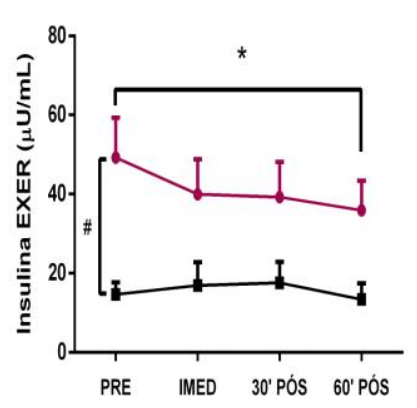

B

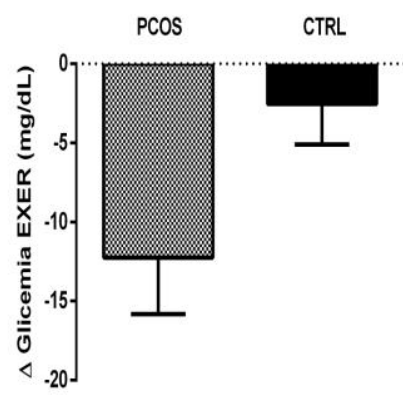

$E$

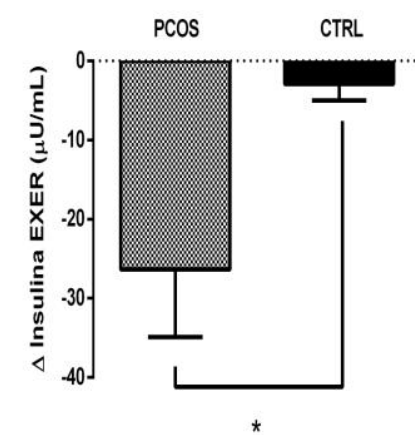

C

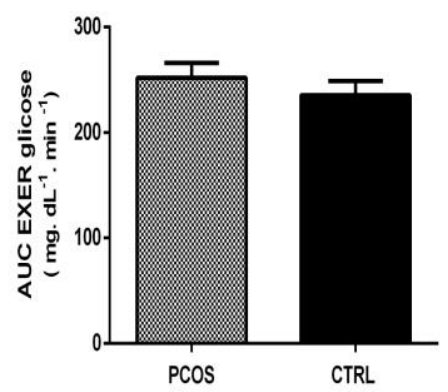

$\mathrm{F}$

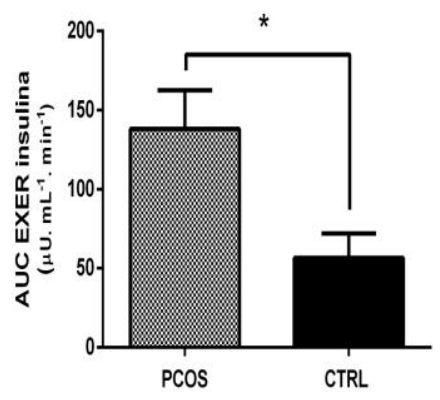

Figura 9. Resposta glicêmica (A) e insulinêmica (B) antes da sessão aguda de exercício aeróbio (PRÉ), imediatamente após a sessão aguda de exercício aeróbio (IMED), trinta minutos após a sessão aguda de exercício aeróbio (30' PÓS) e sessenta minutos após a sessão aguda de exercício aeróbio (60' PÓS). 0 escore delta da glicemia (C) e da insulina (D) em resposta a sessão aguda de exercício aeróbio. Dados expressos como diferença entre os grupos (média e erro padrão). "Diferença significante em relação à condição PRÉ-EXERcícıo. \# Diferença significante entre PCOS vs CTRL $(p \leq 0,05)$.

Para a análise da estimativa da RI, o grupo PCOS apresentou uma RI significantemente maior na condição PRÉ comparado ao grupo CTRL. Em resposta a sessão aguda de exercício aeróbio, houve uma redução significante da estimativa da RI tanto para o grupo PCOS como para o grupo CTRL (figura 10). 


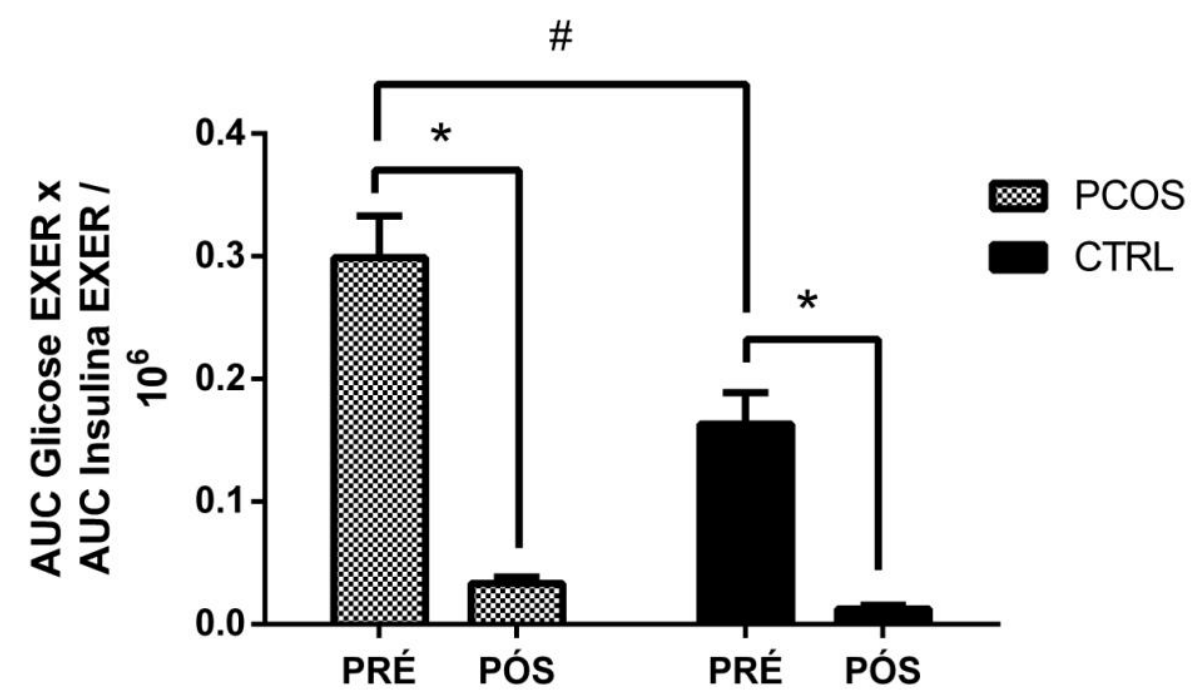

Figura 10. Estimativa da RI antes e após a sessão aguda de exercício aeróbio. Dados expressos como diferença entre os grupos (média e erro padrão). * Diferença significante em relação à condição PRÉ-EXERCícıO. \# Diferença significante entre PCOS vs CTRL $(p \leq 0,05)$.

\subsection{Dosagem de citocinas musculares e plasmáticas em resposta a sessão aguda de exercício aeróbio}

A figura 11 representa as concentrações de citocinas musculares na condição PRÉ e PÓS. A IL-1 $\beta$ (figura 11A) foi significantemente maior no grupo PCOS comparado ao grupo CTRL na condição PRÉ. Em resposta à sessão aguda de exercício aeróbio, a IL-6 (figura 11B) aumentou significantemente em ambos os grupos experimentais. Além disso, as concentrações de IL-6 no período PRÉ demonstraram uma tendência de aumento ( $p=0,07$ ) no grupo PCOS em comparação ao grupo CTRL. Para as concentrações de IL-4, IL-10 e TNF- $\alpha$ no tecido muscular esquelético (figura 11C, D e E, respectivamente), não houve diferenças significantes entre os grupos antes e após a sessão aguda de exercício aeróbio. 
A

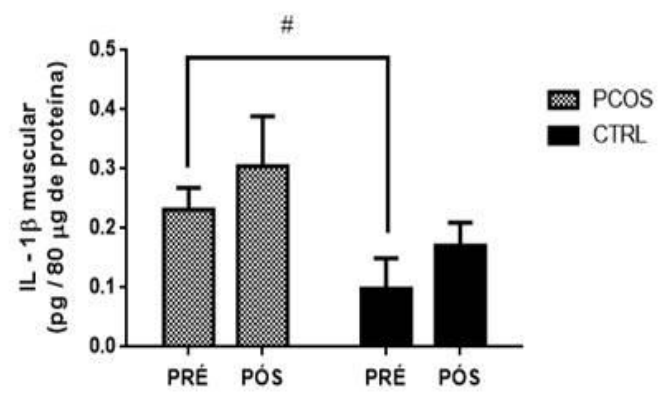

C

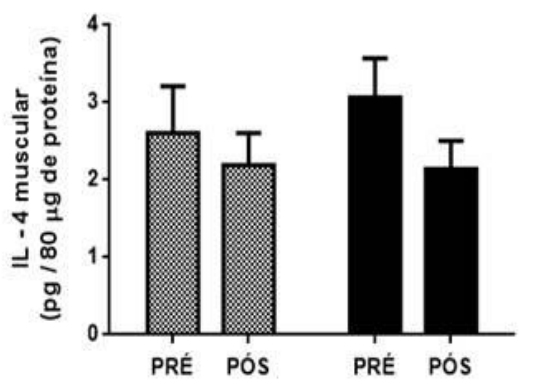

$\mathrm{E}$

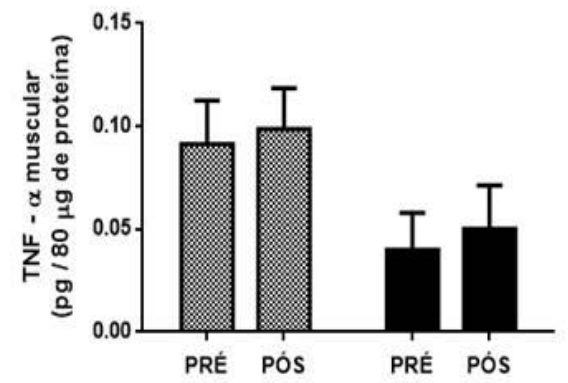

B

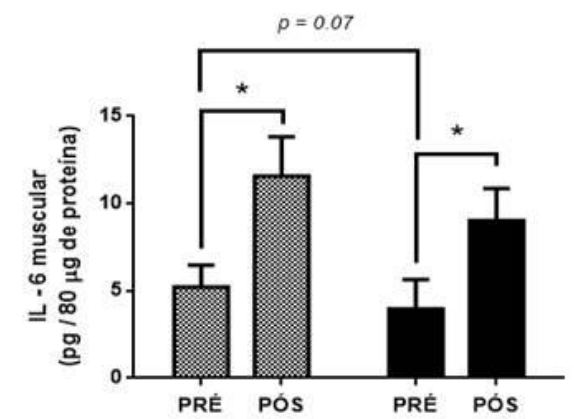

D

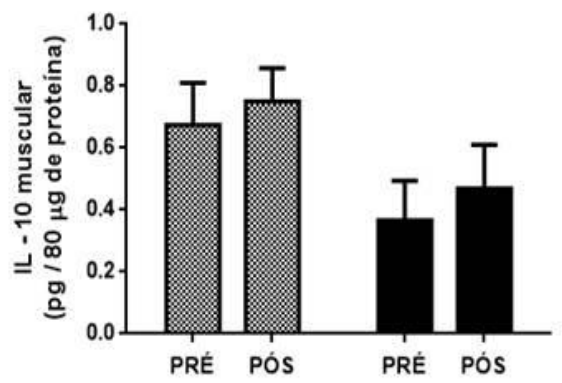

Figura 11. Dosagens de interleucina $1-\beta$ (IL1 - $\beta$, gráfico A), interleucina 6 (IL -6 , gráfico B), interleucina 4 (IL- 4, gráfico C), interleucina 10 (IL - 10, gráfico $D$ ) e fator de necrose tumoral $\alpha$ (TNF - $\alpha$, gráfico E) no tecido muscular esquelético antes e uma hora após a sessão aguda de exercício aeróbio. * Diferença significante em relação à condição PRÉ-EXERCícIO. \# Diferença significante entre PCOS vs CTRL $(p \leq 0,05)$.

A IL-1 $\beta$ plasmática (figura 12A) demonstrou uma tendência de aumento na condição PRÉ $(p=0,077)$ no grupo PCOS em comparação ao grupo CTRL. Apenas o grupo CTRL demonstrou uma tendência de aumento $(p=0,078)$ dessa citocina em resposta à sessão aguda de exercício aeróbio. Para a IL-6 plasmática (figura 12 B), verificou-se um aumento em resposta à sessão aguda de exercício aeróbio no grupo CTRL e uma tendência de aumento da IL-6 plasmática $(p=0,059)$ em resposta a sessão aguda de exercício aeróbio no grupo PCOS. Houve um aumento nas concentrações de IL-10 plasmática (figura 12 D) em resposta à sessão aguda de 
exercício aeróbio apenas no grupo CTRL. Já o grupo PCOS apresentou uma redução significante do TNF-a plasmático em resposta a sessão aguda de exercício aeróbio (figura 12E). A IL-4 plasmática (figura 12C) não foi diferente entre os grupos antes e após a sessão aguda de exercício aeróbio.

A

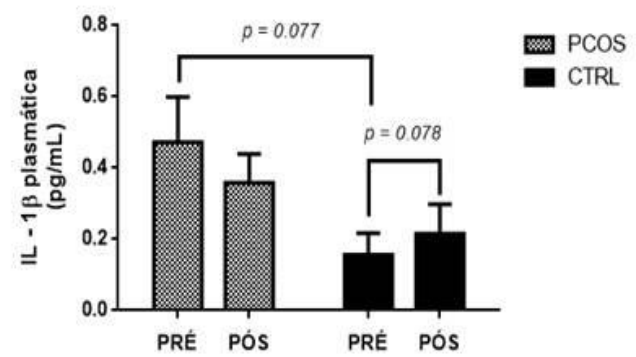

C

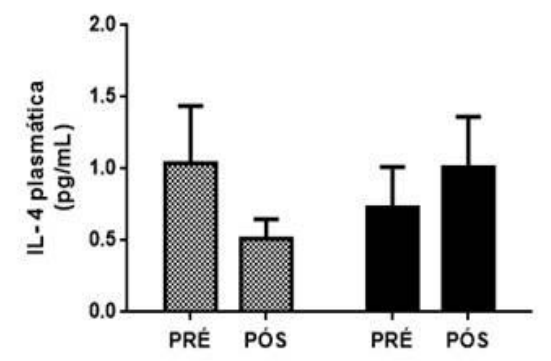

E

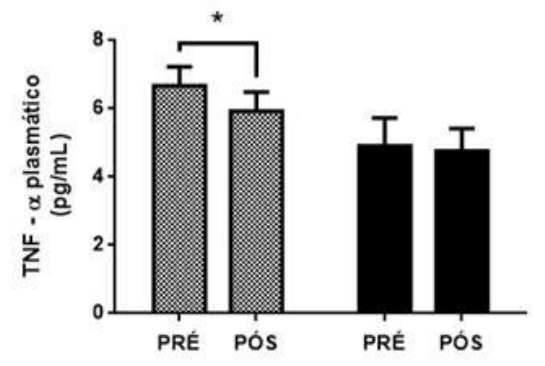

B

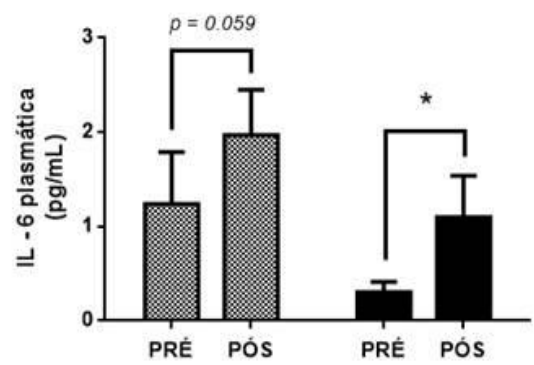

D

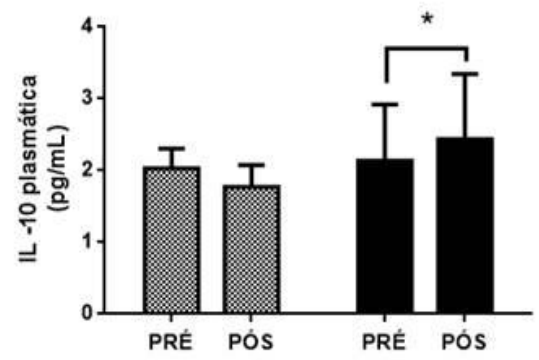

Figura 12. Dosagem de interleucina $1-\beta$ (IL1 - $\beta$, gráfico A), interleucina 6 (IL -6 , gráfico $B$ ), interleucina 4 (IL- 4, gráfico C), interleucina 10 (IL - 10, gráfico $D$ ) e fator de necrose tumoral $\alpha$ (TNF - $\alpha$, gráfico E) no plasma antes e uma hora após a sessão aguda de exercício aeróbio. Diferença significante em relação à condição PRÉ-EXERcícıo. 
8.9. Determinação da expressão de proteínas selecionadas e da translocação do GLUT-4 por Western Blotting

A figura 13 demonstra a eficiência do protocolo de fracionamento celular para o estudo da translocação do GLUT-4 para a membrana sarcoplasmática. A figura $14 \mathrm{~A}$ demonstra as bandas referentes à análise da expressão proteica de caveolina. Essa proteína foi utilizada como marcador de membrana sarcoplasmática. É possível observar que apenas o compartimento citosólico (C3) não expressou a proteína caveolina. A figura 14B demonstra as bandas referentes à análise da expressão proteica da ERK 1/2. Essa proteína foi utilizada como um marcador do compartimento citosólico. É possível observar que tanto as amostras T1, T2 e C3 demonstraram a expressão proteica da proteína em questão.

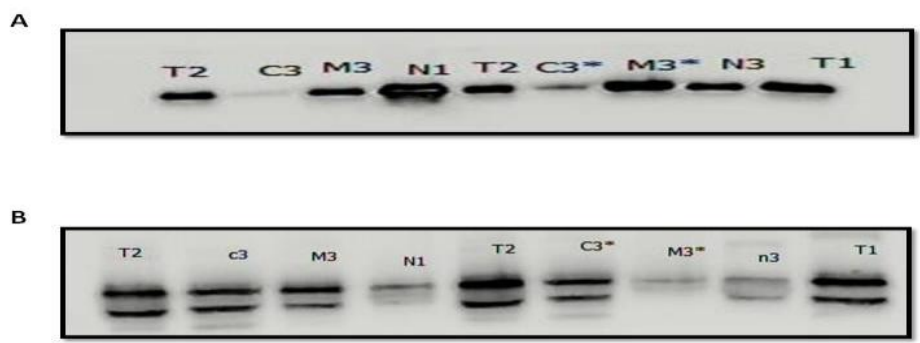

Figura 13. Demonstração das bandas após o processo de fracionamento celular. A figura A e B representa a expressão proteica de caveolina e ERK 1/2, respectivamente. T2 (amostra da voluntária 2 do homogenato que não passou pelo processo de fracionamento celular); C3 (amostra do compartimento citosólico representativo da voluntária 3); M3 (amostra do compartimento membranar representativo da voluntária 3); $\mathrm{N} 1$ (amostra do compartimento nuclear representativo da voluntária 1); N3 (amostra do compartimento nuclear representativo da voluntária 3); T1 (amostra da voluntária 1 do homogenato que não passou pelo processo de fracionamento celular).

Tendo em vista a ausência de diferenças significantes na expressão total da proteína IRS-1 entre os grupos, apresentamos os resultados referentes ao efeito agudo do exercício aeróbio na fosforilação do IRS - 1 Ser 307 na figura 14. A 
fosforilação do IRS-1 Ser 307 apresentou redução significante em ambos os grupos experimentais após a sessão aguda de exercício aeróbio.

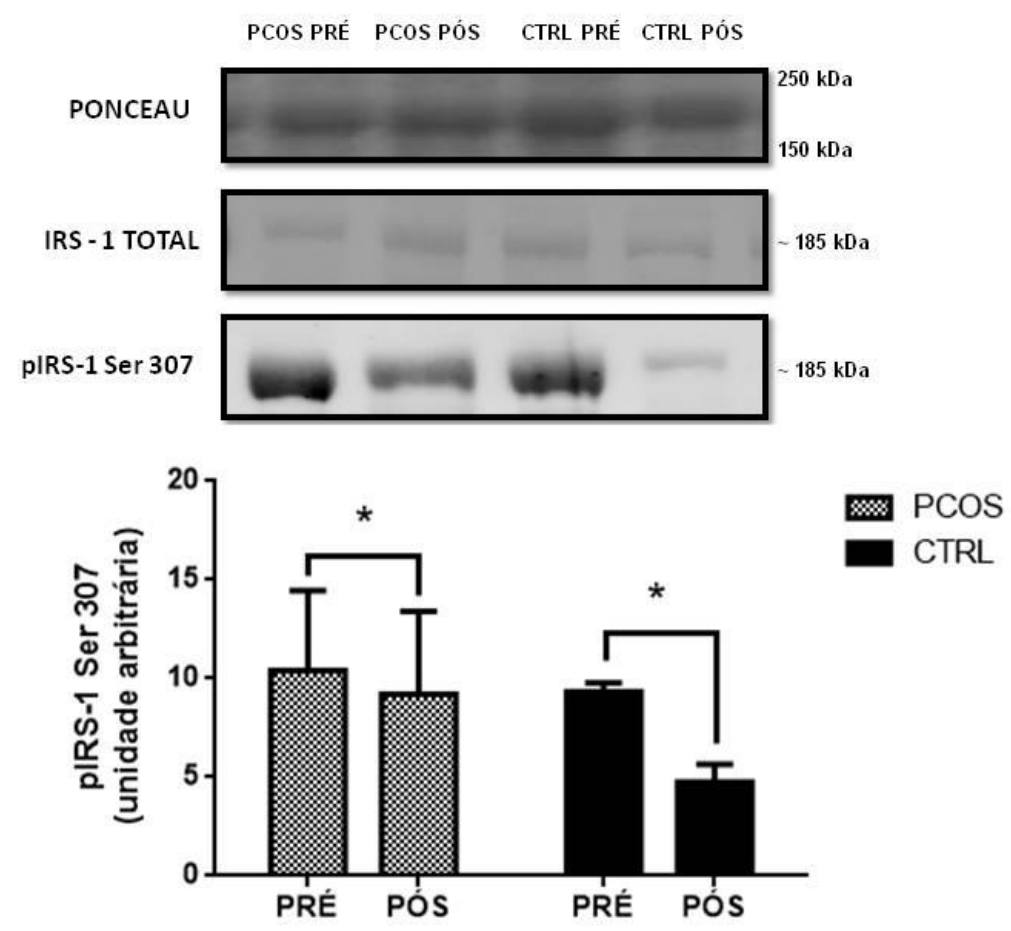

Figura 14. Demonstração das bandas do controle de carregamento interno de proteínas (ponceau), IRS-1 total e pIRS-1 Ser 307 no grupo PCOS e grupo CTRL no repouso (PCOS pré e CTRL pré, respectivamente) e o efeito agudo do exercício aeróbio na expressão proteica de pIRS-1 Ser 307 normalizada pelo ponceau (figura A) no grupo PCOS (PCOS pós) e CTRL (CTRL pós). " Diferença significante em relação à condição PRÉ-EXERCícIO ( $\mathrm{n}=8$ para cada grupo).

A expressão proteica da porção regulatória p85 da PI3-k não demonstrou diferenças significantes em resposta à sessão aguda de exercício aeróbio no grupo PCOS. Todavia, o grupo CTRL demonstrou um aumento significante da ativação dessa proteína quinase em resposta à sessão aguda de exercício aeróbio, bem como uma tendência de diferença significante da atividade dessa proteína na condição PÓS $(p=0,073)$ no grupo CTRL em comparação ao grupo PCOS (figura $15)$. 

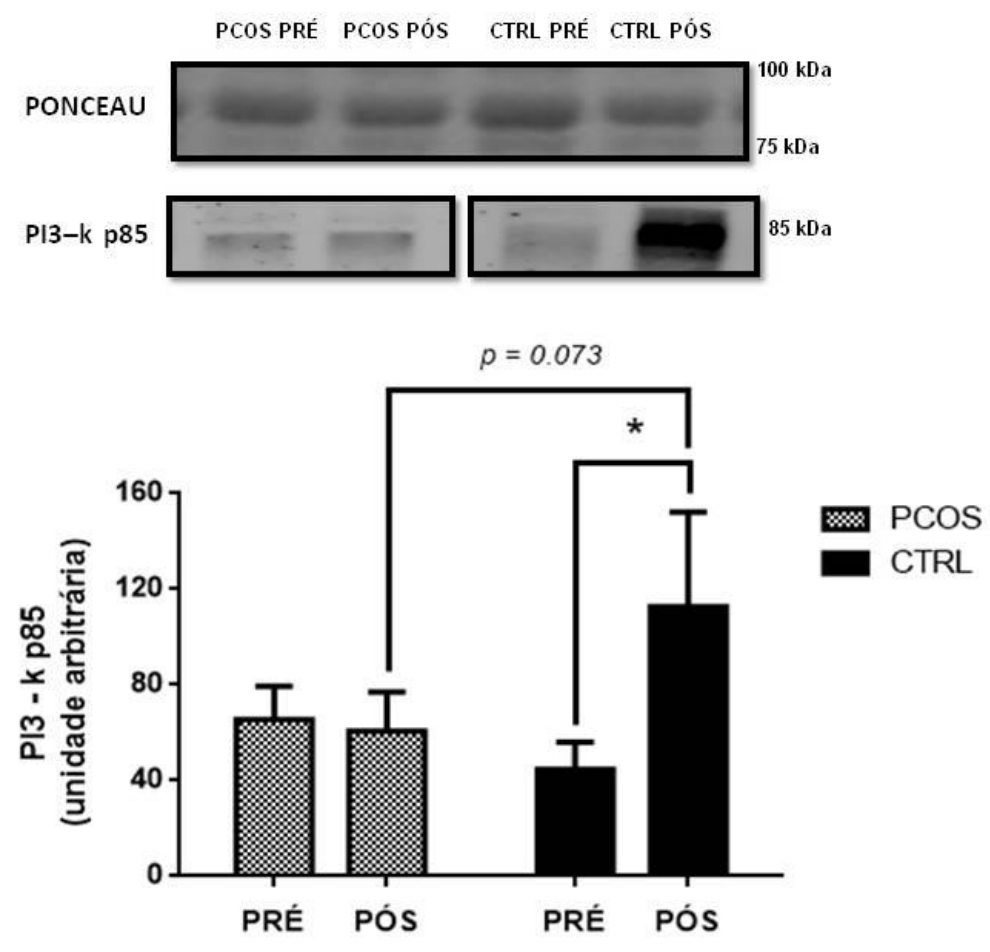

Figura 15. Demonstração das bandas do controle de carregamento interno de proteínas (ponceau) e da PI3-k p85 no grupo PCOS e grupo CTRL no repouso (PCOS pré e CTRL pré, respectivamente) e o efeito agudo do exercício aeróbio na expressão proteica de PI3-k normalizada pelo ponceau no grupo PCOS (PCOS pós) e CTRL (CTRL pós). "Diferença significante em relação à condição PRÉ-EXERCícIO ( $n=7$ para cada grupo).

A fosforilação da Akt Ser 473 foi significantemente aumentada em ambos os grupos em resposta a sessão aguda de exercício aeróbio (figura 16A). Após a normalização da fosforilação da Akt Ser 473 pela quantidade total da proteína Akt (Akt total), tal diferença permaneceu em ambos os grupos em resposta a sessão aguda de exercício aeróbio (figura 16B). O grupo PCOS demonstrou um aumento significante da Akt Thr 308 em comparação ao PRÉ (figura 16C). Entretanto, após a normalização da fosforilação da proteína Akt Thr 308 pela quantidade total de proteína (Akt total), não houve diferença significante (figura 16D). A expressão da proteína $\beta$ - tubulina foi utilizada como proteína normalizadora, pois o nível de sua expressão não se mostrou estatisticamente diferente entre os grupos estudados quando comparados a outras proteínas normalizadoras (ex: GAPDH e $\beta$ - actina). 
A
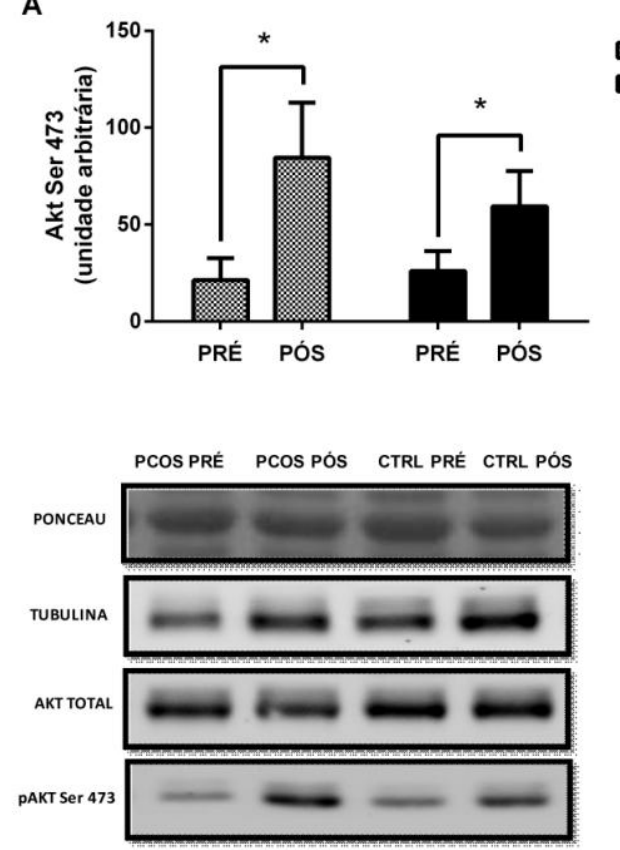

B

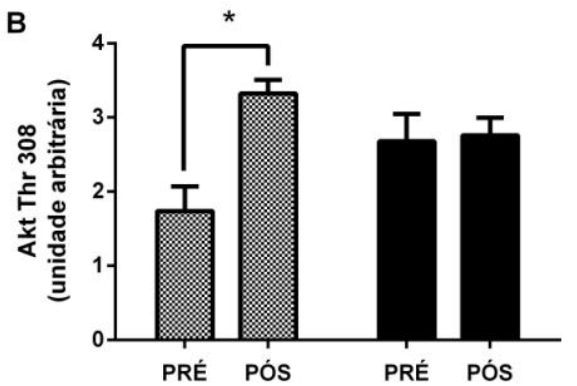

PCOS PRÉ PCOS PÓS CTRL PRÉ CTRL PÓS

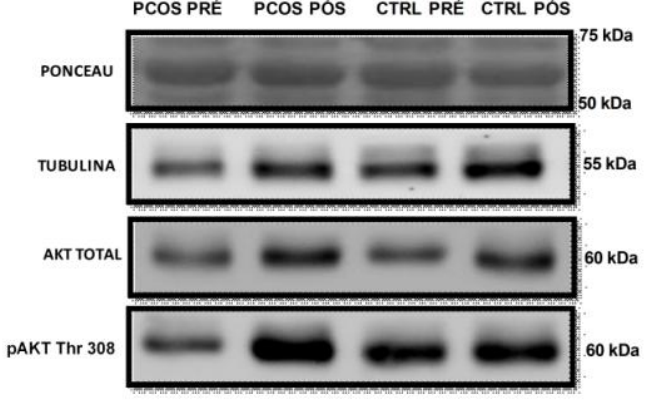

Figura 16. Demonstração das bandas do controle de carregamento interno de proteínas (ponceau), proteína normalizadora $\beta$ - tubulina, Akt total, pAkt Ser 473 e pAkt Thr 308 no grupo PCOS e grupo CTRL no repouso (PCOS pré e CTRL pré, respectivamente) e o efeito agudo do exercício aeróbio na expressão proteica de pAkt Ser 473 (figura A) e expressão proteica de pAkt Thr 308 (figura B) normalizada pelo ponceau (figura C) no grupo PCOS (PCOS pós) e CTRL (CTRL pós). " Diferença significante em relação à condição PRÉ-EXERCício ( $n=10$ para o grupo PCOS e $n=7$ para o grupo CTRL).

A fosforilação da AMPK Thr 172 (figura 17A) foi aumentada em ambos os grupos, porém foi observada diferença estatisticamente significante apenas para o grupo PCOS. Após a normalização da fosforilação da AMPK Thr 172 pela quantidade total da proteína AMPK (AMPK total), houve uma tendência de aumento da ativação dessa proteína em resposta a sessão aguda de exercício aeróbio apenas no grupo PCOS (figura 17B). 


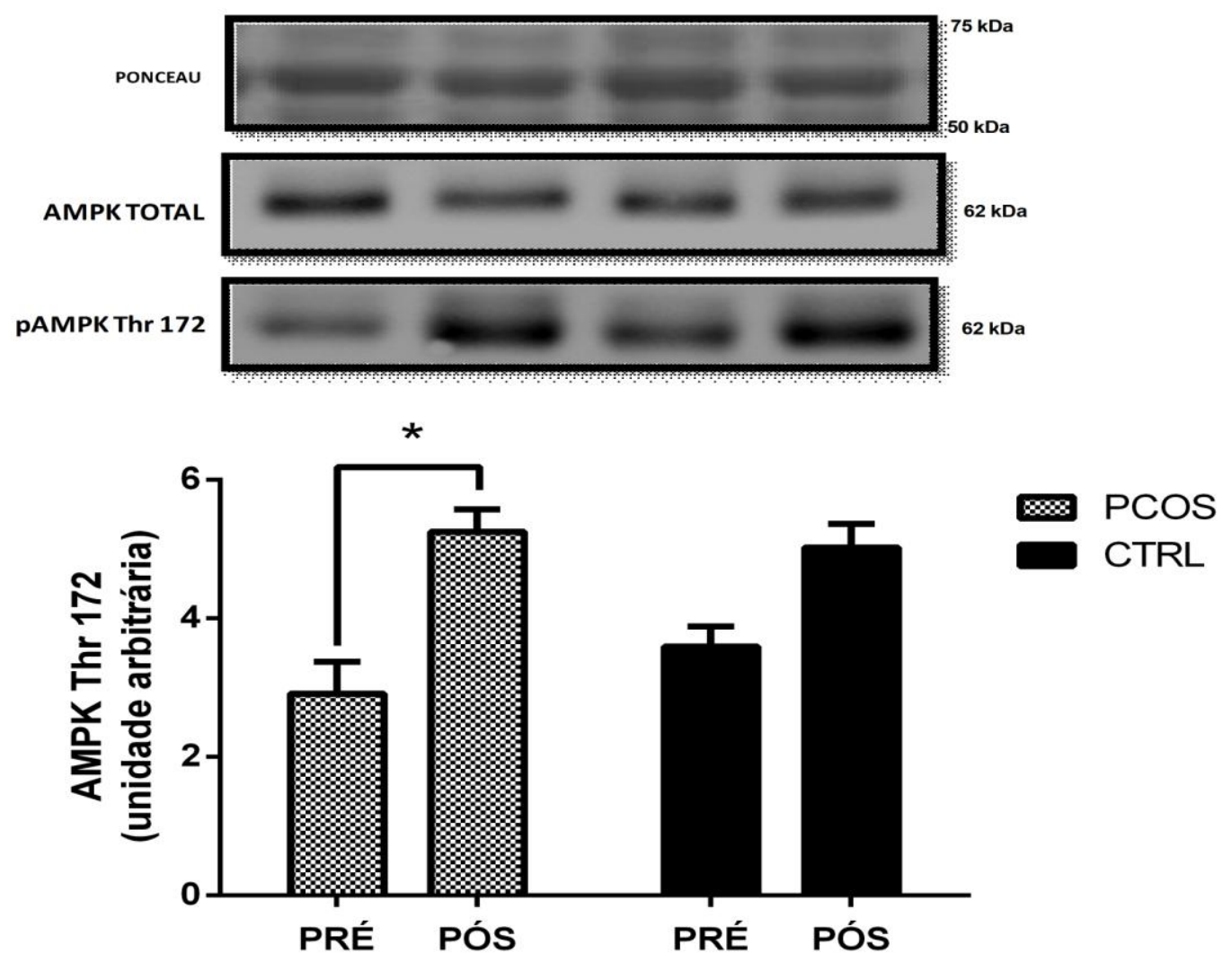

Figura 17. Demonstração das bandas do controle de carregamento interno de proteínas (ponceau), pAMPK Thr 172, proteína normalizadora $\beta$ - tubulina e AMPK total no grupo PCOS e grupo CTRL no repouso (PCOS pré e CTRL pré, respectivamente) e o efeito agudo do exercício aeróbio na expressão proteica de pAMPK Thr 172 normalizada pelo ponceau (figura A) e razão pAMPK Thr 172/AMPK total normalizada pela $\beta$ - tubulina (figura B) no grupo PCOS (PCOS pós) e CTRL (CTRL pós). * Diferença significante em relação à condição PRÉ-EXERCício ( $n=10$ para o grupo PCOS e $n=7$ para o grupo CTRL).

A fosforilação da AS160 Thr 642 (figura 18A) foi significante maior no grupo CTRL em resposta a sessão aguda de exercício aeróbio, enquanto, uma resposta inalterada da fosforilação da AS160 Thr 642 foi observada no grupo PCOS em resposta ao exercício aeróbio agudo. O grupo CTRL apresentou um aumento da fosforilação dessa proteína significante maior que o grupo PCOS no período PÓS (figura 18B). 


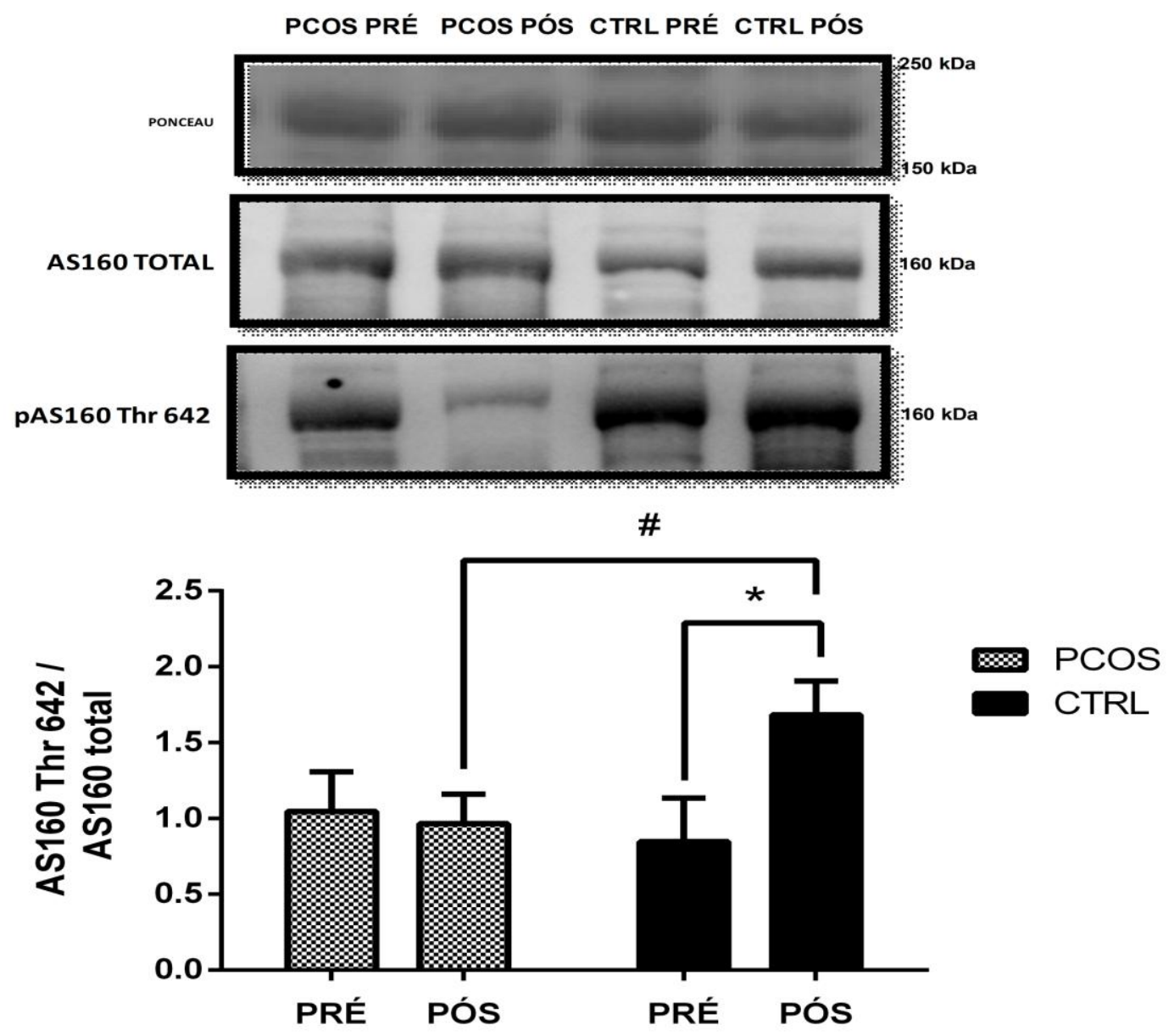

Figura 18. Demonstração das bandas do controle de carregamento interno de proteínas (ponceau), pAS160 Thr 642 e AS160 total no grupo PCOS e grupo CTRL no repouso (PCOS pré e CTRL pré, respectivamente) e o efeito agudo do exercício aeróbio na expressão proteica de pAS160 Thr 642 normalizada pelo ponceau (figura A) e a razão pAS160 (Thr 642)/AS160 total normalizado pelo ponceau (figura B) no grupo PCOS (PCOS pós) e CTRL (CTRL pós). Diferença significante em relação à condição PRÉ-EXERCícıo. \# Diferença significante entre PCOS vs CTRL $(p \leq 0,05)(n=7$ para cada grupo).

Os resultados referentes ao efeito agudo do exercício aeróbio na translocação do GLUT-4 para a membrana sarcoplasmática no músculo esquelético são apresentados na figura 19. A expressão proteica de GLUT-4 total não foi significantemente diferente entre o grupo PCOS e o grupo CTRL (figura 19A). A expressão proteica de GLUT-4 membranar no período PRÉ não foi diferente entre os grupos. Embora ambos os grupos tenham apresentado um aumento na expressão proteica de GLUT-4 membranar após a sessão aguda de exercício aeróbio, a análise 
estatística não detectou diferenças significantes (figura 19B). Contudo, a razão entre o GLUT-4 membranar/GLUT-4 total (figura 20), que indica a translocação da proteína do compartimento citosólico em direção à membrana sarcoplasmática, sofreu uma tendência de aumento significante em resposta a sessão aguda de exercício aeróbio para ambos os grupos, sem diferença entre eles.

A

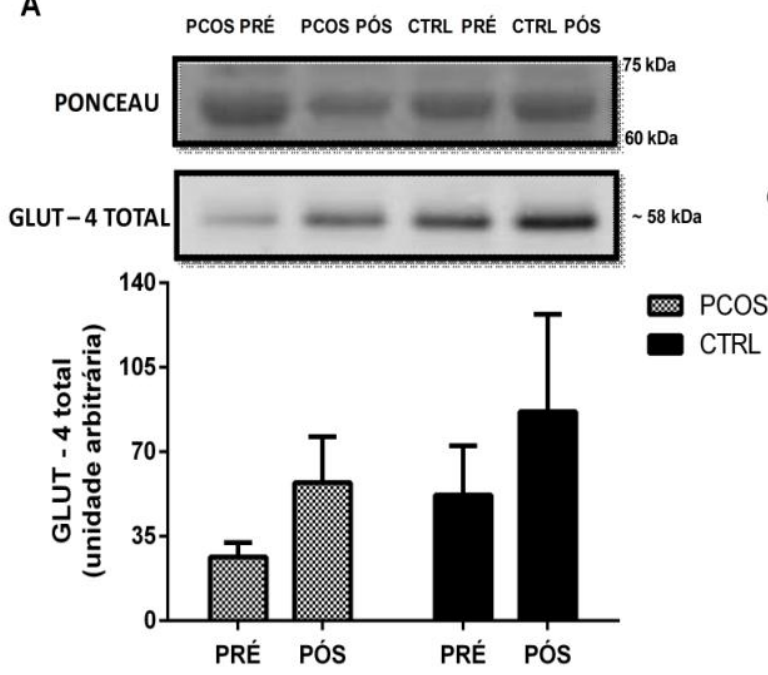

B

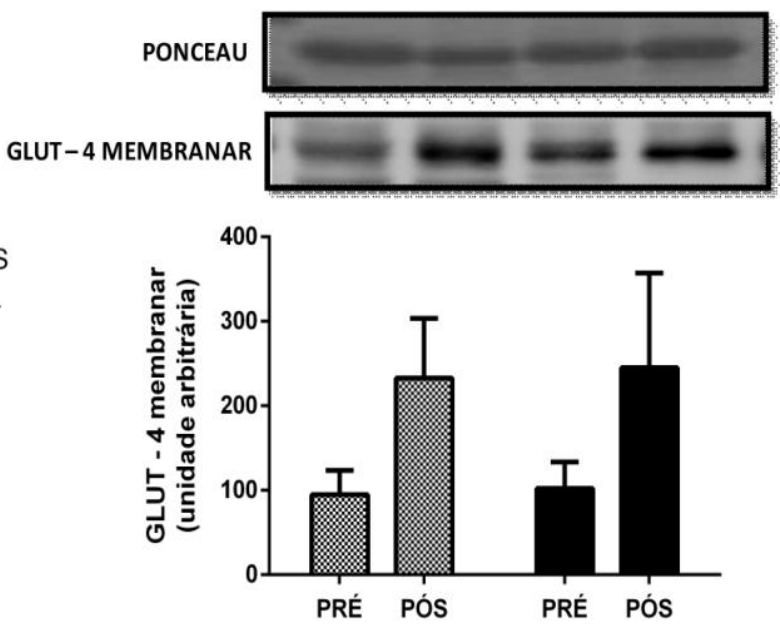

c

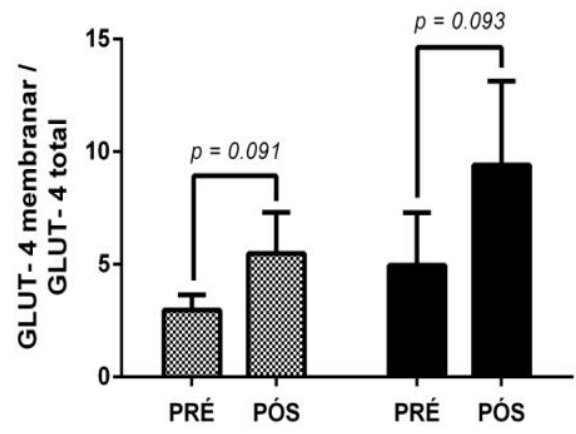

Figura 19. Demonstração das bandas do carregamento interno de proteínas (ponceau) da membrana do GLUT-4 total, fração membranar do GLUT - 4 e taxa de translocação do GLUT - 4 no grupo PCOS e grupo CTRL no repouso (PCOS pré e CTRL pré, respectivamente) e o efeito agudo do exercício aeróbio na expressão proteica de GLUT-4 total normalizado pelo ponceau (figura A), GLUT-4 membranar normalizado pelo ponceau (figura B) e a taxa de translocação do GLUT - 4 estimada pela razão GLUT-4 membranar/GLUT-4 total (figura C) no grupo PCOS (PCOS pós) e CTRL (CTRL pós) ( $n=8$ para cada grupo para análise do GLUT-4 total; $n=8$ para 0 grupo PCOS e $n=5$ para o grupo CTRL para análise da fração membranar do GLUT-4; $n=8$ para o grupo PCOS e $n=5$ para o grupo CTRL para análise da translocação do GLUT-4 ). 


\section{DISCUSSÃO}

O presente estudo teve como objetivo investigar o efeito de uma sessão aguda de exercício aeróbio sobre as vias moleculares de captação de glicose no tecido muscular esquelético de mulheres com PCOS. Coletivamente, os presentes achados demonstram um prejuízo na sinalização de captação de glicose no músculo esquelético ao nível da proteína PI3-k p85 e AS160 Thr 642 em resposta ao exercício aeróbio agudo nas mulheres com PCOS comparada as mulheres CTRL. Entretanto, a translocação do GLUT-4 para a membrana sarcoplasmática não está prejudicada em resposta ao exercício aeróbio agudo nas mulheres com PCOS comparada as mulheres CTRL. Esses dados sugerem que defeitos de sinalização em proteínas específicas não impedem a efetiva translocação de GLUT-4 no músculo esquelético de pacientes com PCOS, provavelmente pela ativação de mecanismos moleculares compensatórios.

A PCOS é a endocrinopatia mais comum em mulheres em idade fértil (March et al., 2010). Independentemente da obesidade, mulheres com PCOS apresentam um aumento inerente da prevalência de RI comparada às mulheres sem a síndrome (Teede et al., 2007). Além disso, a obesidade agrava o quadro de RI, piorando ainda mais o quadro metabólico e reprodutivo, além de elevar a chance de síndrome metabólica, intolerância à glicose e DM2 (Karakas et al., 2010). Sabe-se que o músculo esquelético é o principal território responsável pela captação de glicose mediada pela insulina (O'Neill, 2013). Defeitos em vias de sinalização insulínica no músculo esquelético podem exacerbar a RI intrínseca a síndrome, culminando em resposta atenuada à captação de glicose (Sakagami et al., 2014) como consequência de defeitos na sinalização intracelular. Já são bem documentados os benefícios do exercício físico na melhora do quadro de Rl, independentemente da redução do peso corporal (Coker et al., 2009). Todavia, HARRISON et al., (2012) demonstraram que mulheres obesas com PCOS submetidas a três meses de treinamento aeróbio de moderada e alta intensidade (intermitente) melhoraram a Rl em $16 \%$, porém não restauraram a sensibilidade insulínica tal como as mulheres obesas sem a síndrome. Embora estudos prévios tenham demonstrado defeitos na sinalização à insulina no músculo esquelético em mulheres com PCOS (Lansey et al., 2012), os mecanismos moleculares que justificam uma resposta subótima na sensibilidade à insulina após um período de treinamento físico necessitam ser 
elucidados. Nesse contexto, o presente trabalho teve como premissa que o exercício aeróbio agudo potencializaria a ativação de vias de sinalização de captação de glicose no músculo esquelético, possibilitando explorar possíveis defeitos moleculares que justificassem a atenuação na melhora de sensibilidade à insulina frente ao treinamento físico em mulheres com PCOS.

Ao nosso conhecimento, este é o primeiro estudo a investigar as vias de captação de glicose no músculo esquelético em mulheres com PCOS em resposta a uma única sessão de exercício aeróbio. A capacidade do IRS-1 em ser fosforilado em tirosina após o estímulo com insulina depende da presença de múltiplos sítios de tirosina em localizações estratégicas (Saad et al., 1992). As funções fisiológicas do IRS-1 foram estabelecidas por meio de camundongos knockout para essa proteína. $\mathrm{O}$ camundongo que não expressa à proteína IRS-1 apresenta RI e restrição do crescimento, mas não é hiperglicêmico (Araki et al., 1994). A proteína IRS-1 além de ser fosforilada em tirosina, pode também ser fosforilado no resíduo de serina. $O$ estudo da atividade da IRS-1 no resíduo de serina permite avaliar a RI ao nível molecular, uma vez que a fosforilação dessa proteína neste resíduo indica uma redução da transdução do sinal intracelular e, consequente, menor ativação da translocação do GLUT-4 para a membrana sarcoplasmática (D'Alessandris et al., 2007). Vários estudos têm demonstrado que a obesidade é um fator causal no aumento da fosforilação do IRS-1 em serina (Pauli et al., 2008) e a PCOS per se apresenta um aumento da fosforilação do IRS-1 nesse resíduo (Dunaif et al., 2001). Ademais, o processo inflamatório subclínico é capaz de provocar a fosforilação do IRS-1 no resíduo de serina através da ativação de proteínas quinases como o IKK $\beta$ e JNK. Uma redução da fosforilação do IKKß permite uma maior migração do $N F K \beta$ para o núcleo celular e ativar genes responsáveis pela produção de citocinas inflamatórias como a IL1- $\beta$ e o TNF- $\alpha$ (Hotamisligil et al., 1996). No presente trabalho, não observamos nenhuma diferença significante na atividade da IRS-1 na comparação entre os grupos experimentais. Entretanto, a PCOS demonstrou níveis de IL-1 $\beta$ no tecido muscular esquelético e no plasma significantemente maiores (no período PRÉ) do que as mulheres CTRL. O aumento da produção de citocinas próinflamatórias pode exarcerbar a fosforilação do IRS-1 no resíduo de serina (Hirosumi et al., 1994), que somado ao quadro de obesidade favorece um quadro de RI mais intenso. GONZÁLEZ et al., (2011) demonstraram uma maior ativação do complexo 
$\mathrm{NFKB}$ e, consequente, maior liberação de citocinas pró-inflamatórias independente da obesidade em resposta à sobrecarga de glicose e/ou jejum. O mecanismo que justifica esse achado está na associação entre hiperandrogenemia e RI na ativação da resposta de células mononucleares ao processo inflamatório. Além disso, a administração de andrógenos por 5 dias em mulheres em idade fértil, sem comorbidades e sem sinais de hiperandrogenismo provoca uma maior ativação da expressão gênica do NFKB com consequente redução do IKB (González et al., 2012), demonstrando a participação da hiperandrogenemia no processo inflamatório subclinico. Posto isso, a associação entre a PCOS e a obesidade poderia potencializar a atividade do IRS-1 no resíduo de serina causando um aumento na RI. No presente trabalho, uma única sessão de exercício aeróbio foi capaz de reduzir a fosforilação do IRS-1 Ser 307 em ambos os grupos experimentais. Este resultado corrobora outros achados em que pacientes obesos obtiveram uma melhora da sensibilidade insulínica através de uma maior ativação do $\mathrm{IkB}$, com consequente redução da atividade do NFKB e menor fosforilação do IRS-1 em serina (Bikman et al., 2008).

A ativação da PI3-k é um importante passo para a transdução do sinal intracelular para a translocação do GLUT-4 dependente de insulina (Sheperd et al., 1998). Essa enzima catalisa a fosforilação do fosfatidilinositol-3-fosfato (PIP1), fosfatidilinositol-3,4-difosfato (PIP2) e fosfatidilinositol-3,4,5-trifosfato (PIP3). Este último produto gerado pela PI3-k regula a proteína PDK1 (proteína quinase dependente de fosfoinositídeo), uma serina/treonina que fosforila e ativa a proteína AKT. Diversos trabalhos tem demonstrado um prejuízo na ativação da PI3-k no tecido muscular esquelético em pacientes com DM2 e obesos com RI (Vollenweider et al., 2002). Embora alguns trabalhos tenham demonstrado que o exercício agudo é capaz de aumentar imediatamente a expressão da PI3-k (Frosig et al., 2007), no presente trabalho, uma única sessão aguda de exercício aeróbio não foi capaz de aumentar a ativação da PI3-k somente no grupo PCOS, demonstrando um provável defeito na sinalização insulínica no tecido muscular esquelético em resposta ao exercício físico. DUNAIF et al., (2001) demonstraram uma redução da atividade do IRS-1 associada a PI3-k, bem como uma redução da captação de glicose mediada pela insulina. Todavia, os autores comprovaram um aumento da atividade do IRS-2, sugerindo um mecanismo compensatório à atenuação da ativação do complexo IRS- 
1/PI3-k (Araki et al., 1994). Apesar da atenuação na ativação dessa proteína, a fosforilação da proteína Akt Ser 473 em resposta a sessão aguda de exercício aeróbio demonstrou um aumento significante em ambos os grupos. Isso demonstra que a insulina e a contração muscular utilizam diferentes sinais intracelulares para a captação de glicose que podem ocorrer de maneira independente a ação da PI3-k (O'Gorman et al., 2000) e, na ausência de ativação de PI3-k, a contração muscular isoladamente é capaz de ativar a fosforilação da Akt através de fatores de crescimento (Musi e Goodyear, 2006). Além disso, White et al., (2013) demonstraram a participação da testosterona na ativação da proteína Akt no resíduo Ser 473, assim como outros trabalhos demonstraram a participação de outras proteínas (ex: mTOR) na captação de glicose no músculo esquelético independente da ativação da PI3-k (Tremblay e Marette, 2001). Outros resíduos da proteína Akt participam da transdução do sinal para captação de glicose no tecido muscular esquelético. A ativação das proteínas de membrana PIP2 e PIPP3 levam a ativação da proteína PDK1 que fosforila a proteína Akt no resíduo Thr 308, permitindo a transdução do sinal para a captação de glicose. A fosforilação da proteína Akt Thr 308 em resposta a sessão aguda de exercício aeróbio demonstrou um aumento significante apenas no grupo PCOS. Provavelmente, a RI exacerbada evidenciada na PCOS exige a ativação da Akt em diferentes resíduos para a manutenção da transdução do sinal intracelular para captação de glicose como forma de compensar a atenuação da ativação da PI3-k em resposta ao exercício aeróbio agudo, conforme demonstrado neste trabalho.

A ativação da proteína AMPK, a qual é estimulada pelo aumento da razão AMP/ATP desempenha um papel crucial na captação de glicose dependente da contração muscular. Por esse motivo, essa proteína quinase é alvo para desenvolvimento de fármacos por servir como estratégia alternativa para o incremento no transporte de glicose no tecido muscular esquelético em pacientes com RI (Fuji et al., 2006). Uma única sessão de exercício aeróbio foi capaz de aumentar de maneira similar a ativação da AMPK Thr 172 nos grupos PCOS e CTRL (embora estatisticamente significante apenas no grupo PCOS), demonstrando que ativação dessa proteína não foi negativamente afetada pela PCOS. 
A AS160, considerada com uma "proteína-alvo" da AMPK, atua como substrato da Akt capaz de reter vesículas intracelulares de GLUT-4 (Treebak et al., 2006). Quando fosforilada no resíduo de Thr 642 ocorre uma rápida exocitose das vesículas de GLUT-4, aumento da expressão de GLUT-4 na membrana plasmática e aumento da captação de glicose (Klip et al., 2014). Já é bem estabelecido que a contração muscular é capaz de aumentar a fosforilação da AS160 no resíduo de Thr 642 por um mecanismo independente da via PI3-k/Akt (Klip et al., 2014). Infere-se que o mecanismo seja dependente da ativação da AMPK. TREEBAK et al., (2006) forneceram evidências de que a proteína AMPK é o principal contribuinte para a regulação da AS160 em resposta a contração muscular. Diversas evidências mostram que a AS160 é capaz de modular a RI em diversas doenças metabólicas (Sakagami et al., 2014). Portadoras da PCOS apresentam uma diminuição da fosforilação da AS160 induzida por insulina, o que se associa a uma diminuição da sensibilidade insulínica no músculo esquelético independente da obesidade e da hiperglicemia (Hojlund et al., 2008). Tendo em vista o potencial papel da AS160 na translocação de GLUT-4 e, por conseguinte, na captação de glicose, pode-se afirmar que pacientes com PCOS apresentam um defeito na ativação dessa proteína em resposta ao exercício agudo. Contudo, cabe salientar que, apesar da AS160 ser um importante alvo da AMPK, esta última é capaz de regular diretamente a transcrição do GLUT-4. De fato, experimentos com animais transgênicos demonstram existir uma região do gene responsável pelo GLUT-4 (SLC2A4) de aproximadamente 895 bp que contêm um elemento responsivo ao AICAR (um agonista farmacológico da AMPK), essencial para a formação do RNA mensageiro do GLUT-4 (Goodyear e Kahn, 1998). Sendo assim, é possível especular que a capacidade de ativar a AMPK na PCOS possibilite a preservação da translocação de GLUT-4 vista nessa condição, mesmo diante da ineficaz ativação da AS160.

As evidências que sugerem que mulheres com PCOS poderiam apresentar defeitos nas vias moleculares de captação de glicose ganharam força a partir dos achados de HARRISON et al., (2012), que revelaram a incapacidade de mulheres portadoras dessa síndrome em alcançarem valores de sensibilidade à insulina semelhantes àqueles experimentados pelo grupo controle após um programa de treinamento físico de 12 semanas. Contudo, é possível que variáveis intervenientes que sabidamente afetam à sensibilidade à insulina possam ter sido, ainda que 
parcialmente, responsáveis por esses resultados. Por exemplo, HARRISON et al., (2012) não controlaram o nível de atividade física das participantes, tampouco quantificaram a gordura corporal. Tais fatores influenciam sobremaneira a sensibilidade à insulina (Van Tienen et al., 2012) e, por isso, foram controlados no presente estudo por meio de métodos válidos. Além disso, enquanto empregamos um modelo de exercício aeróbio agudo de moderada intensidade, HARRISON et al., (2012) utilizaram um programa crônico de treinamento combinado com exercícios contínuos de moderada intensidade e intermitentes de alta intensidade. A notória diferença entre os modelos de estudo podem ter produzido respostas distintas de sensibilidade à insulina - dos níveis moleculares aos metabólicos - o que explicaria, também, os achados discordantes entre os estudos.

É importante salientar que o presente estudo possui limitações. Primeiramente, cabe ressaltar que se trata de uma investigação com exercício agudo. Não obstante os o efeito crônico do treinamento físico sobre a sensibilidade à insulina seja interpretado por muitos como a somatória dos efeitos produzidos pelas sessões agudas de exercício, é possível que a resposta ao treinamento físico regular destoe daquela do exercício agudo no que tange à resposta molecular. Dessa forma, estudos futuros devem avaliar o efeito do treinamento físico regular sobre as vias moleculares de captação de glicose em mulheres com PCOS. Em segundo lugar, cabe ressaltar que, no presente estudo, foram eleitas proteínas candidatas que são classicamente associadas à captação de glicose. Contudo, outras vias não canônicas que também participam desse processo (ex.: via da MAPK e da ERK) e que não foram avaliadas neste estudo poderiam ser expressas diferentemente na PCOS. Em terceiro lugar, a RI na PCOS é de etiologia complexa e, decerto, envolve a participação de outros tecidos, por além do músculo esquelético (ex: hipotálamo, fígado e tecido adiposo). Dessa forma, são necessários novos estudos integrativos para avaliar a contribuição dos diversos tecidos na homeostase glicêmica em resposta ao exercício físico na PCOS. Por fim, cabe ressaltar que os dados obtidos neste estudo não podem ser extrapolados para pacientes com baixo nível de atividade física, uma vez que tanto as mulheres com PCOS como as mulheres CTRL apresentaram mais de 13.000 passos, portanto, mulheres fisicamente ativas (Ladabaum et al., 2014). Sendo assim, estudos com mulheres com PCOS eutróficas, fisicamente ativas ou sob tratamento medicamentoso precisam ser desenvolvidos. 


\section{CONCLUSÃO}

Como resultado do prejuízo das respostas moleculares que culminam com a captação muscular de glicose, pode-se observar, pela primeira vez, que apesar do prejuízo na ativação das proteínas PI3-k e AS160 Thr 642 no tecido muscular esquelético de mulheres com PCOS, a taxa de translocação de GLUT-4 não está prejudicada em mulheres obesas com PCOS quando comparadas a seus pares sem a síndrome, em contraste com o que ocorre com pacientes com DM2, os quais apresentam significativa redução na translocação de GLUT-4 em resposta à contração muscular e infusão de insulina (Lansey et al., 2012). Tais achados inéditos reforçam a relevância do treinamento físico como agente terapêutico viável capaz de atenuar a RI e perfil inflamatório em mulheres com PCOS. Como perspectiva, estudos com programas de treinamento físico crônico devem avaliar as respostas fenotípicas em paralelo às moleculares nessa síndrome, o que trará elementos clínicos e mecanísticos relevantes que poderão norteará o manejo clínico de pacientes com PCOS.

\section{REFERÊNCIAS BIBLIOGRÁFICAS}

1. ABDUL-GHANI M.A. et al. Muscle and liver insulin resistance indexes derived from the oral glucose tolerance test. Diabetes Care. 30, 89-94, 2007.

2. ALLEMAND M.C. et al. Effect of testosterone on insulin stimulated IRS1 Ser Phosphorylation in primary rat myotubes - a potential model for PCOS-related insulin resistance. PLoS One. 4(1), e4274, 2009.

3. ARAKI E. et al. Alternative pathway of insulin signalling in mice with targeted disruption of the IRS-1 gene. Nature. 372, 186-90, 1994.

4. ARAKI E. et al. Alternative pathway of insulin signalling in mice with targeted disruption of the IRS-1 gene. Nature. 372(6502), 186-90, 1994.

5. AZZIZ R. et al. Androgen excess in women: experience with over 1000 consecutive patients. Journal Clinical Endocrinology and Metabolism. 89(2), 45362, 2004. 
6. AZZIZ R. et al. Positions statement: criteria for defining polycystic ovary syndrome as a predominantly hyperandrogenic syndrome: an Androgen Excess Society guideline. Journal Clinical Endocrinology and Metabolism. 91(11), 423745, 2006

7. BARCELLOS C.R.G. et al. Prevalence of abnormalities of glucose metabolism in patients with polycystic ovary syndrome. Arquivos Brasileiros de Endocrinologia e Metabologia. 51, 601-5, 2007.

8. BERTOLI A., et al. Lipid profile, BMI, body fat distribution, and aerobic fitness in men with metabolic syndrome. Acta Diabetologica. 40, 1, 130-3, 2003.

9. BIKMAN B.T. et al. Mechanisms for improved insulin sensitivity after gastric bypass surgery. Journal of Clinical Endocrinology and Metabolism. 93(12), 4656-63, 2008.

10. BLAIR S.N. et al. Physical fitness and all-cause mortality. A prospective study of healthy men and women. JAMA. 262(17): 2395-401, 1989.

11. BOUZAKRI K.; KOISTINEN H.A.; ZIERATH J.R. Molecular mechanisms of skeletal muscle insulin resistance in type 2 diabetes. Current Diabetes Review. 1(2), 167-74, 2005.

12. BRUUNSGAARD $H$. et al. Exercise-induced increase in serum interleukin-6 in humans is related to muscle damage. Journal of Physiology. 499, 833-41, 1997.

13. CARON M.A. et al. Variability of protein level and phosphorylation status caused by biopsy protocol design in human skeletal muscle analyses. BMC Research Notes. 10(4), 2-9, 2011.

14. CARVALHO C.R. et al. Novel signal transduction pathway for luteinizing hormone and its interaction with insulin: activation of Janus kinase/signal transducer and activator of transcription and phosphoinositol 3-kinase/Akt pathways. Endocrinology. 144(2), 638-47, 2003.

15. CHEANG K.I.; ESSAH P.; NESTLER J.E. A Paradox: the roles of inositolphosphoglycans in mediating insulin sensitivity and hyperandrogenism in the polycystic ovary syndrome. Hormones. 3(4), 244-51, 2004.

16. COKER R. H. et al. The impact of exercise training compared to caloric restriction on hepatic and peripheral insulin resistance in obesity. Journal Clinical Endocrinology and Metabolism. 94, 4258-66, 2009. 
17. CORBOULD A. Effects of androgens on insulin action in women: is androgen excess a component of female metabolic syndrome? Diabetes and Metabolic Research Review. 24(7), 520-32, 2008b.

18. CORBOULD A. et al. Enhanced mitogenic signaling in skeletal muscle of women with polycystic ovary syndrome. Diabetes. 55(3), 751-9, 2006.

19. CORBOULD A. et al. Insulin resistance in the skeletal muscle of women with PCOS involves intrinsic and acquired defects in insulin signaling. American Journal of Physiology - Endocrinology and Metabolism. 288: 1047-54, 2005a.

20. CORBOULD A. et al. Insulin resistance in the skeletal muscle of women with PCOS involves intrinsic and acquired defects in insulin signaling. American Journal of Physiology - Endocrinology and Metabolism. 288, 1047-54, 2005b.

21. CORBOULD A. et al. Insulin resistance in the skeletal muscle of women with PCOS involves intrinsic and acquired defects in insulin signaling. primary skeletal muscles and adipocytes and impairs glucose homeostasis. American Journal of Physiology - Endocrinology and Metababolism. 288(5), 1047-54, 2005c.

22. CORBOULD A. Insulin resistance in skeletal muscle and adipose tissue in PCOS: are the molecular mechanisms distinct from type 2 diabetes? Panminerva Medicine. 50, 279-94, 2008a.

23. CZECH M.P.; CORVERA S. Signaling mechanisms that regulate glucose transport. Journal of Biological Chemistry. 22, 274(4), 1865-8, 1999.

24. D'ALESSANDRIS $C$. et al. C-reactive protein induces phosphorylation of insulin receptor substrate-1 on Ser 307 and Ser 612 in L6 myocytes, thereby impairing the insulin signalling pathway that promotes glucose transport. Diabetologia. 50(4), 840-9, 2007.

25. DAHLGREN E. et al. Women with polycystic ovary syndrome wedge resected in 1956 to 1965: a long-term follow-up focusing on natural history and circulating hormones. Fertility and Sterility. 57, 505-13, 1992.

26. DANTAS W.S. et al. Metabolic disturbance in PCOS: Clinical and molecular effects on skeletal muscle tissue. The Scientific World Journal. Jun 5 , 178364, 2013. 
27. DOUEN A.G et al. Exercise induces recruitment of the "insulinresponsive glucose transporter". Evidence for distinct intracellular insulin- and exercise-recruitable transporter pools in skeletal muscle. The Journal of Biological and Chemistry. 265(23): 13427-430, 1990.

28. DUNAIF A. et al. Suppression of hyperandrogenism does not improve peripheral or hepatic insulin resistance in the polycystic ovary syndrome. Journal Clinical Endocrinology and Metabolism. 70(3), 699-704, 1990.

29. DUNAIF A. et al. The insulin-sensitizing agent troglitazone improves metabolic and reproductive abnormalities in the polycystic ovary syndrome. Journal Clinical Endocrinology and Metabolism._81(9), 3299-306, 1996.

30. DUNAIF A. Insulin resistance and the polycystic ovary syndrome: mechanism and implications for pathogenesis. Endocrine Reviews. 18(6), 774-800, 1997.

31. ELTING M.W. et al. Prevalence of diabetes, hypertension and cardiac complaints in a follow-up study of a Dutch PCOS population. Human Reproduction. 16, 556-60, 2001.

32. ESCOBAR-MORREALE H.F.; LUQUE-RAMÍREZ M.; GONZÁLEZ F. Circulating inflammatory markers in polycystic ovary syndrome: a systematic review and metaanalysis. Fertility and Sterility. 95(3), 1048-58, 2011.

33. FEBBRAIO M.A. et al. Interleukin-6 is a novel factor mediating glucose homeostasis during skeletal muscle contraction. Diabetes. 53(7), 1643-8, 2004.

34. FIELDS D.A.; HUNTER G.R.; GORAN M.I. Validation of the BOD POD with hydrostatic weighing: influence of body clothing. International Journal of Obesity and Related Metabolic Disorders. 24(2), 200-5, 2000.

35. FRIEDEWALD W.T. et al. Estimation of the concentration of low-density lipoprotein cholesterol in plasma, without use of the preparative ultracentrifuge. Clinical Chemistry. 18(6), 499-502, 1972.

36. FROSIG C. et al. Exercise improves phosphatidylinositol-3,4,5trisphosphate responsiveness of atypical protein $\mathrm{C}$ and interacts with insulin signalling to peptide elongation in human skeletal muscle. Journal of Physiology. 582(3), 1289-1301, 2007.

37. FUJI N.; JESSEN N.; GOODYEAR L.J. AMP-activated protein kinase and the regulation of glucose transport. American Journal of Physiology - 
Endocrinology and Metababolism. 291(5), 867-77, 2006.

38. GIALLAURIA F. et al. Inflammatory markers and visceral fat are inversely associated with maximal oxygen consumption in women with polycystic ovary syndrome (PCOS). Clinical Endocrinology. 70(3), 394-400, 2009.

39. GONZÁLEZ F. et al. Hyperandrogenism sensitizes leukocytes to hyperglycemia to promote oxidative stress in lean reproductive-age women. Journal of Clinical Endocrinology and Metabolism. 97(8), 2836-43, 2012a.

40. GONZÁLEZ F. et al. Increased activation of nuclear factor kappaB triggers inflammation and insulin resistance in polycystic ovary syndrome. Journal Clinical Endocrinology and Metabolism. 91(4), 1508-12, 2006a.

41. GONZÁLEZ F. et al. Inflammation in response to glucose ingestion is independent of excess abdominal adiposity in normal-weight women with polycystic ovary syndrome. Journal Clinical Endocrinology and Metabolism. 97(11), 40719, 2012b.

42. GONZÁLEZ F. et al. Reactive oxygen species-induced oxidative stress in the development of insulin resistance and hyperandrogenism in polycystic ovary syndrome. Journal Clinical Endocrinology and Metabolism. 91(1), 336-40, 2006b.

43. GOODYEAR L.J.; KAHN B.B. Exercise, glucose transport and insulin sensitivity. Annual Review of Medicine. 49, 235-61, 1998.

44. GUALANO B. et al. Creatine in type 2 diabetes: a randomized, doubleblind, placebo-controlled trial. Medicine and Science in Sports and Exercise. 43(5), 770-8, 2011.

45. HARRISON C.L. et al. The impact of intensified exercise training on insulin resistance and fitness in overweight and obese with and without polycystic ovary syndrome. Clinical Endocrinology . 76(3), 351-7, 2012.

46. HEINRICH P.C. et al. Principles of interleukin (IL)-6-type cytokine signalling and its regulation. Biochemistry Journal. 374, 1-20, 2003

47. HIROSUMI J. et al. A central role for JNK in obesity and insulin resistance. Nature. 420, 333-6, 2002.

48. HOJLUND K. et al. Impaired insulin-stimultated phosphorylation of Akt and AS160 in skeletal muscle of women with polycystic ovary syndrome is reversed by pioglitazone treatment. Diabetes. 57, 357-66, 2008. 
49. HOJLUND K.et al. AMPK activity and isoform protein expression are similar in muscle of obese subjects with and without type 2 diabetes. American Journal of Physiology - Endocrinology and Metababolism. 286, 239-44, 2004.

50. HOLMANG A. et al. Effects of short-term testosterone exposure on insulin sensitivity of muscles in female rats. American Journal of Physiology Endocrinology and Metababolism. 262, 851-55, 1992.

51. HOLMANG A. et al. Effects of testosterone on muscle insulin sensitivity and morphology in female rats. American Journal of Physiology - Endocrinology and Metababolism. 259, 555-60, 1990.

52. HOLMANG A. et al. Insulin insensitivity and delayed transcapillary delivery of insulin in oophorectomized rats treated with testosterone. Acta Physiological Scandinavian. 171, 427-38, 2001.

53. HORNG T.; HOTAMISLIGIL G.S. Linking the inflammasome to obesityrelated disease. Nature Medicine. 17(2), 164-5, 2011.

54. HOTAMISLIGIL G.S. et al. Reduced tyrosine kinase activity of the insulin receptor in obesity-diabetes. Central role of tumor necrosis factor-alpha. Journal of Clinical Investigation. 94, 1543-9, 1994.

55. HOTAMISLIGIL G.S. Molecular mechanisms of insulin resistance and the role of the adipocyte. International Journal of Obesity and Related Metabolic Disorders. 24(4), 23-7, 2000.

56. HOTAMISLIGIL G.S et al. Increased adipose tissue expression of tumor necrosis factor-alpha in human obesity and insulin resistance. Journal of Clinical Investigation. 95(5), 2409-15, 1995.

57. HOTAMISLIGIL G.S et al. IRS-1-mediated inhibition of insulin receptor tyrosine kinase activity in TNF-alpha- and obesity-induced insulin resistance. Science. 271(5249), 665-8, 1996.

58. HOTAMISLIGIL G.S.; SHARGILLI N.S.; SPIEGELMAN B.M. Adipose expression of tumor necrosis factor-alpha: direct role in obesity-linked insulin resistance. Science. 259(5091), 87-91, 1993.

59. HOUSTIN N.; ROSEN E.D.; LANDER E.S. Reactive oxygen species have a causal role in multiple forms of insulin resistance. Nature. 440(7086), 944-8, 2006.

60. HUTCHISON S.K. et al. Effects of exercise on insulin resistance and 
body composition in overweight and obese women with and without polycystic ovary syndrome. Journal Clinical Endocrinology and Metabolism. 96(1), 48-56, 2011.

61. JIANG L.Q. et al. Altered response of skeletal muscle to IL-6 in type 2 diabetic patients. Diabetes. 62(2), 355-61, 2013.

62. KARAKAS S.E; KIM K.; DUELBA A.J. Determinants of impaired fasting glucose versus glucose intolerance in polycystic ovary syndrome. Diabetes Care. 33(4), 887-93, 2010.

63. KLIP A.; SUN Y.; CHIU T.T.; FOLEY K.P. Signal transduction meets vesicle traffic: the software and hardware of GLUT-4 translocation. American Journal of Physiology - Cellular and Physiology. 306(10), 879-886, 2014.

64. KOCAK M. et al. Metformin therapy improves ovulatory rates, cervical scores, and pregnancy rates in clomiphene citrate-resistant women with polycystic ovary syndrome. Fertility and Sterility. 77(1), 101-6, 2002.

65. KOPELMAN P.G. Obesity as a medical problem. Nature. 404 (6778), 635-43, 2000.

66. LADABAUM U. et al. Obesity, abdominal obesity, physical activity, and caloric intake in U.S. adults: 1988-2010. American Journal of Medicine. 14, 2014.

67. LANSEY M.N. et al. Deletion of Rab GAP AS160 modifies glucose uptake and GLUT4 translocation in primary skeletal muscles and adipocytes and impairs glucose homeostasis. American Journal of Physiology - Endocrinology and Metababolism. 303(10), 1273-86, 2012.

68. LEBRUN P.; VAN OBBERGHEN E. SOCS proteins causing trouble in insulin action. Acta Physiologica. 192(1), 29-36, 2008.

69. MALIK S.K. et al. Fetuin-A is linked to improved glucose tolerance after short-term exercise training in nonalcoholic fatty liver disease. Journal of Applied Physiology. 115, 988-94, 2013.

70. MARCH W.A. et al. The prevalence of polycystic ovary syndrome in a community sample under assessed under contrasting diagnostic criteria. Human Reproduction. 25(2), 544-51, 2010.

71. MARCONDES J.A.M. et al. Metabolic syndrome in women with polycystic ovary syndrome: prevalence, characteristics and predictors. Arquivos Brasileiros de Endocrinologia e Metabologia. 51, 972-9, 2007.

72. MASTERS S.L. Specific inflammasomes in complex diseases. Clinical 
Immunology. 147(3), 223-8, 2013

73. MATTHEWS D.R. et al. Homeostasis model assessment: insulin resistance and $\beta$-cell function from fasting plasma glucose and insulin concentrations in man. Diabetologia. 28, 412-19, 1985.

74. MERCADO M.M. et al. Genetics of insulin resistance. Current Diabetes Report. 2002, 2(1), 83-95, 2002.

75. MINANNI S.L. et al. Analysis of gonadotropin pulsatility in hirsute women with normal menstrual cycles and in women with polycystic ovary syndrome. Fertility and Sterility. 71(4), 675-83, 1999.

76. MORAN L.J. et al. The contribution of diet, physical activity and sedentary behaviour to body mass index in women with and without polycystic ovary syndrome. Human Reproduction. 28(8), 2276-83, 2013.

77. MUSI N.; GOODYEAR L.J. Insulin resistance and improvements in signal transduction. Endocrine. 29, 73-80, 2006.

78. NESTLER J.E.; JAKUBOWICZ D.J. Decreases in ovarian cytochrome P450c17 alpha activity and serum free testosterone after reduction of insulin secretion in polycystic ovary syndrome. New England Journal of Medicine. 29, 335(9), 617-23, 1996.

79. O'GORMAN D.J. et al. Insulin and exercise differentially regulate PI3kinase and glycogen synthase in human skeletal muscle. Journal of Applied Physiology. 89, 1412-1419, 2000.

80. O'NEILL H.M. AMPK and exercise: glucose uptake and insulin sensitivity. Diabetes and Metabolism Journal. 37(1), 155-62, 2013

81. ORIO F. et al. Cardiopulmonary impairment in young women with polycystic ovary syndrome. Journal Clinical Endocrinology and Metabolism. 91(8), 2967-71, 2006.

82. OSTROWSKI K.; SCHJERLING P.; PEDERSEN B.K. Physical activity and plasma interleukin-6 in humans--effect of intensity of exercise. European Journal of Applied Physiology. 83(6), 512-5, 2000.

83. PAULI J.R. et al. Acute physical exercise reverses S-nitrosation of the insulin receptor, insulin receptor substrate 1 and protein kinase B/Akt in diet-induced obese Wistar rats. Journal of Physiology. 586(2), 659-71, 2007.

84. PEDERSEN B.K. The anti-inflammatory effect of exercise: 
its role in diabetes and cardiovascular disease control. Essays Biochemistry. 42, 105-17, 2006.

85. PIERPOINT T. et al. Mortality of women with polycystic ovary syndrome at long-term follow-up. Journal of Clinical Epidemiology. 51, 581-6, 1998.

86. PIPER M.D.; BARTKE A. Diet and aging. Cell Metabolism. 8(2), 99104, 2008.

87. RAJHOWA M. et al. Insulin resistance in PCOS is associated with defective regulation of ERK $1 / 2$ by insulin in skeletal muscle in vivo. Biochemistry Journal. 418, 665-671, 2009.

88. REYNA S.M. et al. Elevated toll-like receptor 4 expression and signaling in muscle from insulin-resistant subjects. Diabetes. 57(10): 2595-602, 2008.

89. RIBON V. et al. A novel, multifuntional $\mathrm{C}-\mathrm{Cb}$ binding protein in insulin receptor signaling in 3T3-L1 adipocytes. Molecular and Cellular Biology. 18(2), 872-9, 1998.

90. RITCHER E.A.; HARGREAVES M. Exercise, GLUT-4, and skeletal muscle glucose uptake. Physiological Reviews. 93(3), 993-1017, 2013.

91. ROCHA M.P. et al. Dyslipidemia in women with polycystic ovary syndrome: incidence, pattern and predictors. Gynecology Endocrinology. 27(10), 814-9, 2011.

92. ROMER-CALVO I. et al. Reversible Ponceau staining as a loading control alternative to actin in Western blots. Analytical Biochemistry. 401, 318-20, 2010.

93. ROPELLE E.R. et al. IL-6 and IL-10 anti-inflammatory activity links exercise to hypothalamic insulin and leptin sensitivity through IKKbeta and ER stress inhibition. PLoS Biology. 24, 8(8), 2010.

94. SAAD M.J. et al. Regulation of insulin receptor substrate-1 in liver and muscle of animal models of insulin resistance. Journal of Clinical Investigation. 90, 1839-49, 1990.

95. SAKAGAMI $\mathrm{H}$. et al. Loss of HIF-1 $\alpha$ impairs GLUT-4 translocation and glucose uptake by the skeletal muscle cells. American Journal of Physiology Endocrinology and Metababolism. 306(9), 1065-76, 2014.

96. SALTIEL A.R.; KAHN C.R. Insulin signalling and the regulation of 
glucose and lipid metabolism. Nature. 414(6865), 799-806, 2001.

97. SCHATTENBERG J.M. et al. JNK1 but not JNK2 promotes the development of steatohepatitis in mice. Hepatology. 43(1), 163-72, 2006.

98. SHEPHERD P.R. et al. Phosphoinositide 3-kinase: the key switch mechanism in insulin signalling. Biochemistry Journal. 333, 471-490, 1998.

99. SPULBER S.; SCHULTZBERG M. Connection between inflammatory processes and transmittor function-Modulatory effects of interleukin-1. Progress in Neurobiology. 90(2), 256-62, 2010.

100. TARNOPOLSKY M.A. et al. Suction-modified Bergstrom muscle biopsy technique: experience with 13,500 procedures. Muscle Nerve. 43(5), 717-25, 2011.

101. TEEDE H.J.; HUTCHINSON S.K.; ZOUNGAS S. The management of insulin resistance in polycystic ovary syndrome. Trends in Endocrinology and Metabolism. 18(7), 273-9, 2007.

102. THOMSON R.L. et al. Comparison of aerobic exercise capacity and muscle strength in overweight women with and without polycystic ovary syndrome. International Journal of Obstetrics and Gynaecology. 116(9), 1242-50, 2009.

103. THOMSON R.L.; BUCKLEY J.D.; BRINKWORTH G.D. Exercise for the treatment and management of overweight women with polycystic ovary syndrome: a review of the literature. Obesity Review. 12(5), 202-10, 2011.

104. THYFAULT J.P. Setting the page: possible mechanisms by which acute contraction restores insulin sensitivity in muscle. American Journal of Physiology - Endocrinology and Metababolism. 294(4), 1103-10, 2008.

105. TREEBAK T.J. et al. AMPK-Mediated AS160 phosphorylation in skeletal muscle is dependent on AMPK catalytic and regulatory subunits. Diabetes. 55, 2051-58, 2006.

106. TREMBLAY F.; MARETTE A. Amino acid and insulin signaling via the mTOR/p70 S6 kinase pathway. A negative feedback mechanism leading to insulin resistance in skeletal muscle cells. Journal of Biological Chemistry. 276(41), 38052-60, 2001.

107. VAN TIENEN F.H.J et al.. Physical activity is the key determinant of skeletal muscle mitochondrial function in type 2 diabetes. Journal of Clinical Endocrinology and Metabolism. 97, 1-9, 2012. 
108. VERMEULEN A.; VERDOCK L.; KAUFMAN J.M. A critical evaluation of simple methods for the estimation of free testosterone in serum. Journal of Clinical Endocrinology and Metabolism. 84, 3666-72, 1999.

109. VOLLENWEIDER P.; MENARD B.; NICOD P. Insulin resistance, defective insulin receptor substrate 2- associated phosphatidylinositol-3' kinase activation in myotubes from obese patients with impaired glucose tolerance. Diabetes. 51, 1052-59, 2002.

110. WANSINK B.; WANSINK C.S. The largest Last Supper: depictions of food portions and plate size increased over the millennium. Internacional Journal of Obesity (Lond). 34 (5), 943-4, 2010.

111. WELLEN K.E.; HOTAMISLIGIL G.S. Inflammation, stress, and diabetes. Journal of Clinical Investigation. 115(5), 1111-9, 2005.

112. WHITE J.P. et al. Testosterone regulation of Akt/mTORC1/FoxO3a signaling in skeletal muscle. Molecular and Cellular Endocrinology. 365, 174-86, 2013.

113. WILD S. et al. Cardiovascular disease in women with polycystic ovary syndrome at long-term follow-up: a retrospective cohort study. Clinical Endocrinology. 52, 595-600, 2000.

114. WITCZAK C.A.; SHAROFF C.A.; GOODYEAR L.J. AMP-activated protein kinase in skeletal muscle: From structure and localization to its role as a master regulator of cellular metabolism. Cellular and Molecular Life Sciences. 3737-55, 2008.

115. WITHERS D.J. et al. Disruption of IRS-2 causes type 2 diabetes in mice. Nature. 391(6670), 900-4, 1998.

116. WOODS A. et al. Characterization of AMP-activated protein kinase beta and gamma subunits. Assembly of the heterotrimeric complex in vitro. Journal of Biological Chemistry. 271, 10282-90, 1996.

117. YKI-JÄRVINEN H. Glucose toxicity. Endocrine Reviews. 13(3), 41531, 1992.

118. ZIERATH J.R. Exercise training-induced changes in insulin signaling in skeletal muscle. Journal of Applied Physiology. 93, 773-781, 2002. 